University of Louisville

ThinkIR: The University of Louisville's Institutional Repository

Electronic Theses and Dissertations

$12-2017$

\title{
Highly student-rated teachers of multicultural classrooms : a qualitative study of teacher practices.
}

Rose M. Glasser

University of Louisville

Follow this and additional works at: https://ir.library.louisville.edu/etd

Part of the Bilingual, Multilingual, and Multicultural Education Commons

\section{Recommended Citation}

Glasser, Rose M., "Highly student-rated teachers of multicultural classrooms : a qualitative study of teacher practices." (2017). Electronic Theses and Dissertations. Paper 2845.

https://doi.org/10.18297/etd/2845

This Doctoral Dissertation is brought to you for free and open access by ThinkIR: The University of Louisville's Institutional Repository. It has been accepted for inclusion in Electronic Theses and Dissertations by an authorized administrator of ThinkIR: The University of Louisville's Institutional Repository. This title appears here courtesy of the author, who has retained all other copyrights. For more information, please contact thinkir@louisville.edu. 
HIGHLY STUDENT-RATED TEACHERS OF MULTICULTURAL CLASSROOMS:

A QUALITATIVE STUDY OF TEACHER PRACTICES

By

Rose M Glasser

B.A., University of Kentucky, 2008

M.A.T., University of Louisville, 2010

\author{
A Dissertation \\ Submitted to the Faculty of the \\ College of Education and Human Development \\ of the University of Louisville \\ in Partial Fulfillment of the Requirements \\ for the Degree of \\ Doctor of Philosophy \\ in \\ Curriculum and Instruction
}

Middle and Secondary Education Department

College of Education and Human Development

University of Louisville

Louisville, Kentucky

December 2017 
Copyright 2017 by Rose M Glasser

All rights reserved 

HIGHLY STUDENT-RATED TEACHERS OF MULTICULTURAL CLASSROOMS:

A QUALITATIVE STUDY OF TEACHER PRACTICES

By

Rose M Glasser

B.A., University of Kentucky, 2008

M.A., University of Louisville, 2010

Dissertation Approved on

7 November 2017

By the following

Dissertation Committee:

Jennifer Bay-Williams, PhD Co-Chair

Meera Alagaraja, PhD Co-Chair

Susan Peters, PhD

Lateefah Id-Deen, $\mathrm{PhD}$ 


\section{DEDICATION}

This dissertation is dedicated to my parents,

Danny and Becky Glasser.

You fostered my critical knowledge,

taught me conceptual mathematics,

and the value of every soul.

You are wonderful parents and

my best teachers.

This dissertation is dedicated to my kids.

An assortment of flowers makes a

marvelous garden.

Ethnicity, Culture, Individuality all

create beauty.

May you one day live in my

Promised Land

where difference is

a celebration. 


\begin{abstract}
HIGHLY STUDENT-RATED TEACHERS OF MULTICULTURAL CLASSROOMS:
\end{abstract} A QUALITATIVE STUDY OF TEACHER PRACTICES

Rose M Glasser

7 November 2017

In this study, I selected three mathematics teachers teaching in multicultural classes who were highly rated by their students. I examined these teachers' practices in relation to multicultural instructional practices, language and critical knowledge. The participants were two secondary mathematics teachers, and one middle mathematics teacher who exclusively taught English learners who had lived in the United States for less than two years. Some of their students were considered Significantly Interrupted or limited Formal Education. The teachers, Marlon, Yasin and Abigail were from Cuba, Turkey and the United States, respectively.

Using recommendations from Yin (2014), I employed multiple-case, qualitative methodology to explore and analyze these teachers' practices. I focused on the practices replicated by all three teachers, consistent with Yin's argument that the most convincing evidence is when practices occur across various contextual circumstances. The primary data sources comprised of three teacher interviews, classroom observations and lesson artifacts. I analyzed the data in multiple iterations across two phases. I identified categories shared among the teachers, collapsed the categories into subthemes, and the themes emerged. 
The themes revealed several shared practices among the three highly-rated teachers. The teachers recognized and referred to cultural distinctions, made themselves available outside of class, and advocated for their students. The teachers practiced various, frequent, and explicit language strategies. These strategies attended to social English, and the academic language of mathematics together with precursory language and concepts. The teachers positioned students for a successful future based on the teacher's perceptions of their students' future and the purpose of mathematics education. The teachers guided students to practice learner habits, and connected classroom responsibilities with the students' lives. These findings were consistent with previous research in bilingual classrooms, and contribute to the research on multicultural mathematics classrooms. Future research may examine the impact of these practices on student learning. 


\section{TABLE OF CONTENTS}

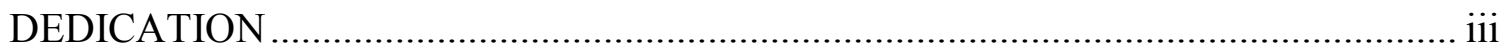

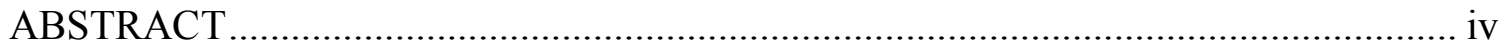

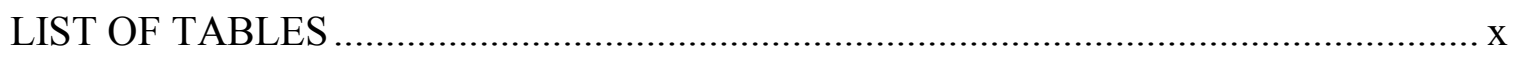

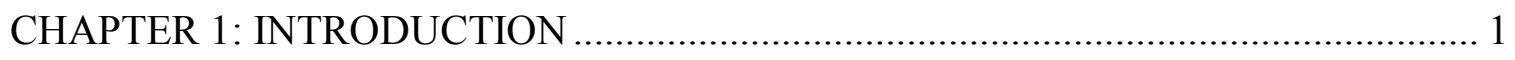

Terminology

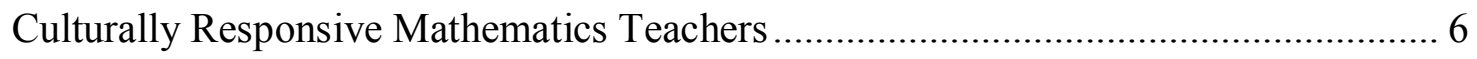

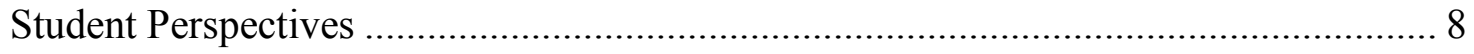

Surveys to Identify Teachers ………………………...................................... 9

Student Perspectives on Effective Teachers ………............................................... 10

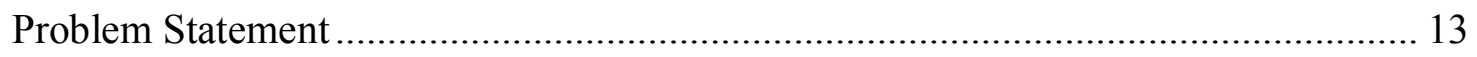

CHAPTER 2: REVIEW OF LITERATURE .......................................................... 15

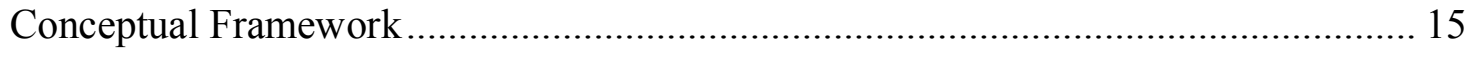

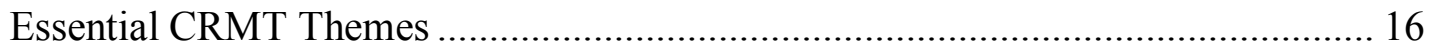

Framework Domains and Interactions .............................................................. 16

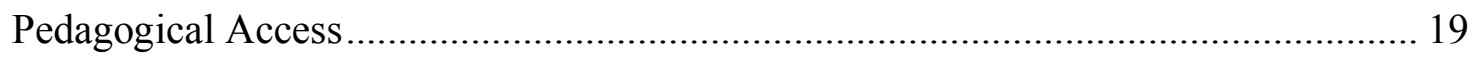

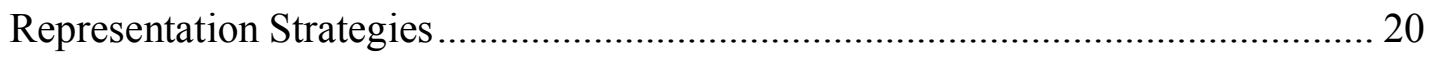

Classrooms with Various Linguistic Levels ......................................................... 21

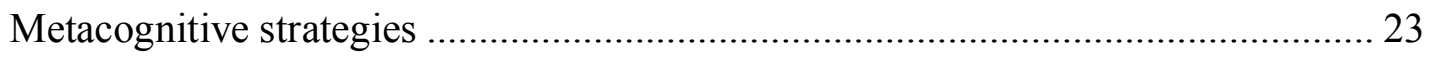

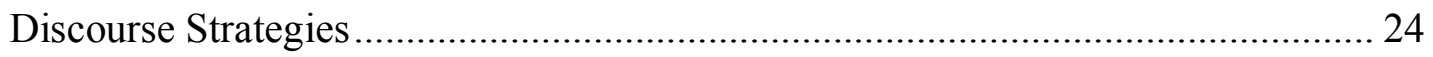




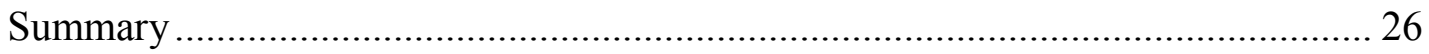

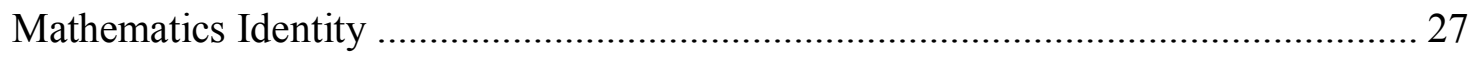

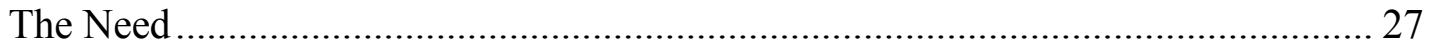

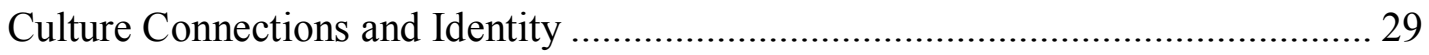

Content Dispositions and Mathematics identity ......................................................... 31

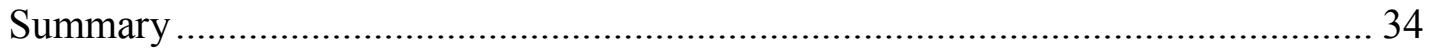

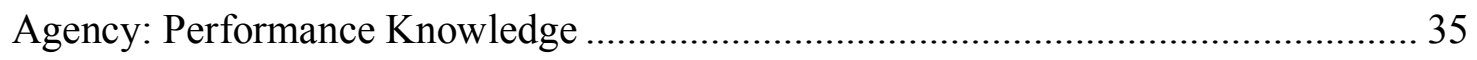

Agency to Do Mathematics .................................................................................. 35

Agency to Connect Mathematics to Society ………………................................. 36

Agency to Use Mathematics to Improve Society ...................................................... 39

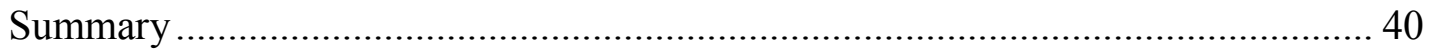

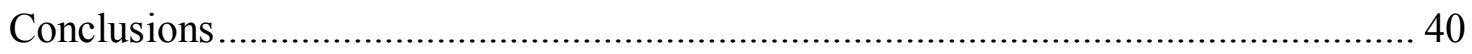

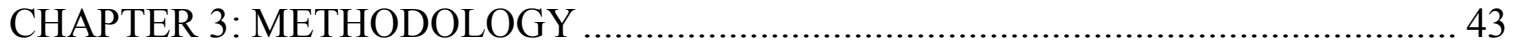

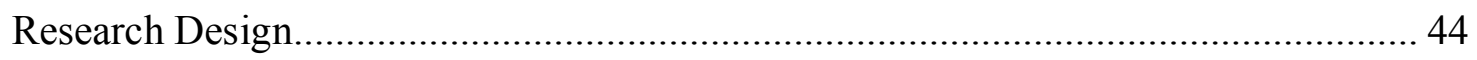

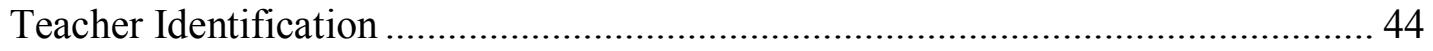

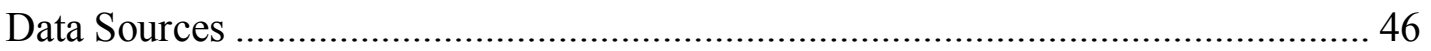

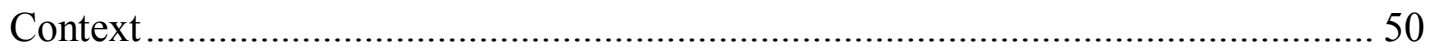

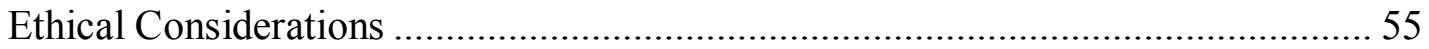

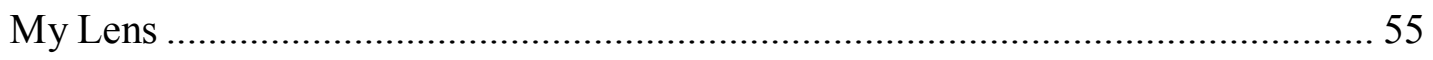

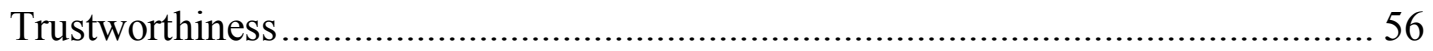

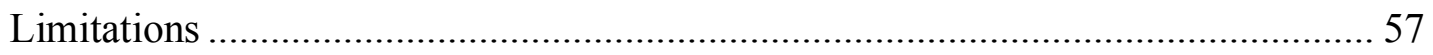

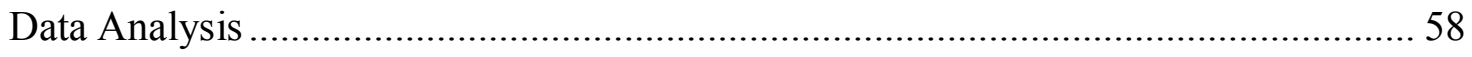

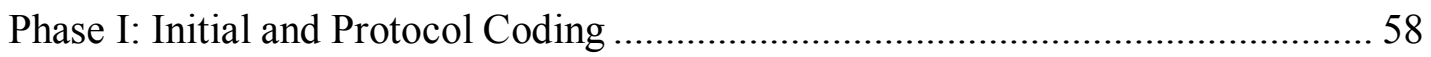


Phase II: Pattern Analysis

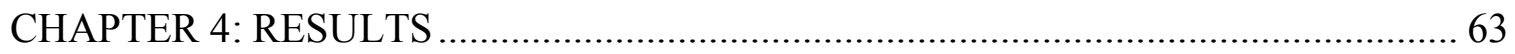

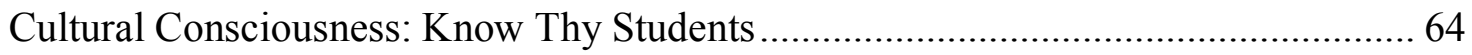

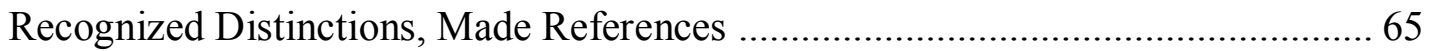

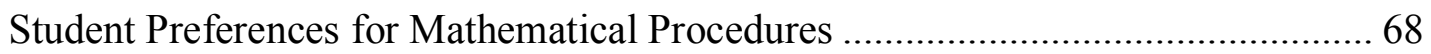

Student Interactions: Positivity, accessibility and advocacy ................................6 69

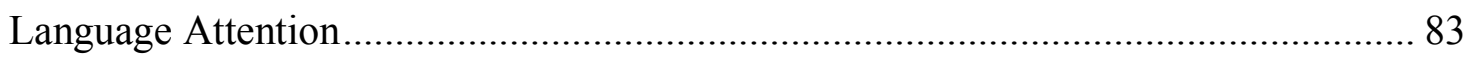

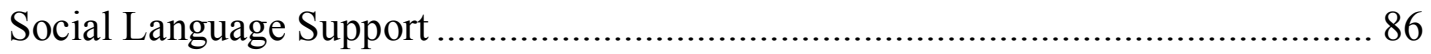

Technical Language of Mathematics ................................................................ 88

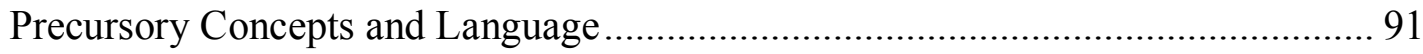

Positioned Students for a Successful Future ............................................................ 95

Learner Habits and Skills ......................................................................... 96

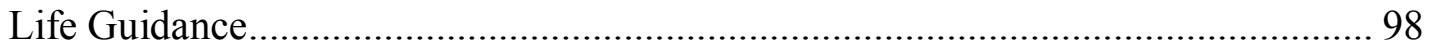

Purpose of Mathematics Education: Teacher Perceptions .................................. 100

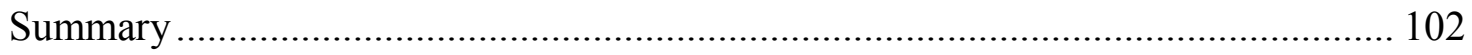

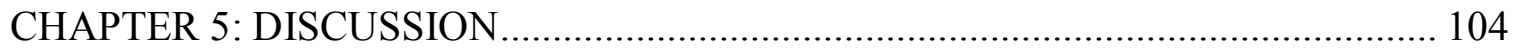

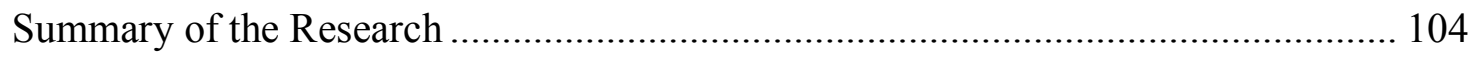

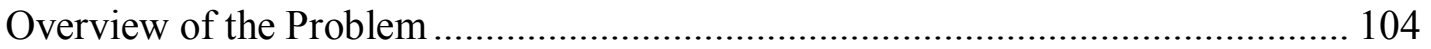

Purpose Statement and Research Questions .................................................. 105

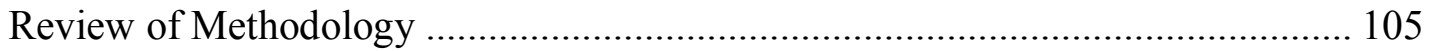

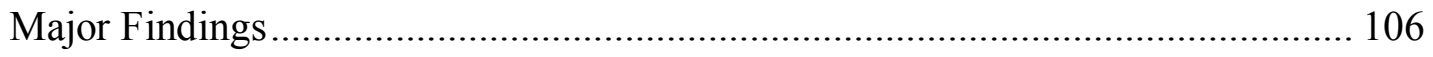

Findings Related to the Literature.................................................................... 108

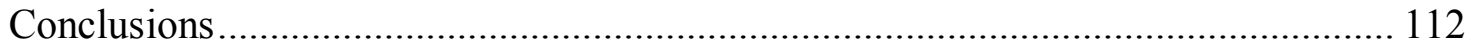


Connections to CRMT

Specialized Recommendations for Multicultural Classrooms ................................... 113

Recommendations for Further Research.............................................................. 115

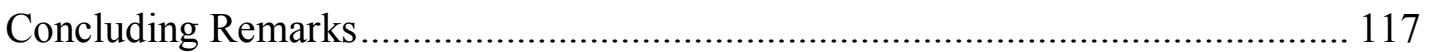

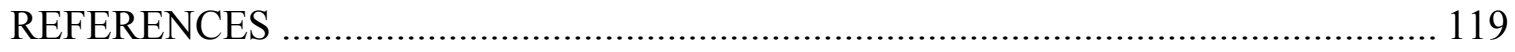

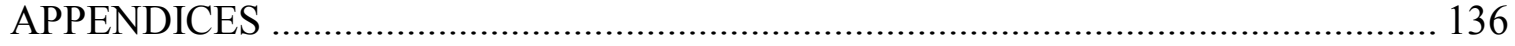

Survey Comparison: Student Voice and Tripod .................................................... 137

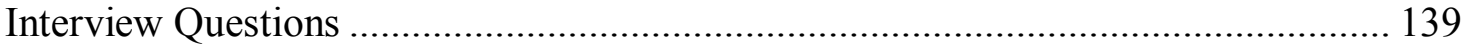

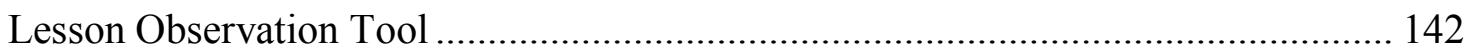

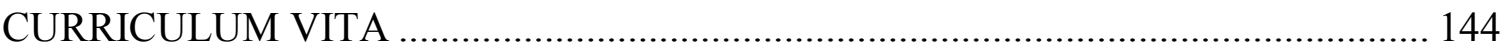




\section{LIST OF TABLES}

$\begin{array}{lll}\text { TABLE } & \text { PAGE }\end{array}$

1. Student Perspectives on Effective Teachers ......................................................... 10

2. Hypothesized Student Voice Sections with CRMT Dimensions ............................... 13

3. Student Voice Results by Category and Teacher............................................ 46, 70

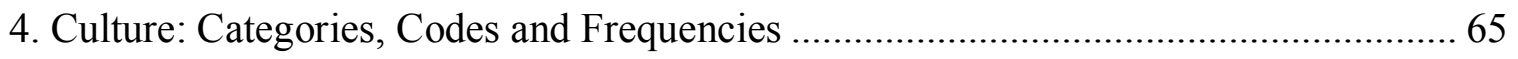

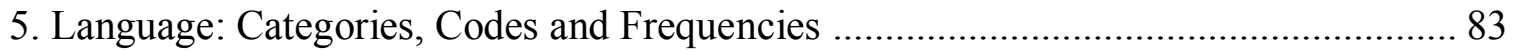

6. Critical Knowledge: Categories, Codes and Frequencies ....................................... 96 


\section{CHAPTER I}

\section{INTRODUCTION}

The importance of mathematical proficiency for every student is well documented by the United States (US) Department of Education. A number of scholars call mathematics proficiency the gateway to higher paying jobs (Allexsaht-Snider \& Hart, 2001; Martin, 2003). The National Research Council ([NRC], 2012) synthesized research from twenty-first century employment opportunities with Common Core State Standards for Mathematics (CCSS-M). The recurring themes across these calls and research summaries (NRC, 2001; Leinwand et al., 2014) included a need for mathematics proficiency that focuses on: conceptual understanding, procedural fluency, strategic competence, adaptive reasoning, and productive disposition. Current and imminent shifts in employment opportunities has increased the necessity to prepare students with mathematical proficiency. To be prepared for employment in the $21^{\text {st }}$ century skills include non-routine problem solving, critical thinking, positive mathematical identity, persistence, motivation, attitude, self-development, self-regulation, and collaboration (NRC, 2012).

Yet, these dispositions and skills are not common in U.S. Classrooms. Hiebert and Stigler (2000) analyzed videos of mathematics classroom from the Third International Mathematics and Science Study (TIMSS). They found that typical U.S. mathematics teachers state concepts rather than work through them, do not provide any opportunities for students to use deductive reasoning or develop a proof, and practice procedures for 
$96 \%$ of students' seatwork. While this study predates the NRC report, more recent evidence also suggested instruction has yet to change to impact students' mathematical proficiencies. For example, the National Assessment of Educational Progress (NAEP) found that only $25 \%$ of twelfth grade students' scored a mathematical proficiency in 2015 (National Center for Education Statistics [NCES], 2016). These mathematics test scores indicated that $75 \%$ of $2014-2015$ high school graduates were not well prepared for the 21st century employment. The disaggregated data from NAEP test scores of 2015 twelfth - graders revealed all groups as distant from the maximum score of 300 . The groups averaged: White (160), Black (130), Hispanic (139), Asian/Pacific Island (170), and American Indian/ Alaskan Native (138). These results are a slight decrease from 2013, and the similar to mathematics scores from 2005. These nationwide results provided evidence that U.S. mathematics education has not adequately prepared every student for their future.

\section{Underserved Populations}

Nationwide, groups of students, specifically, Black, English learners (ELs), Latinx ${ }^{1}$, low income, and American Indians, have been underserved in their mathematics instruction. Research repeatedly has suggested that these groups of students have relatively fewer opportunities to engage in developing mathematical proficiencies, for example having the opportunity to solve conceptual or open-ended problems, learn mathematics with understanding, or have access to courses considered to be college bound or advanced placement (Guti. rrez 2000; DeAraujo, 2012; Lubienski, 2008; Schoenfeld, 2002). For example, DeAraujo (2012) explored whether mathematics

\footnotetext{
${ }^{1}$ Latinx is the gender-neutral term for the people of the Latin American culture.
} 
teachers of ELs provide tasks requiring high cognitive demand. The data showed teachers consistently modified tasks and lowered the cognitive demand of the problem and students were expected to arrive at one solution by one pre-selected way, and seldom were students allowed to provide a meaningful explanation.

Because opportunity is one of the best predictors of mathematical proficiency (NRC, 2001), a lack of opportunity is a significant systemic problem in the U.S. education system. Moses and Cobb (2001) argued that since economic success depends on science and mathematics literacy, then mathematics education is the most crucial social issue today. They establish mathematics education- or rather, the lack of mathematics education as a civil rights issue. In expansion of the comparison civil rights and access to mathematics, Schoenfeld (2002) writes;

Disproportionate numbers of poor, African-American, Latino, and Native American students drop out of mathematics and perform below standard on tests of mathematical competency, and are thus denied both important skills and a particularly important pathway to economic and other enfranchisement (italics added, p. 13).

Schoenfeld positions the lack of mathematics education as systemic racism that deprives necessary twenty-first century skills to selective student groups. This nationwide educational deficiency predetermines lower paying occupations to poor, Black, Latinx, and Native American populations (2002). Moses and Cobb (2001) argued that since specific demographics pre-determine the quality, access, and opportunity of mathematics education, the underserved populations are not afforded equal opportunities to attain economic success. They compare this systemic deprivation of mathematics education to be on a similar scale as the lack of registered Black voters in 1961 Mississippi. 
Researchers have also found practices that increase opportunities for underserved populations and have recommended practices to improve learning opportunities for every student. For example, Boaler (2006) explored how a mathematics department positioned their multicultural students in order to increase student achievement. She found that effective instruction included roles for every student, student responsibility for classmates, high expectations, effort valued over ability, and open-ended problems with multiple solution paths. Schoenfeld (2002) recommended that to improve students' learning opportunities in mathematics, instruction must shift from a sole focus on the what (the standards) to also focus on the how (pedagogical access).

Gutiérrez (2008) suggested researchers focus on effective instructional practices and learning environments that will positively impact underserved populations. This dissertation study is a response to Gutiérrez' call for increased focus instructional practices that supports underserved populations, and thus explores characteristics of effective teachers of multicultural students. Effective teachers in this case refers to students' assessment of their teachers based on a student voice survey (described later in this chapter). In the next sections, I first review terminology, then briefly discuss the historical research on effective classrooms of underserved populations, then introduce the essentialness of student perspectives, and conclude with the research questions.

\section{Terminology}

Equity-focused researchers argue that definitions may limit someone's views of complex issues. Definitions are not stagnant, but evolve in their meaning and vary among people (Stinson \& Wager, 2012). With this caution in mind, please view the 
terminology definitions as a resource. These definitions should not limit the evolution of terminology, but provide a space to build, transform, and characterize terms.

Academic discourse: The combination of gestures and speech to communicate knowledge that is content specific (Shein, 2012).

Academic language: Content specific language that includes English and mathematics content (WiDA Consortium, 2012).

Access: The availability of systemic or pedagogical resources (Gutiérrez, 2008). For mathematics education, this includes, but is not limited to: quality mathematics teachers, safe and productive learning environments, classroom manipulatives, and opportunities to learn with a depth of mathematics (Leinwand et al., 2014).

Achievement: The determination of how close a person has met their goal. In the mathematics classroom, these goals are typically the standards of mathematics.

Advocacy: The effort to educate various audiences for the purpose of supporting an individual or group of people.

Agency: A person's perception of authority or power to create change for one's self, environment, or community.

English learner (EL): A student primarily characterized as a non-native English speaker who is still reaching to achieve English proficiency in reading, writing, speaking, and listening. ELs tend to vary in their prior educational experiences, number of native languages, and language proficiency.

Identity: In this research, identity (Gutiérrez, 2008) refers to a student maintaining connections to his/her culture, and family. A person's significant narratives are produced, altered, and reflected through interactions with the environment. 
Multicultural classrooms: In this research, the term refers to classrooms where the majority of the students are from underserved groups, and expand to at least three culture groups. At least one student identifies with a non-native culture of the region. Classrooms might include English language learners.

Social language: Everyday instructional and conversational language (WiDA Consortium, 2012).

\section{Culturally Responsive Mathematics Teachers}

Culturally responsive mathematics teaching (CRMT) has its roots in culturally responsive pedagogy. The iconic research of Ladson-Billings $(1994,2009)$ studied effective teachers of Black students, and launched the formulation of culturally responsive $^{2}$ pedagogy (CRP). CRP, "empowers students intellectually, socially, emotionally, and politically by using cultural referents to impart knowledge, skills, and attitudes" (1994, pp. 17-18). The three-year, four-phase study followed eight teachers selected from the joint recommendations of administrators and parents of Black students. She found that effective teachers of Black students developed students who achieved academically, displayed culture competence, and critiqued the existing social system. CRP rejects deficit beliefs that some teachers or society members may hold about culturally diverse students, and instead operates by recognizing and building on students' strengths. Instructional strategies are incorporated that match students' identities and learning styles while providing access to the content. The teacher builds knowledge between students' home and school experiences with intentional incorporation of students' culture in the curriculum. All subjects and skills are routinely taught with

\footnotetext{
${ }^{2}$ Ladson-Billings' originally titled used the term "culturally relevant".
} 
multicultural information and resources; the students learn to value their heritage as well as other cultures.

Although Ladson-Billing explicitly studied effective teachers of Black students, Gay (2000) synthesized research inclusive of multiple cultures, and identified particular practices that supported student learning. The teacher practices identified by Gay were later extended to guidelines (Gay, 2009) for the mathematics classroom, known as Culturally Responsive Mathematics Teaching (CRMT). The CRMT guidelines include teachers holding beliefs about high expectations that translate into the classroom environment; beliefs that knowledge is socially constructed; and beliefs that academic achievement involves more than high test scores. Academic success in mathematics incorporates student self-esteem, self-efficacy, and mathematics dispositions (2009). CRMT goes beyond acknowledging students' diversity and cultures. The teacher would value, discuss, promote, and compare students' diversity (cultural hybridity) in mathematics education and create an inclusive environment for all students (2009).

CRMT can be described in eight dimensions, observable in mathematics teaching (Aguirre \& Zavala, 2013). The dimensions are: (1) intellectual support, (2) depth of student knowledge and understanding, (3) mathematical analysis, (4) mathematical discourse and communication, (5) student engagement, (6a) Academic Language support for English language learners, (6b) scaffolding strategies for English language learners, (7) culture support, and (8) critical knowledge. Collectively these dimensions address agency, mathematics identity, cultural, and high quality mathematics, discussed in detail in Chapter 2. 


\section{Student Perspectives}

The $\mathrm{R}$ in CRMT is for responsive. Responsive infers an interaction between the students' culture, individual needs, and the content instruction. Most of the CRMT research has selected teachers based on administrator, researcher, or parent recommendations. Given that the students are the intended recipients of CRMT, student perspectives provide valuable information to CRMT. Yet, when I conducted a search across five databases with iterations of keywords including student rated, student voice, student perspective, student selected, or student measure with culturally responsive mathematics or culturally relevant mathematics, the search yielded limited results. Four studies (Dickson, Chun, \& Fernandez, 2016; Hubert, 2014; Jefferson-Isaac, 2006; Murray, 2014) incorporated CRMT, and in some way, student perspectives. No research was found where the students identified effective teachers, and then the researchers studied these teacher practices.

Although under-researched, student perceptions of quality teachers are very important. Tschannen-Moran, Bankole, Mitchell, and Moore (2013) found student perspectives as a significant predictor for identifying effective teachers. Their student academic optimism measure was a better predictor of student achievement than SES status -the historically strong predictor of student achievement. Student ratings can be more predictive than principal or teacher self-ratings (Wilkerson et al., 2000), correlate highly with student achievement (Kyriakides, 2005), and those correlations remain consistent regardless of student race or income (Ferguson, 2012). In the next section, I introduce the student survey used in this research to identify teachers. Then I share the 
research on the effective teachers from the multicultural students' perspectives, sorted into the survey categories.

\section{Surveys to Identify Teachers}

The tripod survey (Kane, McCaffrey, Miller, \& Staiger, 2013; Measures of Effective Teachers [MET] project, 2010) is a student perception survey of one teacher and their classroom environment. The tripod survey results were found reliable and valid to predict student academic achievement (Kane et al., 2013; MET project, 2010; Polikoff, 2015).

The state's Department of Education modified the tripod survey, named it the student voice survey, and required implementation throughout the state. The student voice survey included twenty-five items, placed into seven categories. The categories were constructed from the student voice/ tripod survey, respectively: support/ challenge, transparency/ clarify, understand/ consolidate, discipline/ control, engage/ captivate, nurture/ care, and trust/ confer. Each student voice category had three to four items. The items referred to teacher pedagogy practices, "My teacher has several good ways to explain each topic that we cover in this class", student preferences, "My teacher makes learning enjoyable", or their classmates' behavior, "My classmates behave the way my teacher wants them to".

A comparison of the student voice / tripod surveys showed some tripod items were excluded, but no items were rephrased. For more specific comparisons, please refer to Appendix A, survey comparison. Although modifications appeared minimal, the reliability and validity of the student voice survey is unknown. 


\section{Student Perspectives on Effective Teachers}

Even though limited research was found on CRMT and students' perspectives, progress has been made to discover the perspectives of students on effective teachers. I matched research for each student voice category with the research results from student perspectives of effective teachers, see Table 1. The teachers from most of these research instances were not in the context of the mathematics classroom (for a notable exception, see: Id-Deen, 2015, 2016). These student perspective results were consistent with the student voice survey, and collectively implied the survey is a good measure to identify effective teachers of multicultural classrooms.

Table 1

Student Perspectives on Effective Teachers

Students

Studied /

Results Data type(s)

Support

Students report teachers have a positive impact on their learning when teachers:

- provided frequently encouragement and personalized attention when needed (Phelan, Yu, \& Davidson, 1994)

Multicultural / interviews

- cared for students on personal and academic levels (Miron and Lauria, 1998)

Black / interviews

Students learned best when teachers held high, rigorous academic Low achieving expectations, while also maintaining flexibly and creativity (Lee, 1999). / interviews

Transparency

Low achieving students learned when teachers patiently presented material in multiple ways, frequently answer questions, and offered Low achieving individual assistance (Lee, 1999).

/ interviews

\begin{tabular}{lc}
\hline Understand & \\
\hline Teacher verbal discourse may be firm and demanding, but should not \\
diminish or damage student performance or potential (Howard, 2002). & $\begin{array}{c}\text { Black / } \\
\text { interviews, } \\
\text { classroom } \\
\text { observations }\end{array}$ \\
\hline
\end{tabular}




\section{Discipline}

Students resisted being silenced (Id-deen, 2016).

Black /

interviews

When ethnicity was used to perceive disciplinary practices, students and teachers agreed with their ethnic groups rather than their classmates or coworkers, respectively (Sheets, 1996).

Students and the data indicated disciplinary events as a series of circular, repetitive events. The most common type of conflict was interpersonal conflict (Sheets, 1996).

Black, White, Chicano, Filipino / interviews, classroom observations, school records

\section{Engage}

Students favored teachers who: used cooperative or social pedagogy in their classrooms; utilized interesting, and interactive styles of learning; actively engaged students in learning (Lee, 1999).

Effective teachers maintained control and organization in student interactions about the content by simultaneously being stern, and focused (Lee, 1999).

Students favored teachers:

Low achieving

/ interviews

- who allowed students to safely express their opinion, provided new learning experiences, factual knowledge and group activities (Hollins and Spencer, 1990).

- who had knowledge and understood student background; connected this knowledge to students' culture and academic content, and showed commitment to academic development (Howard, 2002).

Low achieving / interviews

Black / interviews

Black / interviews, classroom observations

\section{Nurture}

Students favored teachers who

- created family or community classroom environment, connect with families; refuses to accept anything less than a student's best; show commitment to social development (Howard, 2002);

- took the initiative to connect with the student; whose relationship can be characterized with care and trust. This was especially important in a layered environment with a turnaround classroom (Id-deen, 2016).

- were characterized as fair, caring, and praises effort to be the most important factors of school climate (Slaughter-Defoe and Carlson, 1996).

\section{Black / interviews, classroom observations}

Black / interviews

Latinx / survey

Students rated teacher-student relationships to be the most important characteristic of school climate (Slaughter-Defoe and Carlson, 1996). 
Students had less conflict in emotionally supportive environments

High Risk /

(Hamre \& Pianta, 2005).

classroom

observations

Positive teacher- student relationships correlated with:

- compliance of classroom rules, school interest, connection

Black / survey

towards school, and better involvement in school activities (Rey,

Smith, Yoon, Somers, \& Barnett, 2007).

- academic success; lower conflictive behavior (Cornell, Shukla,

\& Konold, 2016)

Multiple schools, and ethnic groups $(\mathrm{n}=87,391)$ /

survey

\section{Trust}

Student trust in teachers was a strong predictive factor of compliant behavior (Gregory and Ripski, 2008). [Discipline-referred students]

Black $(n=29)$, other $(n=3)$ / survey and interviews

Trust was the most important construct of student-reported relationships (Murray and Zvoch, 2011).

Black / survey and interviews

In Table 2, I hypothesized ways the student voice categories align with CRMT dimensions. The student voice categories of support, discipline, and trust do not have a counterpart in this table, nor do the dimensions of critical knowledge or mathematical analysis. Of particular interest to this study was the placement of the specific dimensions of language support, culture and critical knowledge. I hypothesized language support aligning with transparency, and culture with nurture. The critical knowledge dimension does not appear to align with a student voice category, and was placed accordingly. It is possible that these dimensions do not exclusively align to one category. 
Table 2

\begin{tabular}{|c|c|}
\hline Student Voice Category & CRMT Dimension \\
\hline Support & \\
\hline Transparency & $\begin{array}{c}\text { Intellectual Support } \\
\text { Language Support }\end{array}$ \\
\hline $\begin{array}{l}\text { Understand } \\
\text { Discipline }\end{array}$ & Depth of Student Knowledge and Understanding \\
\hline \multirow{3}{*}{$\begin{array}{l}\text { Nurture } \\
\text { Trust }\end{array}$} & $\begin{array}{l}\text { Student Engagement } \\
\text { Mathematical Discourse and Communication }\end{array}$ \\
\hline & Culture \\
\hline & $\begin{array}{l}\text { Critical Knowledge } \\
\text { Mathematical Analysis }\end{array}$ \\
\hline
\end{tabular}

\section{Problem Statement}

Mathematics education in the United States has not effectively met the needs of all learners. In particular, students in underserved populations do not have access to opportunities to develop their mathematics identity, a sense of agency, and deep mathematics content knowledge. Yet, there are instructional practices that have been found to adequately meet the mathematics learning needs of every student. Specifically, culturally responsive mathematics instruction (CRMI) provides a comprehensive list: (1) intellectual support, (2) depth of student knowledge and understanding, (3) mathematical analysis, (4) mathematical discourse and communication, (5) student engagement, (6a) Academic Language support for English language learners, (6b) scaffolding strategies for English language learners, (7) culture support, and (8) critical knowledge. One important lens into whether mathematics instruction is meeting a student's need is the student's lens. In this research, I identified mathematics teachers in multicultural classrooms who have been highly rated by their students. Then I studied their practices within the three 
CRMT dimensions of language support, culture, and critical knowledge. Specifically, I sought to answer the following:

To what extent, and in what ways, do highly student-rated teachers incorporate

1. multicultural instructional practices,

2. language support, and

3. critical knowledge

in their multicultural classrooms?

After identification of mathematics teachers with high student voice results, I conducted a multiple case study on their prevalent practices. The data collection focused on the three CRMT dimensions, and the analysis examined their prevalent practices. 
CHAPTER II

\section{REVIEW OF LITERATURE}

Culturally Responsive Mathematics Teaching (CRMT) provides the foundation for the conceptual framework for this study. Therefore, the CRMT themes are extensively discussed with the CRMT dimensions from the research questions: access and language support, mathematical identity and culture, and agency and critical knowledge.

Following the discussion of my framework, this chapter provides a review of research related to language support necessary for students to be mathematically proficient, as well as cultural considerations specific to mathematics learning. Included in this discussion is attention to interactions that result in students' positive mathematics identities, practices and dispositions. Finally, the chapter briefly reviews the literature on human agency, in particular the levels of mathematics instruction within critical knowledge. The CRMT themes are interwoven within each dimension.

\section{Conceptual Framework}

Equity does not mean that every student should receive identical instruction; instead, it demands that reasonable and appropriate accommodations be made as needed to promote access and attainment for all students (NCTM, 2000, p. 12).

My researcher lens, the CRMT essential themes, and research on aspects of CRMT influence my conceptual framework. I discussed these, and then described the interactions within my framework domains. 


\section{Essential CRMT Themes}

This research is set in the context of multicultural mathematics classrooms -a context that alludes to a varied sample of students' educational background, and stages of linguistic development. Boaler (2003) suggests standardized tests in this context do not accurately reflect student achievement. The three CRMT themes of access, identity, and agency influence and interact together along the route to the last theme of mathematical achievement. Although standardized tests tend to be more common and convenient than other suggested measures, these other measures are important outcomes of mathematics teaching (Boaler, 2008).

\section{Framework Domains and Interactions}

My conceptual framework is based on my research synthesis described later in this chapter. Figure 1: Development Based Interactions depicts specific domains that represent the interconnected relationship of the teacher and students. Each component of the framework interacts with the components on either side, with the outcomes for students represented on the right side of the diagram. The teacher provides pedagogical access on the left, and the students display their content practices on the right, akin to a continuous handshake between the teacher and students. Each component and the related terms are described below. 


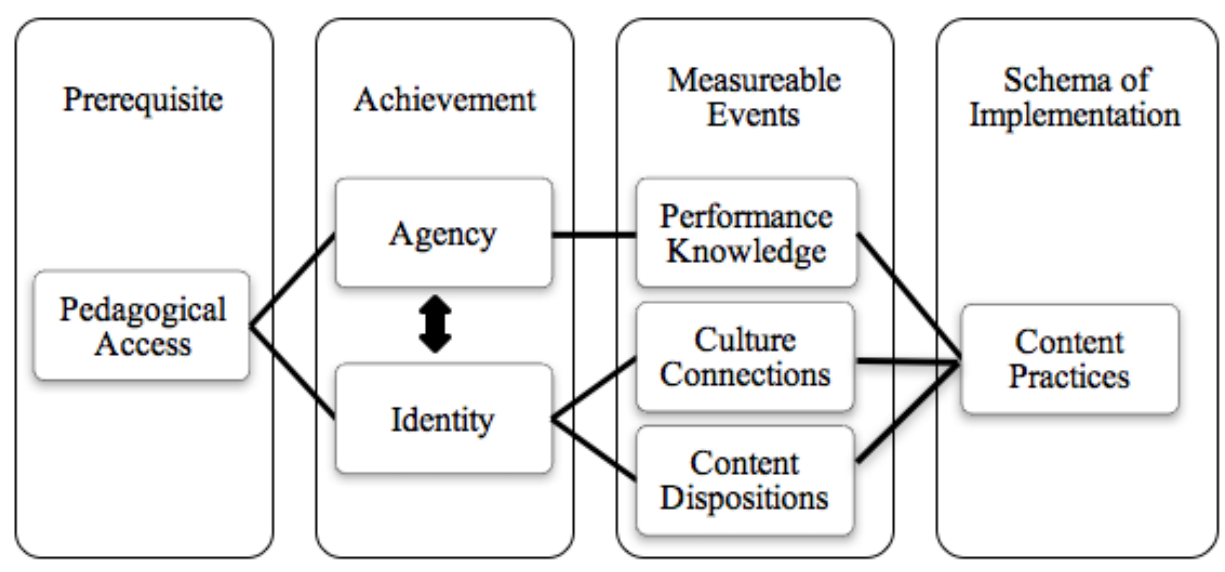

Figure 1: Development Based Interactions

Historically, student achievement is commonly compared across groups of students without regard to the systemic and pedagogical access provided to the students (Lubienski, 2008; Lubienski \& Gutiérrez, 2008). But, as I convey to my students, the output depends on the input, or in this context, the achievement depends on the access. Access denotes the availability of resources, both systemic and pedagogical. This research focuses on the issues that teachers have the authority to change - the pedagogical access; systemic access issues are beyond the scope of this study. Pedagogical access includes the opportunity to learn important, quality mathematics at rigorous levels from an effective teacher with the technology, tools, curriculum and resources that support the process of student learning. Pedagogical access influences and is influenced by agency and mathematics identity.

To characterize agency, I reviewed the research (i.e., Burton, 1999; Pickering, 1995) on the ways mathematicians practice agency. Pickering (1995) researched these ways and the coined the term dance of agency (p. 21). The dance refers to the individual's engagement in two agency types, human and discipline. Human agency creates, evaluates or analyzes an idea or concept; it is characterized as flexible and active. 
If the new idea or construct does not work, the individual returns to the concept to renegotiate. Disciplinary agency follows the established patterns within mathematics; it is characterized as more procedural, and passive. Inside the mathematics classroom, students may demonstrate human agency as they formulate, justify, or generalize a hypothesis (Boaler, 2002a; Wagner, 2007). Outside the mathematics classroom, students may demonstrate human agency as their perception of their own authority or power to create change for themselves, their environment, or their community (Turner, 2012).

For the remaining theme, mathematics identity, I use Martin's (2003) definition:

Mathematics identity refers to the beliefs that individuals and groups develop about their mathematical abilities, their perceived self- efficacy in mathematical contexts (that is, their beliefs about their ability to perform effectively in mathematical contexts and to use mathematics to solve problems in the contexts that impact their lives), and their motivation to pursue mathematics knowledge (Martin, 2003, pp.16).

Mathematics identity incorporates the ways students view their culture, and themselves within mathematics. It includes student disposition, motivation, and self- efficacy of mathematics. Now that I have provided brief descriptions of these CRMT themes, I discuss their interactions, and the other domains within my framework.

Here, I discuss these interactions from left to right for simplicity, but they also interact from right to left, and in loops. On the left, the teacher initiates the type of pedagogical access ${ }^{3}$, derived from the teacher's explicit and implicit philosophy of teaching. Moving from left to right, the type of access determines the ways students are approved (by the teacher) to display their agency and mathematics identity in the classroom. The students' response(s) are measurable in the next column of domains: Measurable Events. Performance knowledge is expressed through the ways students

\footnotetext{
${ }^{3}$ From this point forward, I refer to pedagogical access as, simply, access.
} 
interact with the content. Content dispositions are expressed through student beliefs, i.e., ability, motivation or relevancy. Cultural connections are expressed through students' combined beliefs, and interactions with the content. Observations of the students' content practices are assumed to be the implementations of the pedagogical access provided by the teachers, and thus inferred through the entire route is the teacher's philosophy of teaching. For example, if a teacher chooses to teach procedures (access), the teacher grants students' access to disciplinary agency. The students expected response is to learn procedural knowledge (performance knowledge), as reflected in their practice of procedures (content practices). These students may connect their beliefs about mathematics (mathematics identity) on whether they prefer to receive knowledge (content dispositions).

\section{Pedagogical Access}

Significant research has studied the connections between mathematics teaching practices and students' mathematical development. The National Council for Teachers of Mathematics (NCTM)'s recent publication, Principles to Actions: Ensuring Mathematical Success for All (Leinwand et al., 2014), outlines eight practices for teachers. Accomplished mathematics teachers adhere to mathematics pedagogy that includes: higher cognitive development, mutual respect, mathematical analysis, collective understanding, and engagement of students (Leinwand et al., 2014). These effective teaching practices support development of the CCSS-M mathematical practices for students found in the Common Core State Standards for Mathematics ([CCSSO], 2010). In these mathematical practices, mathematics is more than computations; students must also reason, argue, and critique -thus language is essential for students to develop 
mathematical proficiency. In classrooms where teachers provide opportunities for these practices to develop, students are granted pedagogical access to learning these mathematical proficiencies.

While there are general strategies that are effective for learning mathematics, ELs require additional strategies that attend to their linguistic and cultural differences (O'Day, 2009). Unfortunately, reports (Rubinstein-Avila \& Lee, 2014) indicate mathematics teachers do not feel adequately prepared to teach ELs. For the rest of this section, I focus on language supports for teachers to meet students' needs, especially for ELs in the mathematics classroom. I address the importance of multiple representations, highlight classrooms with various linguistic levels, and then discuss metacognitive and discourse strategies.

\section{Representation Strategies}

Significant research describes the importance of multiple representations in students mathematics learning (NCTM, 2000; 2003). In particular, research has provided evidence that student learning increased:

- with concrete manipulatives or illustrations/sketches (Butler, Miller, Crehan, Babbitt, \& Pierce, 2003),

- with the use of visual, kinesthetic and/or technological resources in a familiar context (Monk \& Nemirovsky, 1994),

- with visual representations with a variety of problems and in a variety of ways (Stylianou \& Silver, 2004),

- when curriculum emphasized variety and shifts between representations (Cramer, Post, \& del Mas, 2002), 
- when students were given the opportunity to invent, critique, modify and polish their representations (DiSessa, Hammer, Sherin, \& Kolpakowski, 1991).

- when approaches were utilized based on students' reasoning process and built on everyday contexts (Fujimura, 2001).

Mathematical representations that support student learning include contextual, visual, technological, physical/kinesthetic, and idiosyncratic representations (Butler et al., 2003; Cramer et al., 2002; DiSessa et al., 1991; Fujimura, 2001; Monk \& Nemirovsky, 1994; Stylianou \& Silver, 2004).

Moschkovich (2013) found that multiple representations engage ELs in mathematics, which in turn enhanced their learning. ELs communicate their thinking in various ways: gestures, native language, oral language, pictures, manipulatives, and technology (Moffett, Malzahn, \& Driscoll, 2014). For ELs with low linguistic levels, multiple representations were found to be especially useful to communicate their ideas, participate in class, and engage in the mathematical practices. In a $6^{\text {th }}$ grade mathematics classroom with ELs, the teacher used multiple representations as tools for the students to learn with higher cognitive demand (Hwang, Su, Huang, \& Dong, 2009). The students used virtual manipulatives, verbalization and multimedia whiteboards to express their geometric reasoning. These representations provided linguistic and mathematics support for the students to discuss, apply, discover and justify.

\section{Classrooms with Various Linguistic Levels}

In mathematics classrooms of various linguistic levels, all students can be active and successful with high quality mathematics instruction (Bell \& Pape, 2012; Brenner, 1998b). For example, the International Network for Public Schools (INPS), a multilingual 
and multicultural school systems that only admits ELs within their first four years of arrival to the United States, have a higher average graduation rate and higher average percent of ELs passing the English and mathematics exams than ELs in other New York city schools (García \& Sylvan, 2011). INPS researchers attribute their success, in part, to their heterogeneous classrooms (García \& Sylvan, 2011). These heterogeneous backgrounds include students with varied language proficiency, cultural background, and prior academic experiences, including ELs classified as significantly interrupted or limited formal education. Brenner (1998b) also found that ELs need various linguistic levels in the classroom to support the development of mathematical discourse because students gain access to language input or others and are more likely to hear appropriate mathematics language. Conversely, EL mathematics classrooms with similar linguistic levels (i.e., homogenous grouping) have been found to offer instruction that lowers the cognitive demand of mathematics tasks (DeAraujo, 2012), thereby denying students access to rigorous mathematics (i. e., pedagogical access).

Additionally, classrooms with ELs benefit from instruction that explicit attends to their linguistic needs. When a district in San Diego took initiatives to reform nine elementary schools, it was assumed that the ELs would benefit from the general "good" teaching initiatives (O'Day, 2009). The initiatives included several effective strategies: conceptual emphasis, interactive and direct approaches to literacy, differentiation, flexible grouping, scaffolding and accountable talk. These initiatives, effective for fluent English-speaking classmates, were not effective with ELs. O'Day (2009) concluded that ELs learning needed explicit language support in oral development, vocabulary, and syntax. 


\section{Metacognitive strategies}

Metacognition is the knowledge and self - regulation of (Ardasheva \& Tretter, 2012) explicit cognitive processes. Explicit instruction with metacognitive strategies showed promise for language learners, increasing their participation and achievement. Vandergrift and Tafaghodtari (2010) found that explicit instruction with metacognitive strategies correlated with higher student achievement, even for students self-assessed to be less-skilled listeners. And, in another study, students rated metacognitive (e.g., "I look for ways to be a better student of English"), social, and cognitive language learning strategies as valuable strategies that assist their achievement academically (Ardasheva \& Tretter, 2012).

Metacognitive prompts can increase student learning. Belenky and Nokes (2009) integrated metacognitive prompts in a college probability course. They found that neither abstract nor concrete materials were not independently effective in increasing student learning. However, when each were accompanied with meta-cognitive prompts (e.g., what is your approach to solving this problem, how does the solution relate to what you did), the concrete materials were effective for improving students' probability achievement. The metacognition prompts were especially impactful for students who self-reported low engagement in probability. Belenky and Nokes (2009) conclude that students need explicit instructions on how to use and reason with the concrete materials. Metacognitive strategies help students to reflect on their own thinking, shaping their mathematical identities and sense of agency, as well as supporting their mathematical achievement. 


\section{Discourse Strategies}

Discourse to serve two functions: social and cognitive (Zahner \& Moschkovich, 2010). Moschkovich (2002) argues that academic discourse must focus on much more than explicit attention to vocabulary to attend to mathematical meaning making and social interactions within the classroom. She explains, "in order to develop communication skills, students need to participate in negotiating meaning and in tasks that require output" (Moschkovich, 2008, p.579). For example, one discourse strategy is to recognize gestures as communication (Shein, 2012). In studying a $5^{\text {th }}$ grade mathematics teacher, Shein (2012) found that the teacher supported comprehension by integrating gestures and speech. The teacher revoiced students, while also mimicking the students' gestures (e.g., pointing, concrete manipulatives, etc.). As students are able to engage in discourse about mathematical concepts, they concurrently acquire vocabulary. As described earlier, being able to describe one's thinking and having others attend to one's ideas about the mathematics shapes a student's mathematical identity and sense of agency.

To develop language and mathematics, students must be positioned as active participants in the mathematics classroom so that they are able to practice the use of language and to process their mathematical thinking (Bell \& Pape, 2012). HansenThomas (2009) describes the process of positioning; the process flows from the initial passive-receptive learning to experimentation to an ultimate ownership of discourse and mathematics content. Bell and Pape (2012) highlight the need to scaffold practices to position students as competent doers of mathematics. When a student displayed hesitancy, the teacher talked "about talking about mathematical thinking" and focused 
students on specific ideas. The teacher encouraged students to understand beyond the correct answer, and the students responded with questions or elaborations on one another's ideas. In essence, the teacher's expectations resulted in an evolution in the development of a students' mathematics identity, shifting students to believe that they could understand mathematics. The teacher encouragement is an example of a teacher positioning the students with agency to justify, evaluate, rethink, test and verify mathematical ideas.

Productive discussions are classroom exchanges in which students' comprehension, learning and higher-level thinking is supported. A meta-analysis found that the most productive discussions include structure, focus, and the delegation of authority to students (Soter et al., 2008). Productive mathematical discussions for ELs attend to establishing discussion norms (Moschkovich, 1999), using and revoicing student ideas (Enyedy et al., 2008), accepting student suggestions, and encouraging students to explore and clarify their ideas (Bell \& Pape, 2012). Teachers can use student ideas to facilitate discussion, and reference previous ideas.

Classroom discussions impact student learning. For example, in an algebra classroom authority was delegated to students by requiring them to justify their reasoning and explicitly encouraging them to take mathematical risks. With this approach, the teacher created a learning environment that enhanced the rigor of mathematics instruction and students of various linguistic levels were each positioned for success (Dunleavy, 2015). Students benefited from being positioned as the one's with the mathematical knowledge because it promotes conceptual understanding, requires translation from first language to English, provides examples of academic English modeled well, engages 
students in evaluating problems, and requires an increased precision to students understanding (Enyedy et al., 2008). In other words, ELs are able to engage in the practice of mathematically proficient students, utilizing mathematical practices: justify, evaluate, rethink, test and verify mathematical ideas (Bell \& Pape, 2012).

\section{Summary}

The NRC (2001) concluded that classroom environments should value each student's ideas, methods, mistakes to help students learn. Teachers should give students' autonomy in their methods of problem solving, and scaffold students to justify and verify their reasoning. ELs and students from other cultures benefit from these strategies, as well as strategies that attend specifically to their linguistic and cultural needs.

The research described effective practices to support ELs in language and mathematics development. Inclusive to various student linguistic levels, research showed effective mathematics classrooms that utilized student collaboration in communities of practice and classroom discourse. Intentional, effective supports for student academic discourse include metacognitive learning techniques, multiple representations within mathematics, and engagement of students in receptive and expressive discourse practices. The research indicated students increased participation and/or achievement when a teacher implemented at least some of these strategies. Only one research study was found that indicated general ${ }^{4}$ ELs perspectives (Ardasheva \& Tretter, 2012); students indicated support in language when taught explicit metacognition strategies. In this way, the studies collectively indicated that the way students engage with the content can impact their participation, shape their mathematics identity, and impact their mathematical

\footnotetext{
${ }^{4}$ In this instance, general indicates classrooms not specific to mathematics.
} 
learning. Therefore having access to learning mathematics must include attention to what students are learning and how they are learning it (Schoenfeld, 2002).

\section{Mathematics Identity}

The next section, I describe the emerging literature on the student's mathematics identity in the mathematics classroom. Mathematics identity incorporates the ways students perceive mathematics in the context of their lives, their motivation to practice mathematics, and their dispositions within mathematics (Martin, 2003). Recall from the conceptual framework that a student's mathematics identity is shaped by cultural connections and content dispositions. Therefore, in the sections below I first addressed the need for cultural competency, and the influential effect of stereotype threat on students. Then I discussed research where mathematics teachers connect to the context, culture, and identity of their students. In my conclusions, I connected student mathematics identity, practices, and knowledge with the development of student mathematical proficiency.

\section{The Need}

Teacher education on social diversity and cultural competency continues to be a much-needed topic in college education (Gutiérrez, 2013). Ladson-Billings (2009) reported six characteristics of teachers who have culturally responsive practices: had high regard for themselves and others, encouraged students to make connections in their community, national and global identities, believed in all students can succeed, excavated knowledge of students, perceived him/her -self as part of the community, and perceive teaching as an art. Gresalfi and Cobb (2006) found that student engagement correlated to students' disposition of mathematics. 
Love and Kruger (2005) created a 48-item questionnaire to test the correlation of teacher beliefs with student achievement. The questionnaire used Ladson-Billings' (1994) teacher beliefs and assimilationist beliefs, described as, "teaching style that operates without regard to the students' particular cultural characteristics... [T] teacher's role is to ensure that students fit into society" (Ladson-Billings, 1994, p. 22). In the Love and Kruger (2005) questionnaire, assimilationist beliefs were reverse coded, and all beliefs were examined for correlations with high student achievement for Black students. The results predicted significance in only 4 questions (eight percent). Love and Kruger (2005) imply that these findings have important consequences on the transferability of effective teacher beliefs for Black students.

Teachers own ethnicity impacts the way in which they respond to their students based, and these differences shape their students' mathematics identities. Gregory, Skiba, and Noguera (2010) found that generally teachers responded differently to White and Black students. In an examination of teacher perceptions of motivation and achievement in Black and White students, Tyler, Boykin, and Walton (2006) found that teachers tend to perceive White behavior as positive, and Black behavior as negative. In hypothetical scenarios, the teachers rated higher motivation and achievement scores to the students who exemplified the traditional European values of competition and individualism in comparison to the students who exemplified the traditional African values of communalism and verve.

This is important because when students perceive a negative stereotype, they are likely to perform at lower levels than their capability (Walton, Spencer, \& Erman, 2013). Tyler et al. (2006) suggested explicitly training teachers in cultural competency to 
counteract negative stereotypes, and enable teachers to respond in manners beneficial to students.

\section{Culture Connections and Identity}

When teachers understand the culture of their students, teachers can connect with their students on personal levels and with contexts that increase students' mathematical understandings. The teachers can use familiar context to build student mathematical understandings. For instance, Monk (2003) uses a well-understood context and an interactive technology tool to deepen a student's conceptual understanding of college calculus. The contextual familiarity can be used as a mathematical tool to proficiency.

Contextual connections can be made to cultures, especially cultures not considered mainstream. In an Alaskan district, a mathematics unit was designed for the students to connect with their culture. In the 25 intervention schools, compared to 25

control schools, these predominantly Yup'ik, Inupiaq, and Athabaskan $2^{\text {nd }}$ grade students improved academically when taught with two units of Math in Cultural Context (Kisker et al., 2012).

Additional instances validate the transferability of cultural connections with mathematics achievement; Native Alaskan / American Indian students benefited from a culturally based math curriculum. The quantitative evidence displayed significant improved student academic performance, and qualitative evidence determined the interaction of the curriculum, community and teachers to be the cause of the improved academic performance (Lipka et al., 2005). Similarly, native Hawaiian children use their cultural knowledge base to develop meaningful problem solving (Brenner, 1998a). When teachers are able to bridge the mathematics content to students' cultures, there have been 
significantly positive results on student achievement.

Because mathematics connects with students' cultures, it simultaneously connects with students' identities. In New Zealand, a study was conducted with mainly Māori students at a primary and secondary school. Meaney, Trinick, and Fairhall (2013) attribute the academic success evidenced in this study to the incorporation of identity within the curriculum, with identity incorporated through language and culture. The relationship between math achievement and identity is described as complementary.

The previous examples were from a mono-cultural niche outside of the mainstream culture, but within their surrounding students' cultures. However, multicultural classrooms are diverse linguistically and culturally, therefore creating a different context in which a teacher is asked to bridge culture and mathematics. The INPS network is an example of a school with a multiple cultures (Fine, Stoudt, \& Futch, 2005). Many students in these schools have been displaced from their homeland to the district as migrants who cannot return to their native lands. The students are not part of a broad niche outside of the mainstream culture. Rather, the classrooms represent students from multiple cultures that are unfamiliar with one another. Additionally, INPS students were positive about the school, stating they felt academic and social achievement, and felt college ready. The schools created an environment that incorporates native language usage and culture. Assignments allowed the students to learn about their native cultures, causing one student to comment that she learned more about her home culture in New York than in her country. The students perceived their language and culture as valuable assets within the school. Furthermore they adopted a global citizen worldview that valued other cultures as assets. The study highlighted the importance of teachers 
providing assignments where students were able to express and explore their own culture and the cultures of others (Fine et al., 2005).

Student identification is one of three variables of student academic optimism correlated with student achievement (Tschannen-Moran et al., 2013). A confirmatory factor analysis explored achievement and student academic optimism: student identity with schools, student trust in teachers, and academic press ${ }^{5}$ with students from a district that serves over 34,000 students of whom $59 \%$ qualify for free or reduced lunch. The district has 35 elementary, 9 middle, and 5 high schools with student populations of $63 \%$ Black, 23\% White, and 4\% Hispanic. Results indicate that student academic optimism is a greater predictor of student achievement than SES. Furthermore SES held no significant correlation with student academic optimism, "leading us to consider the possibly that SES may not be as influential as once thought when other conditions of the school environment are taken into consideration" (Tschannen-Moran et al., 2013, p.167). The strong influence of academic optimism on student achievement is a connection to the role that student mathematics identity and perceptions of the school may play in shaping students' mathematical learning outcomes and content practices.

\section{Content Dispositions and Mathematics identity}

As described within the conceptual framework and research on CRMT, developing positive content dispositions and mathematical identity are important outcomes in and of themselves, but are also important to student development of content practices. Boaler researched the relationship between students' mathematical identities

\footnotetext{
${ }^{5}$ The academic press (also known as academic emphasis) variable is a focus on learning, high expectations, confidence in students' ability to be successful, and expectations of academic norms and practices.
} 
and achievement across three studies (Boaler, 1997, 2002a; Boaler \& Greeno, 2000). In the first study, Boaler $(1997 ; 2002 a)$ found that students in the two settings (reform and traditional) developed very different practices of mathematics. Only the students from reform classrooms demonstrated mathematical actions representative of the Mathematical Practices, and the students' procedural practices were more flexible across a range of situations. Hense, the first study indicated that how students learned mathematics shaped the way in which they engaged with their mathematics. The second study suggested that practice of mathematics connected with the students' identities in mathematics (Boaler, 2002a; Boaler \& Greeno, 2000). Students in traditional classes described mathematics to be received from the teacher or textbook. The students evaluated their like or dislike for mathematics based on their regard for the passive position of receiving knowledge. Students who rejected mathematics wanted to "pursue subjects that offered opportunities for expression, interpretation and human agency" (Boaler, 2002a, p. 44). The students in the traditional classrooms generally described mathematics passively, with irrelevance to their future selves (i.e., their mathematical identity). In contrast, the students in reform classrooms (Boaler, 2002a) described the benefit of mathematics to generate more of themselves, and their identities. These students were required to discuss, judge the validity of ideas, and create their own approaches. Boaler (2002a) described mathematics learning as a,

'dance of agency' as they [students] move between the standard methods and procedures they know and the new situations to which they would apply them. They do not only talk about their own ideas, they talk about adapting and extending methods and the interchange between their own ideas and standard mathematical methods. (Boaler, 2002a) 
These students practiced mathematics with human agency, and developed positive mathematical identities and dispositions.

In the third study, Boaler (2002a) expanded her description of students' relationship to the discipline of mathematics to be the interchange of knowledge, identity and practice (Figure 2). Students in reform classes were observed and monitored for their learning. The students were required to use and apply mathematics. They would propose, explain, justify and critique mathematical approaches. Boaler described the students' engagement with mathematics as both Knowledge

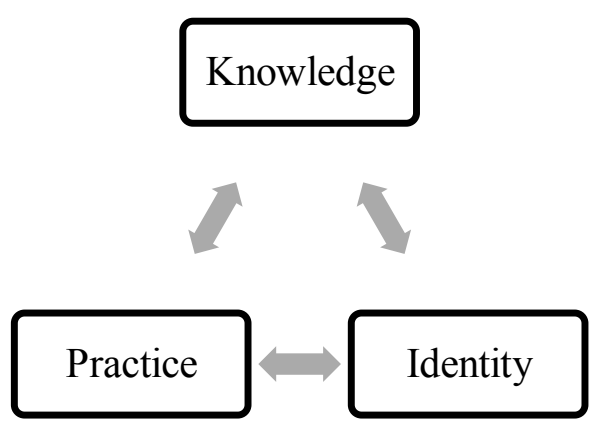

Figure 2 Mathematics Relationship (Boaler, 2002a)

disciplinary agency and human agency. The students with human agency were able to transfer their mathematics knowledge to new mathematical situations, and saw the value and benefit of mathematics. Across these studies, connections were made to role that engaging the content practices has on shaping students identities, whether in traditional or reform classrooms.

The NRC (2001) described students' overall knowledge and dispositions toward mathematics as their mathematical proficiency. Productive Disposition, one of the five strands of mathematical proficiency, develops with the other proficiency strands.

Productive Disposition,

refers to the tendency to see sense in mathematics, to perceive it as both useful and worthwhile, to believe that steady effort in learning mathematics pays off, and to see oneself as an effective learner and doer of mathematics (italics added, $\mathrm{p}$. 131). 
This description connects students' perception, practices, and identity within mathematics to their overall mathematical proficiency. The value of mathematics is influenced by the students' persistence, perceptions, practices, and beliefs in mathematics. The research reported in Adding it $U p$ related to productive disposition focuses primarily on student attitudes, efficacy, and beliefs about the nature of mathematics. Other aspects of the productive disposition strand have not been examined, such as student beliefs about the importance of mathematics in their lives (as opposed to general society) (NRC, 2001).

More recent research correlates student beliefs about mathematics reasonability and usefulness with their mathematics proficiency. Langlie (2008) found a strong, positive correlation between Black and Hispanic student achievement and teachers who report emphasizing mathematical interest, importance, and application to science and business. Langlie (2008) concludes students need to interpret mathematics as a useful endeavor to accomplish.

\section{Summary}

It is a common to believe that mathematics benefits general society, but less common to believe that mathematics benefits oneself as an individual. Research indicated the interconnected influence on students' mathematics identity, practices, and achievement. It follows that these interconnections influence students' mathematics dispositions. The research to connect mathematics identity, practices, and achievement connections are not high in frequency but nevertheless align with other research domains. For instance, the negative influence of stereotype threat on achievement is repeatedly documented in research. The access to positive mathematics identity and practices 
improved student achievement. Teachers have accomplished this through a) connections to student culture and b) mathematical practices that incorporate human agency.

\section{Agency: Performance Knowledge}

The following sections are placed into and discussed in three levels that represent a progression of critical knowledge: agency to do mathematics, connect mathematics to society, and use mathematics to improve society. The levels should be seen as a progression of critical knowledge. For students to use mathematics to improve society, they have to use mathematical practices and connect mathematics to society. Although the levels are progressive, it is unclear whether mathematics classrooms should be required to meet each level.

\section{Agency to Do Mathematics}

The traditional nature of mathematics classrooms does not allow students to practice mathematics in a manner similar to that of mathematicians. In fact, Burton (1999) explained that many mathematician practices are not practiced in traditional mathematics classrooms. Particularly, mathematicians approach mathematics in several different ways, make connections between mathematics and other disciplines (1999), use visual representations (Stylianou \& Silver, 2004), incorporate a mix of both standard and idiosyncratic methods of thinking (Greeno \& Hall, 1997), and tend to enjoy the aesthetically pleasing nature of mathematics (Burton, 1999).

Lockhart (2009) described mathematics as an eloquent art form, which is undermined systematically in the classroom and in society. He passionately argued for mathematics classrooms to employ such human agency.

Mathematics is the art of explanation. If you deny students the opportunity to engage in this activity - to pose their own problems, make their own 
conjectures and discoveries, to be wrong, to be creatively frustrated, to have an inspiration, and to cobble together their own explanations and proofs - you deny them mathematics itself (p. 5).

Mathematics is an art form about discovering, conjuring, and reasoning. Mathematicians' practices set a standard for how students should practice mathematics.

Students are capable of conjuring, evaluating, and formulating new hypotheses (Bell \& Pape, 2012; Dunleavy, 2015). If a student becomes hindered, instructional scaffolds and peers can provide support. Society may assume that mathematicians work in solitary, but multiple studies verify the frequent collaboration of mathematicians (Burton, 1999).

Large and small group collaboration gives agency to students that align with the mathematician practices. In a classroom reflective of the CCSS-M mathematical practices, the students create hypotheses. The students' methods or conjectures are shared with the group. The class critiques with agreed upon verification methods. The result either brings confirmation from the broader mathematical community or brings a transformed hypothesis. As students emulate these mathematician practices, agency is formed through the authority given to the students to work as mathematicians (e.g., Bell \& Pape, 2012; Dunleavy, 2015).

\section{Agency to Connect Mathematics to Society}

At the next level of agency is seeing that mathematics can be used to understand societal issues. It adds an additional component to the critical knowledge -the critique of the power dynamics of the economic, political and social system. Teachers explicitly connect mathematics content, students' cultures, and students' identities with the power dynamics of the community, society, and politics. The goal is to empower students to 
raise their consciousness to the extent of oppression, motivate the students to change the oppressive circumstances, and learn how to effectively change the system (Gutstein, 2007). The term used to describe such teaching is critical mathematics (CM). Literature in this domain focuses on examples of such teachers and the challenges and successes they have encountered. Several are shared in the paragraphs that follow.

Gregson (2013) described an example of connecting mathematics and societal issues through a description of a full time mathematics teacher who was committed to engaging her students in community and social issues, Katherine Myles. Myles lives and teaches in her community where she is an activist and has influenced the foundation of her school's commitment to social justice. Because she was committed to empowering her students to critically evaluate the world around them, especially in relation to their community, Myles connected her lessons to relevant, community issues because she saw the benefit in preparing students to fight oppression.

In his remedial, high school geometry course, Brantlinger (2014) also used critical mathematics material that emphasized social relevance and politics without his opinion interfering with his student opinions. As he attempted to raise student consciousness of social inequities, he ran into tensions in creating a non-evaluative space and developing a critical mathematics perspective. The students did find the system to be inherently inequitable, but rather spoke against minorities in a hegemonic way. In his experience, several students expressed desire for more traditional mathematics (2013), actively resisted (e.g., saying "you should teach history if you want to discuss politics" (p.1067)), or displayed resentment towards the sociopolitical issues (2014). On one such day, Brantlinger showed a chart meant to invoke a sociopolitical consciousness. As the 
students began to interpret the chart, a student commented, "It's a racist ass chart man" (2014, p. 212), and another student asked him to remove it. Brantlinger (2014) assumed that a critical mathematics perspective would assist students to see the validity and importance of diverse perspectives, yet there was no evidence that the critical perspectives deepened mathematical understanding or understanding of social power structures.

The two examples provided her show the complexity at this level of developing agency. In one case, the teacher advocated for her stance; in the other case, the teacher tried to remain neutral. In one case the results were insights to better understand society and in the other case, their was not deepening of sociopolitical consciousness. Teachers are challenged to consider how and when social justice issues should be connected to mathematics learning. Pais, Fernandes, Matos, and Alves (2012) describe a high school mathematics teacher who believed in the importance of connecting mathematics to social issues, but felt pressure to only offer such instruction with a math club rather than during mathematics courses. Bartell (2013) also described teachers who have difficulty adequately connecting the social justice goals to the mathematics content. In the planning phase, the teachers focused more on the social justice goals, and intentionally created a lesson with mathematics and social goals. But in the classroom, the teachers did not focus on the social justice goals. Kitchen (2005) also recognized these struggles as a college professor. He taught explicit and implicit strategies in his mathematics methods course. His strategies included: a foundation built on trust and respect in the classroom community, the inclusion of multiple and diverse cultures in mathematics, and the contextualization of the political and social mathematics of the media. 


\section{Agency to Use Mathematics to Improve Society}

In this third level, agency implies action, so mathematics is used in order to address an agenda to overcome inequities. Several researchers have suggested that helping students learn to use mathematics to unveil injustices and to work towards justices is necessary to meet equitable standards (Aguirre \& Zavala, 2013; Martin, 2003). Gutstein $(2007,2006)$ provided examples of using mathematics to understand and engage in political advocacy. For example, he developed a project that compared the cost of a B2 Bomber with college tuition (Gutstein, 2006). He further outlined ways to develop student agency using Mathematics in Context and a series of real-world projects (Gutstein, 2007). One supplemental project started with a student's description of her brother, who was in the Navy, not having money for college. The goal was for the students to engage in a political discussion about the allocation of society's resources.

Another example of using mathematics to examine society is to challenge systematic access of schools (Turner, 2012). In one such case, the teacher positioned her students to claim mathematical authority and critically evaluate the overcrowded school space, in relation to number of enrolled students. The students took a political stance, critiqued the system, and engaged in challenging the system. In another case, an afterschool math and girls club for diverse students, fifth grade girls used mathematics to advocate for their school to remain open (Varley Gutiérrez, 2012). The district school board used mathematics to argue the school needed to be shut down (e.g., low enrollment, low performance on standardized tests, and capacity of surrounding schools was deemed sufficient to hold these school members). The girls investigated and critiqued the school board's data, and were able to challenge the district mathematical 
arguments with other mathematical data, and their action resulted in the survival of the school (Varley Gutiérrez, 2012, p. 152). The investigation process and critique of data allowed the students to connect mathematics to their community and act as social agents. The end result increased student empowerment, mathematical reasoning, and ultimately saved the school from a vote to close.

\section{Summary}

The agency research was divided into three progressive levels of critical knowledge. The first level, students emulate mathematician practices as they create hypothesis, share methods and conjectures, verify and validate with their peers, and either confirm or transform accordingly. At this level, students realize that they are able to use mathematics as active participants of mathematics in a variety of methods. The research presents clear, consistent and convincing evidence that students learn with the human agency of mathematician practices. In the latter two categories, research provides illustrations of how to make such connections, examples of being an agent of change, and evidence of the challenges and difficulties that may exist in trying to teach critical mathematics, however, these two levels have been difficult for teachers to implement and have not been studied at scale.

\section{Conclusions}

This literature provided insights into the ways teachers may provide access to the CRMT foundational areas of language learning, culture and critical knowledge. The language learning research recognizes the importance and necessity of explicit attention to students' linguistic and language needs as they develop their mathematical identities. Students learn with discourse practices that incorporate various linguistic abilities, 
mathematical practices, metacognitive learning techniques, and multiple representations, impacting both a student's mathematics identity and agency. Research suggested a high need for making culture connections as a way to support the development of mathematical identities. In fact, research indicated that mathematics proficiency itself is interconnected with student culture, mathematics identity, and content practices. Agency has multiple levels. Classrooms with human agency reflect mathematics practices and release authority to students. Agency also involved connecting mathematics to society and using mathematics to positively change society.

Rochelle Gutiérrez says, teaching is identity-in-the-making. Research strongly supports this stance. Students' mathematics identity and agency is connected in complex ways to access to mathematics learning opportunities in the classroom, which I refer to as pedagogical access. While research has identified some connections between pedagogy and students' identities and agency, more research is needed that might identify specific teacher actions that impact students' emerging mathematical identities. To that end, no research to date has originated with students' perspectives on which teachers they find to be highly effective. Additionally, the large majority of research on culturally responsive mathematics instruction, in particular as it relates to developing a sense of mathematics identity, is focused on one culture. An unanswered question is what teaching practices might result in a high level of mathematics identity and agency in classrooms with three or more cultures represented. The limited research on multicultural classrooms does not focus specifically on the mathematics classrooms. The study described in the next three chapters contributes to the research base because it addresses these two voids in the literature: it begins with student voice in terms of teachers they describe as highly 
effective and it then looks at how such highly-rated teachers who teach in multicultural ${ }^{6}$ classrooms implement mathematics instruction.

${ }^{6}$ As indicated previously, a multicultural classroom is characterized by three or more cultures in a classroom, with at least one student who identities with a non-native culture of the region. 


\section{CHAPTER III}

\section{METHODOLOGY}

For nearly two decades, Culturally Responsive Mathematics Teaching (CRMT) research has been conducted with teachers identified as effective by researcher(s), administrators or parents. Research on teachers identified by students may inform the CRMT field about teacher practices that evoke positive student responses. The results from this research may offer opportunities to discuss the implications of emphasizing or deemphasizing under-rated or over-rated factors, respectively, in CRMT research.

The study used multiple-case qualitative design to explore the prevalent teacher practices in their multicultural mathematics classrooms. Focus was given to three CRMT dimensions: language, culture and critical knowledge. I examined the following questions:

To what extent, and in what ways, do highly student-rated teachers incorporate 1) multicultural instructional practices, 2) language support, and 3) critical knowledge in their multicultural classrooms?

Teachers were identified from a result analysis of a student-response survey. The students rated their teacher and classroom environment on seven categories with multiple items for each category. The items included, "My teacher has several good ways to explain each topic that we cover in this class" (Transparency), and "My teacher checks to make sure we understand what s/he is teaching us" (Understand). The complete list of items separated by categories are located in Appendix A, survey comparison. The 
teachers' practices were researched to examine their prevalent CRMT practices with a modified CRMT tool (Aguirre and Zavala, 2013) for data collection. Data sources included interviews, observations, and lesson artifacts.

\section{Research Design}

Three cases were chosen to explore the contemporary classroom phenomenon of student-rated, effective teachers. In accordance with Yin (2014), a case study approach is applicable to 1) descriptive research questions (p. 19), and 2) when the researcher cannot control or manipulate the behavior events in the existing phenomenon (p. 12). When the case is not unique, there are advantages of using multiple cases. Yin (2014) specified, the research skills are not limited to one case, and there is an analytical possibility of direct replication under varying contextual circumstances. Yin described the number of cases as discretionary judgment. In this particular study, a three-case design was selected to research teachers' practices in-depth.

In the first section, I began with general correlations between teacher effectiveness and highly student-rated teachers. I compared the tripod survey, found to be valid and reliable (Kane et al., 2013; MET project, 2010), with the student voice survey - used in this research. Then I discussed the Teacher survey, and the setback that changed the final identification and selection process of the teachers. In the next section, I described the data sources in detail, and explained their purpose and selection rationale.

\section{Teacher Identification}

The nature of this design was to capture multicultural classrooms with varied samples of students' educational background, and linguistic development. Boaler (2003) suggested that standardized tests for these students may be skewed, particularly with 
English learners. Therefore, standardized test data was not used to identify effective teachers with classrooms of multiple cultures and linguistic levels. Instead, teachers were identified through the results of a student voice survey.

The forerunner to the student voice survey was the tripod survey. The tripod survey was found to be a valid measure of teacher effectiveness in 7 different U.S. districts (Kane et al., 2013), and was distinguished as the measure with the highest reliability (Measures of Effective Teachers [MET] project, 2012). Shortly following this research, the Council of Chief State School Officers (2012) endorsed the tripod survey. This influenced the state's Department of Education to modify the tripod survey to the student voice survey, and require annual results for all qualifying teachers. The modifications from the tripod survey to the student voice survey were minimal. The words from the student response items were not altered, but some items were excluded: all of the reverse coded items, and 5 other items. These surveys with their specific differences can be found in Appendix A, survey comparison.

The student voice results identified the teacher-subjects, and this design aligned with my positionality that student perspectives are necessary for CRMT.

Student Voice results. The student voice results came from an annual student response survey required each year by the state's Department of Education. The district provided access for multilingual students through translations of the survey into at least six languages. The state and district required precise regulations to accurately capture student responses. For instance, as students responded, the rated-teacher was not allowed in the room. And, a minimum of 10 student responses were required. 
Table 3 (below) displayed the positive teacher-subjects' results by student voice category. Every category score averaged its student-rated items. The students responded to the survey items on a five point Likert scale. If the students rated the teacher as either Yes-Always or Yes-Mostly the student response was viewed as positive. The table 3 scores reflect the positive responses from students in the teacher-subjects' classrooms from the year of this research.

Table 3

Student Voice Results by Category and Teacher

\begin{tabular}{lccccccc}
\hline & Support & Transparency & Understand & Discipline & Engage & Nurture & Trust \\
\hline Marlon & 77 & 81 & 79 & 68 & 80 & 63 & 75 \\
Yasin & 86 & 86 & 87 & 50 & 81 & 82 & 71 \\
Abigail & 85 & 87 & 87 & 82 & 83 & 79 & 82 \\
\hline
\end{tabular}

Teacher Survey. A teacher survey was used to identify potential teachers. The survey requested that teachers provide demographics about themselves and their students, and self-report their student voice results. The student demographic information was necessary to identify the types of various cultures represented in the teachers' classroom, and whether the teacher met the multicultural requirement.

\section{Data Sources}

I followed Yin's (2014) recommendations for qualitative case studies design. This included the use of multiple data sources (Yin, 2014) to increase construct validity. Data sources included classroom observations, teacher interviews, and lesson artifacts. Yin (2014) described field experience, i.e., classroom observations, as convincing. Simon (2006) described teacher interviews as beneficial for the examination of teacher perceptions. Yin (2014) described artifacts as useful information; lesson artifacts provided information about instructional practice and community interactions. To 
follow, each section described the data source, its purpose, and methods to increase trustworthiness.

Teacher Interviews. Three teacher interviews occurred during the observation period. The interview protocol questions were intended to prompt the teachers to explicitly discuss their pedagogical philosophy. Each interview focused on one of the three dimensions identified in the research question: multicultural instructional practices, language support, and critical knowledge. These semi-structured interviews utilized an interview protocol (Appendix B), and lasted between 30-45 minutes. Time was reserved for 2-3 follow up questions for clarification or additional information.

Before analysis, the interviews were audio-recorded and transcribed.

Transcriptions omitted filler words (i.e., umm), repeated phrases, and side conversations (i.e., a co-worker walks into the room during the interview). These interview portions were not transcribed because the portions did not interfere or add additional meaning to the data itself.

Observations. Observations assisted the examination of teachers' practices and teacher-student interactions (Glesne, 2016). Observational data was collected with the Lesson Observation Tool (Appendix C), and for two of the three teachers these observations were also audio recorded. Field experiences provided firsthand descriptions of the implementation of content practices, and the pedagogical access provided by the teachers. The pre-determined time frame for classroom observations was from the unit's concept introduction to student summative assessment, approximately, every day for two to four weeks. When observations, interviews and artifacts no longer provided new 
information, observations were deemed unnecessary because data had achieved saturation.

Lesson observation tool. The CRMT lesson analysis tool (Aguirre \& Zavala, 2013) was modified for the purpose of this research, and became the Lesson Observation Tool (Appendix C). The original tool was intended for teacher self-reflection and nonevaluative professional growth. The tool modifications shifted focus to the three major dimensions identified in these research questions, and created additional space for observation notes. Of the eight CRMT dimensions, only the three dimensions relevant to the research questions remained: multicultural instructional approaches, language support, and critical knowledge. The elimination of frequency and valuation language from the original observation tool created space for notetaking. The final sub-topics, and guiding questions were positioned in the left column. In addition, modifications aligned to my Development Based Interactions, and any additional research presented in the chapter 2, literature review. These sub-topics were positioned in the right column.

Pre-observation quality control. Two methods of quality control were used for observations. The first method occurred before observations commenced. I formed a team consisting of myself, and two doctoral students. The team watched a mathematics lesson video (used for practice, and not included in these research results), and recorded data with the lesson observation tool. The team compared the data and discussed their observations related to 1) identifying aspects of instruction aligned with the dimensions and 2) capturing those instances in sufficient detail. The team sought to reach common understanding and consensus on the observational data to record. Then the team watched another video lesson and repeated the process. They continued until observations 
independently recorded similar data. I enhanced my observational ability with the gained experience from these practices.

The second method of quality control occurred post observations. For the teachers that opted to be audio recorded, I listened to the first lessons and repeated the process of recording that data on the lesson observation tool. The original and new tools were compared. If additional data arose, it was combined with the original lesson observational tool. I continued to listen to the audio lessons until the additional data ceased. As I observed, I jotted down any instances to revisit, and listened to the recording within the next three days. During the data analysis, I revisited the audio recordings if I wanted to find the exact phrasing from the teacher(s) or student(s).

Lesson Artifacts. In addition to interviews and observations, I collected lesson artifacts such as handouts, student work, and teacher visuals. Handouts are an unobtrusive source of information that teachers develop or review. Lesson artifacts were only collected if they were relevant to the research questions. For instance, a handout would not be collected if it contained mathematics problems devoid of language support or context. However, if a handout was collected if it included information across or between culture groups. When a student's response indicated a possible connection to a research question, then the students' response was collected as an artifact.

Journal and Voice Memos. Every day I was in the field, I collected data and practiced reflexivity. Most days I wrote in a journal, but when time was short, I dictated my reactions and responses as a voice memo. Sometimes, I used both the journal and voice memos. The voice memos captured ideas as I transitioned between classrooms, or anytime I was unable to immediately write, i.e., when driving. In both mediums, I 
recorded my initial thoughts, feelings, and reactions. I also recalled incidents or interactions, especially those outside of the classroom i.e., at lunch, random comments from the teachers to me, or as I transitioned from one classroom to another.

The dual format of both the journal and voice memos allowed me to record my initial reactions, and my more dominant internal processing of the data. I transcribed the voice memos to the journal every week. As the author of both the journal and voice memos, I did not use direct transcription, but I kept all the ideas presented, even the ideas later deemed as irrelevant. This "Data Collection" journal was upload and coded in NVivo. This journal assisted me to track specific codes, reflect, and provide specifics in the ensuing Data Analysis.

\section{Context}

Here, I provided contextual information on the sociopolitical setting. The data collection occurred in 2017, a couple months after President Trump was sworn into office, which due to his efforts to change immigration policies had created significant emotional duress for students. Due to delays beyond my control, the lesson observations began with six weeks of school left, and ended with one week of school left. To follow, I provided information on the district, school, teachers and their classrooms.

District. The district is a major school district in the east-central United States with a multicultural student population of $37 \%$ Black, $7 \%$ Latinx, $7 \%$ other, and $49 \%$ White. Of the more than 100,000 students in the district, approximately 7,000 students are ELs that speak a combination of 123 first languages. Two national, non-profit organizations influenced the regional placement of refugee families. As a result, numerous classrooms in this district are multicultural. 
In general, the district contains high poverty populations with an average of one in six students below poverty line. However, many schools reflect concentrated poverty and show educational disparities. For example, approximately two-thirds of schools average $97 \%$ poverty in comparison with the district's $16 \%$ average. The range of reading proficiency ${ }^{7}$ fluctuates from $18 \%$ proficient high school students to another at $92 \%$ proficient.

As part of an ongoing effort to improve student scores, the district and state incentivize their teachers to earn their National Board certification. In this measure, the district achieved an average of 2.6 national board certified teachers per school. This is beyond the state's legislative goal of one national board certified teacher per school, and implies the potential of excellent teachers. Therefore, the district represents the demographics of a multicultural classrooms, and shows high potential for successful teachers.

School. All teacher-subjects taught at one school, Green Valley institute for English learners. Green Valley is a $6^{\text {th }}-10^{\text {th }}$ grade, sheltered instruction school with $95 \%$ free and reduced lunch, $66 \%$ refugee status, and 100\% migrant population. The students were tracked into classrooms based on the students' background in formal education. On average, each classroom represented six to eight languages, and more student cultural groups.

To be accepted into the school, students tested below a 2.5 on a WiDA diagnostic measure of receptive and expressive skills. The WiDA measure placed the students' English development on a progression from Entered to Reached development that ranged

\footnotetext{
${ }^{7}$ For simplification, I use proficiency to be inclusive of distinguished scores.
} 
from 1 to 6 , respectively. In general, a 2.5 verbal score recognizes the student can communicate socially with some detail.

The original research design intended the teachers to come from various qualifying schools within the district. However, the district restricted access to qualifying teachers, and the net result meant 1) the teachers taught at one school, and 2) positioned me as more of an insider. Due to prior connections at Green Valley, I knew the teachersubjects before this research: Abigail (eight years), Marlon (seven years), and Yasin (seven months).

Teacher-subjects, their students, and classrooms. These mathematics teachers were invited to participate in the study based on two criteria: a) their teaching occurred in multicultural classrooms, and b) these teachers had received high ratings in the student voice results survey. High ratings were considered an average of $75 \%$ or higher. Although not a qualifying criterion, it is noteworthy that each teacher happened to be recognized for a prestigious teaching award within the last year. In the subsequent section, I presented a profile of each teacher. The identify of the teachers and their students were protected with pseudonyms.

Yasin. Yasin is a Turkish migrant, recognized in his local community for his volunteer work with Syrian refugees. It was Yasin's first year at Green Valley, but he had several years of teacher experience at a dominantly White middle school. At Green Valley, Yasin's student demographics included: Somali, Arabic, Turkish, Syrian, Central American, Congolese, Ethiopian, and Mongolian. His classroom was a mixed group of $6^{\text {th }}-8^{\text {th }}$ graders with significantly interrupted or limited formal education. The students' 
backgrounds challenged Yasin, but he welcomed the challenges and requested the same classes for the next school year.

Yasin's small classroom had limited options for classroom setup. The students sat at tables arranged in rows, often times with elbow partners shared their language(s). Yasin's students rated him highest on support, transparency, and understand in the student voice survey. When a visitor from a local University saw Yasin's instruction, the visitor nominated Yasin for an award presented at a prestigious ceremony with the Mayor present. Yasin did not choose the option to have his class sessions audio recorded.

Marlon. Marlon migrated from Cuba where he taught mathematics, physics, and astronomy. He earned his Master's degree in Russia as a Russian language learner, and then taught at a Russian college in Russia. Back in Cuba, Marlon almost completed his doctorate about Albert Einstein and a biographic book to motivate students in physics and mathematics. His dissertation defense date was set, but he moved to America before his defense. Due to government restrictions on his teaching credentials, he just recently (2 years ago) moved into a teaching position at this school.

The previous year Marlon taught middle and high school classes, but he exclusively taught high school students at the time of data collection. His observed classroom was considered a high school, special topics mathematics classroom. The class allowed students to earn their elective mathematics credit and prepared students for algebra the next year. His student came from Cuba, Guatemala, El Salvador, Honduras, Uganda, Somali, and Iraqi. Together, the students' native languages included Spanish, Kinyarwanda, Somali and Arabic. 
During class time, students sat at tables shaped in a double $\mathrm{U}$, an inside and outside $\mathrm{U}$-not to be confused with a $\mathrm{W}$. The students did not have assigned groups or seats, and they regularly chose to sit next to students who shared their language. The students rated Marlon strongest student voice categories as transparency, understand and engage. This indicates Marlon's explanations are clear, his feedback helps the students learn, and the students enjoy his teaching style.

In the data collection time with Marlon, there were a couple of unexpected events. For several days, I arrived for my observations to find that Marlon had been pulled from the classroom to translate to Spanish for a state mandated test. In addition, he had health issues that kept him away from the classroom for several days. When the interruptions ceased, it was so close to the end of the school year that it seemed specific math learning targets were not present. As a result, Marlon's data is limited in comparison to the two other teachers.

Abigail. Abigail is a White American with seven years of teacher experience at Green Valley. She described Green Valley as a pleasant environment where she has the opportunity to view the world through her students. At time of observations, she was in the process of completing her National Board teacher certification for mathematics.

The observed classroom was an algebra class with thirty-two students that ranged in WiDA proficiency levels from 1.5 to 3.2 with the most frequent and median at 1.9. Her students migrated from seventeen different countries, and speak thirteen different native languages. Spanish speakers were the majority in the class with a mix of native Spanish speakers, plus students from countries where Spanish is a common, regional 
language. Abigail doesn't fluently speak another language, but intentionally learns several words/ phrases from her students' languages.

Abigail's desks were setup in rows, but rarely remained in place. The students moved their desks around as needed, and returned the desks to rows at the end of class. Students rated Abigail's highest student voice categories as transparency and understand. The principal nominated Abigail for a district award only presented to five teachers in the district. After interviews and observations that spanned a year, Abigail won!

\section{Ethical Considerations}

I adhered to ethical considerations in multiple ways, which included the approval of the Institutional Review Board (IRB), and the district. I invited potential participants to be subjects in this research. I disclosed the research purpose, obtained permission to collect data from the teacher-subjects, and provided the letter to inform parents of student-subjects. I used pseudonyms to protect the identities of the teachers, students and district. There were no foreseen risks for either teachers or students, the potential benefits may contribute to the support of teachers and students in a multicultural, mathematics classroom. The published data results were made available to the district.

\section{My Lens}

I believe that students' perspectives are essential to CRMT, and students can identify effective teaching when they experience it. Although I desire teachers and students to proportionally reflect one another identities, at this time, teachers are largely White (Boser, 2014). So I regarded it necessary to research effective White teachers of multicultural classrooms, in order to provide beneficial examples of the ways White teachers might connect to their multicultural students. This belief connects to my own 
White identity, and my desire to connect, educate and empower my multicultural students.

\section{Trustworthiness}

As recommended by Maxwell (2005), I examined specific threats and articulated how I strengthen validity or reliability. The threats included the potential for false or exaggerated interview answers, and my own researcher bias. I conclude with several practices used to maintain the rigor of this research.

To decrease the threat of potential false or exaggerated interview answers, teachers were assured of protected anonymity. I built rapport with them and assured them of my gratitude and delight to be in their classroom. During the interview, all of my questions were asked with positive pre-suppositions. For example, instead of do you consider, I asked in what ways do you consider. The latter example holds a positive presupposition that assumes the teacher already considers. As the teacher responded, I frequently asked the teacher a follow-up question to elaborate or exemplify. Data sources were examined for data triangulation.

District restrictions restricted the calculation of the top quartile student voice results. As a result, the highly-rated teacher's score was the subjective cutoff of $75 \%$ positive responses. Although unplanned, each teacher happened to win an individual and prestigious teacher award within six months of the observation. This provided more evidence of the teachers' effectiveness.

To decrease the threat of researcher bias, I wrote my positionality (here and within a journal) and continued to document possible bias in my journal and with voice memos. I reflected on the data collection process, my interactions with the teacher and 
observations from the classroom. I examined my own values, assumptions and biases. I reflected and communicated my positionality with these intentional efforts.

In summary, I maintained several case study practices (Yin, 2014, pp 19-21, 45) throughout the research process to increase trustworthiness. Triangulation of data sources verified the findings, as well as the teacher selections. Before observations ${ }^{8}$, two team members and I came to a consensus upon the process of data collection. The observations of Marlon and Abigail included audio recordings for accuracy of data collection. During data analysis, I revised and revised codes across multiple iterations, and created an audit trail of the two phases (Miles, Huberman, \& Saldaña, 2013; Saldaña, 2013).

\section{Limitations}

The research examined and described the prevalent practices of three highly rated teachers of multicultural students. The research provided a snapshot of the common practices of three teachers at one multicultural school for ELs.

This research was restricted by district and state requirements. One requirement limited the access of teachers. Another requirement did not allow the calculation of the top quartile positively recorded percentages of the student voice results. This resulted in a rather arbitrary cutoff of $75 \%$ positive responses. Another requirement limited the survey to the student voice survey, rather than the preferred tripod survey-found as a valid measure of teacher effectiveness (Kane et al., 2013; MET project, 2010). No research was found on the student voice survey as a valid or reliable measure of teacher effectiveness.

${ }^{8}$ These practices were described in Methodology $>$ Research Design $>$ Data Sources $>$ Observations. 


\section{Data Analysis}

This research used multiple case -study methodology (Y in, 2014) to analyze the data. The Development Based Interactions provided a fundamental role in the explanation and interpretation of the research questions. The data collection provided evidence of teacher actions related to CRMI, specifically cultural connections, attention to language, and critical knowledge. Y in (2014) suggested that implications are stronger when replication occurs across various case study contexts. Therefore the focus of data analysis was to identify recurring themes and common teacher practices related to the three components of CRMI listed above.

Saldaña (2013) recommended two phases of data analysis, and multiple iterations of data analysis within each phase. The first phase of data analysis included two iterations of coding: initial and protocol coding. The second phase organized and themed the data into focused coding.

\section{Phase I: Initial and Protocol Coding}

Yin (2014) suggested that effective case study researchers collect and analyze data simultaneously. So, phase one commenced during the five weeks of data collection and lasted until approximately a week after data collection. Following each lesson observation, I uploaded the data to NVivo (an electronic coding program), reviewed the data and began initial codes (Saldaña, 2013). In this iteration of initial codes, only one teacher's lesson observations were coded in a setting, so that data gathered from one lesson would not bias data gathered from another lesson. This continued for the five weeks of data collection, and after the completion of the data gathering. Later, I analyzed codes and categories found across the teachers. I used NVivo features to explore and 
analyze my data, and continuously educated myself on this program with live online seminars and tutorial videos. The NVivo "coding stripes" feature allowed me to view the data, and the assigned codes. I used this feature throughout the analysis to visit, code, revisit, and recode the data.

In initial coding (Saldaña used this term to replace open coding), I characterized the teacher or student action that I noticed. For example, when a student read the lesson objective, I coded it as "lesson objective" and when a teacher made a reference to the community I coded it as "community reference." At the end of this initial coding there were over 60 codes. If a code became too broad (e.g., Vocabulary Focus), I recoded the data into more focused codes, (e.g., Basic English, Prior Academic Vocabulary, and Current Academic Vocabulary). I assigned code descriptions for all remaining codes. For instance, Prior Academic Vocabulary ${ }^{9}$ refers to academic vocabulary from grades levels that are two - three years below the state standards. The code descriptions uncovered redundant codes which were then combined to ensured consistent identification and transparency across the data, and facilitated the sorting process. The descriptions also allowed codes to be more accurate depictions of the data. For instance, the Real Life Mathematics code originally indicated any reference to mathematics outside of school. But as I reviewed this code, I noticed that the teachers referred to mathematics in a variety of ways. To distinguish these differences, I created codes within Real Life Mathematics. Specifically, Application -reference to the use of mathematics in an everyday setting, Examines Society Issue -reference to the use mathematics to

\footnotetext{
${ }^{9}$ Academic Vocabulary refers to grade level terminology, and possibly terminology from the prior year's state standards.
} 
understand a deeper issue in society, and Future -reference to why the students need mathematics in their life.

In the second iteration of coding, I implemented protocol coding (Saldaña, 2013), and revised the codes. I looked at each of the codes from the initial process and mapped them to the CRMT dimensions to see to what extent they aligned and whether the language of my codes was consistent with the research in the field. I continuously returned to the raw data within each code to ensure that the descriptors and labels were representative of the data. I then re-coded the data with the three CRMT dimensions (Aguirre and Zavala, 2013) that aligned to my research questions: culture, language and critical knowledge. The data was examined, re-examined, coded and re-coded. If the code or data did not align, the data was re-categorized, or the code was relabeled to reflect the data.

To discover potentially overlooked codes or categories, I sought alternative ways to view the data. I examined other research studies that offered teacher characteristics. I moved or duplicated the data to new categories to see if it was a better fit. I took breaks from the data analysis for a couple days, and upon my return brought a refreshed perspective. I used NVivo features to identify frequent words or synonyms. I searched for limited or missing codes or categories. For each teacher, I created NVivo sets that assigned the raw data to each teacher.

\section{Phase II: Pattern Analysis}

Informal pattern analysis occurred throughout the five weeks of data gathering, as I recorded reflections in a journal (Glesne, 2016) to note aspects that I perceived as important, develop and capture my thoughts, free my mind for new perspectives, consider 
patterns, and exceptions to those patterns. I frequently organized my thoughts or new ideas with a chart; I compared teachers scores across the student voice categories, indicated the highest rated categories for each teacher.

Formal pattern analysis allowed themes to emerge (Saldaña, 2013), and occurred lasted for approximately eight weeks after the codes were finalized. I developed matrixes (Miles et al., 2013) in NVivo to examine, compare and analyze the data. These matrixes compared the rows of codes with individual teacher columns and a total column. The intersecting cells specified the frequency of each code per column, but NVivo allowed farther examination of the matrixes.

I selected a particular cell, and another screen materialized with the specific coded instances. From this screen, I examined and analyzed the raw data from these mutual codes or categories.

For example, I selected the mutual code of Exercise Your Brain. I viewed the raw data and determined the code to be accurate yet limited in the description. The accuracy came from the teachers each referred to the brain multiple times. The limitation came from the way Marlon referred to the brain wasn't similar to the way Abigail and Yasin referred to the brain. Marlon referred to the brain as the decision maker. Abigail and Yasin referred to the brain as a muscle that needs to be grown. Abigail expressed that exercising the brain makes the students smarter; similarly, Yasin expressed that mistakes can make the students learn. References to the brain, however, were too dissimilar among the case teachers for it to ultimately be coded as a subtheme. However, the context around these references may be found in the subthemes: Guidance for Success in America (Marlon), and Purpose of Mathematics Education (Abigail and Yasin). 
I triangulated teacher practices with observations, interviews, and artifacts. I sought frequent, consistent, and common codes and categories. I examined the research categories that were limited or missing within these teacher practices. I sketched tentative themes and subthemes with teacher practices in a matrix. I reflected about the themes and subthemes in my data analysis journal. I incorporated research into this matrix. The research included three propositions of culturally relevant pedagogy (Ladson-Billings, 2009), standards for mathematical practices (Leinwand et al., 2014), strands of mathematics proficiency (NRC, 2001). I discussed with my team, arranged accordingly, discussed again, rearranged, and repeated. After several iterations, the final themes emerged from my data.

In chapter 4, I discussed the emergent three prevalent themes with their subthemes. Before each theme, I provide a condensed version of the matrixes with the finalized codes, total frequencies, and indication of common codes across the three teachers. 


\section{CHAPTER IV}

At the white number 2 platform, I anxiously waited for my train. Something was wrong; it was only my third day abroad, but French trains are not late. I hailed a handsome Italian man, showed him my ticket, indicated my confusion, and mumbled a couple incoherent Spanish phrases. He kindly pointed to the platform with the recently dissipated people, departed train, and responded in Spanish. Not understanding a word, I pressed him to tell me why, gesturing again to the 2 above my head, and the 2 on my ticket. Oh, the color, the color was wrong - I should have waited at the red number 2 platform, the express platform. I had no experience with train platforms, no idea about the special express platform, but I did have expertise in missing trains - it was the second train I missed that day!

Personally, I found experiences with new cultures to be extremely frustrating, confusing, and exhausting. When the person (from the above vignette) helped me with explicit instructions, it alleviated my stress and opened doors. In the data analysis that follows, the teachers frequently and explicitly directed students on how to achieve success in the classroom by effectively navigating cultural differences that existed within and outside

the classroom. They interwove cultural references into their classrooms, and emphasized specific language strategies. Outside of class, these teachers interacted with the students in similar ways while keeping their vision on the students' future and potential for successfully navigating American culture.

\section{RESULTS}

The teachers provided opportunities for students to learn mathematics and information for students' interactions within the United States education system through the application of students' social and culture references while at the same time supporting their language needs. The teachers did this through setting explicit 
expectations, building on students' prior education skills, developing students' social and academic English, and interacting with students in a variety of positive ways as a student advocate. Because this is a multi-case analysis, the data reported is limited to those themes that were noted across all three teachers (though differences in how they were exhibited will be discussed within each theme). Except where noted otherwise, each of the themes and subthemes were noticed across all three teachers. However, the ways in that the themes and subthemes occurred were often unique to each teacher. Following the discussion of subthemes, I characterize each teacher's level of demonstrating each subtheme. The themes are organized in the order of the research questions.

\section{Cultural Consciousness: Know Thy Students}

The teachers interacted with their students that reflected awareness to their student's cultures. The teachers verbally recognized distinctions in culture groups, encouraged their students to choose their preferred procedure, and produced interactions with their students that shared characteristics of positivity, accessibility and advocacy. Even though, the teachers did not display deep knowledge of each students' culture, taken together, the qualities portray the teachers with a type of cultural consciousness.

In Table 4 (below), I provided the codes and frequencies that led to the development of this theme and subcategories. The examination of this data included the frequency, and occurrences across teachers. Though the final subcategories were primarily determined by the ways the teachers implemented these codes. The data emerged with three subcategories 1) teachers recognized and referred to cultural distinctions, 2) teachers honored student preferences for mathematical procedures, and 3) 
teacher-student interactions with shared features of positivity, accessibility and student advocacy.

Table 4

Culture: Categories, Codes and Frequencies

\begin{tabular}{llc}
\hline Categories & Codes & Frequency \\
\hline Classroom Expectations or Roles & Leadership and initiative from students & 14 \\
& Of the classroom community* & 55 \\
& Of the language* & 30 \\
& Of the math* & 37 \\
& Student obligations to students & 11 \\
& American* & 37 \\
& Familiar* & 23 \\
& Student* & 56 \\
& Student and student comparison* & 15 \\
Dispositions & Humor* & 22 \\
& Teacher care* & 13 \\
Student-Teacher Interactions & Teacher corrections in a positive way* & 33 \\
& Family* & 10 \\
& Outside of School* & 14 \\
& Resources i.e., community* & 12 \\
\hline
\end{tabular}

* Characteristic of all three teachers

\section{Recognized Distinctions, Made References}

The teachers did not display intimate knowledge of each of their numerous students' cultures. However, the teachers recognized and referred to cultural distinctions, expectations and life experiences. The teachers recognized cultural distinctions between broader groups i.e., Latinx, as well as, cultures within those groups, defined by national boundaries or geography i.e., Guatemalan. The students' life experiences included their recent immigration experiences and places around town that they were familiar to these students. The teachers intentionally made references common among multiple student cultural groups. These references occurred mostly in small or simplistic ways. The cultural recognitions allowed the teachers to respond according to their students' culture, and the references found common ground among the students. 
In teacher-student discourses, the teachers considered their students' cultural background and differences. In an interview, Marlon mentioned nationality distinctions, and I inquired farther, "Would you do something different between a Cuban and Guatemalan student". He responded with, "Of course", then elaborated that Guatemalans become independent at 12 or 14 years old, and then are considered a man or a woman, while Cubans tend to live with their parents even after they turn 18 years old. Marlon tended to use his cultural knowledge to intentionally change his discourse style according to students' culture. In observations of Marlon's interactions outside of class, I noticed differences in Marlon's tone, style and body language as he spoke to Cuban and Guatemalan students - my Spanish is severely limited and cannot keep up with the meaning of these conversations. I noticed that in discourse with Cuban students, Marlon appeared strict, loud and absolute. In one such conversation, I may have assumed that Marlon and the students were passionately arguing over a topic. However, the students patiently listened to Marlon, responded to him with brief -a sentence or two- explanation or inquiry, graciously thanked Marlon and left for lunch. Marlon turned to me. His smile broadened as he chuckled and shook his head. Motioning to the dismissed students, Marlon provided a short word explanation -"drama". Rather than the suspected argument, these students had sought out Marlon for advice. In contrast, Marlon's conversations with Guatemalan students appeared very different. Marlon's voice was noticeably quieter, and the student spoke more. Conversations tended to conclude with Marlon identifying students' choices, and the students' reflection of these choices.

In the classroom, the teachers referred to references that were common to their students. Abigail tended to include objects from the students' life. For instance, Abigail 
developed a lesson around the arc of a parabola with a soccer ball. The soccer ball's final designation was meant to go into the air, and into the soccer goal. Trying to push the students to consider the context of the problems, Abigail paraphrased her students' conclusions, "I kick the soccer ball and it goes down into the ground".

In another way, rather than use the terms of the native city residents, the teachers used terms that were familiar to their migrant students, and matched their jargon with their students' jargon. For instance, in class, Yasin used the affectionate and neighborhood term of Somali Mall in reference to the $7^{\text {th }}$ street flea market. Even on tests, Yasin made references to familiar foods, such as baklava, an Arabic dessert. In prior lessons on surface area, Yasin referred to Injera -a round flatbread. In interviews, Yasin articulated that Injera easily connected to Ethiopian, Somali, and Kenyan cultures the more dominant cultures of his classroom.

Yasin humorously recalled his unit on fractions. Yasin referred to one-seventh of a falafel, and his students had protested because it did not make conceptual sense. They said, "Who does that? One falafel, you need to talk about more than the whole".

Later, the students told Yasin, "Your obsessed with falafel Mister teacher".

"It was lovely", Yasin mused.

In summary, each teacher recognized and referred to American and their students' cultures. Collectively, the data recorded these occurrences over 100 times. The teachers recognized cultural uniqueness and common practices. And, Marlon advises teachers to understand all students' cultures. 


\section{Student Preferences for Mathematical Procedures}

The latter example begins to illustrate how these teachers recognized their students' varied mathematical resources and needs. All of the teachers recognized the importance of conceptual understanding over rote learning of procedures. They each allowed students to choose their preferred procedure, but expected the students to use American numeracy norms.

The students came into the school with numerous ways to solve problems, and Marlon provided students with the freedom to choose their preferred procedure, which often reflected the students' cultural procedure. The walls showcased posters with options of multiple procedural paths. Marlon grew up using Cuban mathematical procedures. Though he could have chosen to teach his students only Cuban procedures, his walls reflected procedures of his students' native culture procedures, as well as American procedures.

Abigail also accepted various mathematical procedures. As students made mistakes, Abigail demonstrated 1) deconstructing a cultural procedure, and 2) deducing the reasoning for conceptual development. Then she showed her awareness and validation for the students' cultures through her elaboration on the students' native procedure. When necessary, she brought these procedures to students' attention to address a potential misconception;

Cubans, I am talking to you... When you do your flip and change the sign [artifact shown on the right] you get confused right here. Cause you think, I need positive four, negative four. That's not equal. It's okay to say, 'flip and change the sign' [the number is flipped to the other side, and the sign is changed], but you have to understand why you do that. You do that because you do the same thing on both sides to keep an equation

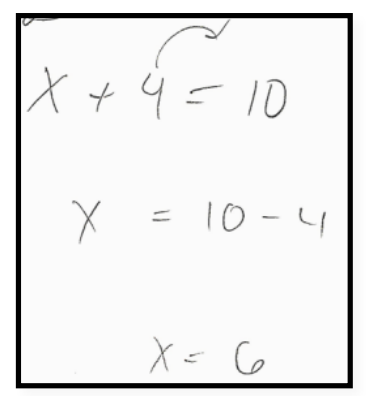


balanced...

Later I brought this moment to her attention. Abigail explained this is a common Cuban procedure to isolate a variable. Furthermore, akin to any procedure, this procedure had the potential to hurt the students' conceptual thinking. In classroom practices, rather than require the students to switch to a different procedure, Abigail encouraged the students to reason about the procedure. Abigail responded to any conceptions in a direct manner without an adverse tone, even if the conception was inaccurate or years below grade level.

Although, procedurally students were given their preferences, they were also required by all the teachers to use specific American numeracy norms. One American norm is about how to write numbers. Multiple countries use commas and decimal points in the reverse of how Americans use decimals and commas. For instance, the same number is represented as 5,217.3 in America, and as 5.217,3 in Cuba. In class, Abigail taught simply and directly about this American norm by stating "In the United States you put a comma here". In reflection, she expressed her objective in communicating this to her students, "You want to teach them that [American numeracy norm], but not say it in a way like, you're wrong, but say it like, you're right in Cuba, but we need to do it this way here". Her expressed intent was to indicate a straightforward, non-judgmental message, and provide important information for students' success in American mathematics classrooms.

\section{Student Interactions: Positivity, accessibility and advocacy}

The teachers produced interactions with their students that shared features of positive regard for students, teacher accessibility and advocacy on their students' behalf. 
Yet the teachers were drastically different in their means, settings, and time commitments. The teacher-student interactions transpired in a variety of unique ways. These ways were so drastically unique to each teacher that this subtheme is organized by teacher rather than the features of these interactions. Differences in teacher-student interactions may reflect the specific identity, culture and passions of the teachers. Before I describe these interactions, I first discuss the student voice results, and overview the shared features of the students-teacher interactions.

In harmony with my belief that student perspectives are essential to the studentteacher relationship, I discuss the student voice results by category and teacher. This table was first introduced as Table 3 in Chapter 3: Methodology.

Student Voice Results by Category and Teacher

\begin{tabular}{lccccccc}
\hline & Support & Transparency & Understand & Discipline & Engage & Nurture & Trust \\
\hline Marlon & 77 & 81 & 79 & 68 & 80 & 63 & 75 \\
Yasin & 86 & 86 & 87 & 50 & 81 & 82 & 71 \\
Abigail & 85 & 87 & 87 & 82 & 83 & 79 & 82 \\
\hline
\end{tabular}

The teachers commonly scored high in support, transparency and understand. In the remaining categories, score comparisons across teachers show Abigail held three of the high scores, and Yasin held the high score in nurture. I did not quantitatively classify the significance of these differences, I mention these differences because of their potential relationship within student-teacher interactions. Before data collection, I hypothesized CRMT dimensions aligning to student voice categories: language support aligning with transparency, nurture with culture, and critical knowledge as not aligning to a student voice category.

As indicated by the student voice results, the students appeared to have positive interactions with these teachers. The data revealed the teachers' common features of 
their interactions. Specifically, the teachers expressed interest and regard for their students. They each set aside time to be available to students during the school day, but outside of class. As teachers perceived a need, they advocated for their students. The interactions resulted in an overall outcome of positive student -teacher relationships.

In the subsequent sections, I described each teacher's interactions individually.

First, I include brief descriptions of the teachers' instructional styles as an indication of the ways the teachers differed in style. These descriptions provided information to be used in the Chapter 5: Discussion, which display the differing contexts of the teachers. After the descriptions, I focus on the similar features across teacher-student interactions. These features include the teachers' perspective of their students, the ways teachers were accessible to students, as well as, the ways the teacher advocated for their students.

\section{Marlon}

Marlon typically began class with any announcements, and information for his students, which related to educational habits, and guidance to successfully navigate America. At the beginning of one lesson, Marlon encouraged students to practice their English for the rest of the class time. Marlon indicated that upon his arrival to America, he afraid to use English. His fear was so strong that he didn't want to go to necessary or fun places such as the grocery store or the mall. In conclusion, Marlon asked students to practice their English for this class, even if they only spoke one word. More instances of this information are discussed in "Positioned Students for a Successful Future". After these announcements and opening remarks, Marlon discussed the mathematics learning with his students, provided the students with class assignment, and dictated whether the students were to practice as a class, in groups or individually. 
In observations, Marlon asked students to work an almost equal amount of time as a whole class, in groups and individually. In whole class practice, Marlon directed students to share their mathematics on the board, and explain their process to the class. In group practice, Marlon encouraged the students to discuss mathematics with their surrounding peers. In individual practice, the students appeared to comply with Marlon's instructions with a quietness that was only interrupted with the sound of pencil scratching on paper. At these times, Marlon either worked at his desk or circulated around the room and provided students with individual feedback.

Occasionally I passed by Marlon's classroom during a non-observation class. For approximately, $90 \%$ of these times, the students appeared to work individually. Although it is possible that Marlon changed some of this teaching styles due to my presence, it seemed equality probable that Marlon's instructional style differed in these noninstructional classes due to the anticipated end of the school year.

Marlon always conveyed a strong teacher presence, which may be attributed to his Cuban background. Marlon appeared to easily gained students' attention and their perceived compliance. For instance, Marlon implemented a new procedure with only eleven days left of school. Marlon instructed all of the students to place their cell phones in a shoe caddie until the end of class. The students quietly stood up, and turned over their cell phones without complaint. Similarly, the students chose their own seats, and appeared to sit next to their friends. However, when Marlon requested his students to silently work, the students complied with a stilled silence. In general conversations, two of Marlon's colleagues casually offered their shared perception that Marlon's discipline was extremely high. 
In contrast to these colleagues, the student voice results indicated the students did not perceive discipline as Marlon's highest category. The students rated Marlon highest in the categories of transparency, and engage. The specific survey items indicated students perceived Marlon's explanations to be clear, and student enjoyment of Marlon's teaching style.

Marlon's teaching style included humor aspects. Although not an intentionally documented measure, the codes revealed Marlon and his students laughed as a whole class an approximate average of three times each class. Additionally, Marlon redirected his students in positive manners. In one such instance, Marlon heard Mirana discuss her life when she was supposed to be working on her mathematics problems with her group. He addressed Mirana in Spanish, and her response made Marlon chuckle in amusement. Then Marlon paraphrased their conversation to me; Mirana is a genesis, she can do mathematics and talk about her life at the same time. Mirana laughed, agreed, replied to Marlon in Spanish, and redirected herself to the mathematics.

In other instance, Marlon noticed some students were daydreaming. Without mention of the students' names, Marlon dramatically said, "I know people who sleep with open eyes". Then Marlon tried to get the attention of an imaginary student with a dramatic wave of his hands. "Hey, Hey" Marlon said. Switching his own stance to act as the imaginary student, Marlon imitated awaking from a daze while the class burst into laughter.

More instances of Marlon's positive interactions exist simultaneously with the next feature of Marlon's interactions: accessibly. Marlon regularly made himself available for his students to come and discuss personal matters with him outside of class 
time. The students regularly showed up during this time. In fact, our interviews were scheduled during this time and we were frequently interrupted. It never seemed as though the students arrived to ask Marlon questions on mathematics. Instead, the students came to seek Marlon's advice about personal life issues -a possible indicator of students' positive interactions and respect for Marlon.

Marlon mentioned his love for his students, and his role as an example and resource for his students.

I will teach you, I will love you, I will help you. And you need to think that you need my skills. You need my example - you need my experiences to grow up or to be master.

As previously described Marlon provided resources and information for the students at the beginning of class time. He also provided this information -that he considered essential- to the local Latinx community. For instance, Marlon created three Spanish volumes of the district's specific education policies. This was not a translation, Marlon created it as information to the Latinx community from the perspective and cultural style of a Latinx.

Additionally, Marlon wrote publications in the monthly edition of the Latinxcommunity newspaper. He published articles on education and politics. In November, when Trump became President Elect, many students were distressed due to the unknown changes in immigration policies. In response, Marlon published consecutive articles for the newspaper. The articles described American school system, policies, and how to use education to stay in America. Here, Marlon indicated that America favors educated Latinxs; essentially, if one did not have documentation, and wanted to stay in America, 
they had to get an education. In short, Marlon's advocacy focused primarily on politics and systems, and the audience was the families in the community.

\section{Yasin}

In the student voice results, the students rated Yasin's strongest student voice categories as support, transparency, and understand. Yasin's highest items for these categories indicated: every day, the students learned a lot, Yasin knew and checked for student understanding, and the provided feedback helped the students learn. During class time, Yasin consistently led whole class discussions. Yasin asked questions, illustrated problems on the smart board, and sought students' responses. Contrasting Marlon, Yasin rarely required students to be completely silent. Actually, Yasin questioned several traditional American educational procedures, such as, students must be quiet, or students must walk in a straight line. Across teachers, Yasin held the highest ratings for categories of Support and Nurture. Of these two categories, the highest items that indicated that every day students learned a lot, and the students believed Yasin cared about them.

Indeed, Yasin deeply cared for his students. Yasin described his relationship with his students:

I know my kids really well... They love me, and I love them - it's a two-sided relationship. Even some trouble makers, they love me, and I love them.

Here, Yasin described a reciprocated love among himself and his students, regardless of students' behavior. Over multiple-distinct instances, Yasin mentioned his connection to his students, specifically, his knowledge and interactions with the students and their families. Yasin described the necessity of parental and community involvement in the classroom, along with teacher involvement in the community. 
Part of Yasin's accessibility to students was through his extreme activity with a local Community Center. The Center welcomes migrants, and hosts a variety of community events from cultural organizations. To exemplify, Yasin initiated and organized an event to welcome numerous incoming Syrian refugees. The event received so much publicity that a congressman and the Mayor attended the event. The vision of the Center includes the promotion of a peaceful atmosphere for cross-cultural relationships with cultural and social activities. The Center strived to spark authentic friendships between cultural groups and Americans, or as it frequently occurs, friendships between Muslims and Christians.

Through the Center, Yasin interacted with many families before and after becoming their child(ren)'s teacher. Yasin regularly provided extra mathematics every Saturday for three hours -including summer Saturdays. Students regularly attended these Math Saturdays just because they desire to learn more. During the school day, Yasin was also available to students as they ate lunch. He typically socialized with students at this time; inquired about their lives, listened and responded to students' personal concerns.

I frequently accompanied the students and Yasin to lunch. Here, the students routinely requested Yasin to establish whether their food was halal (permissible by Islamic law to eat). One day, Yasin expressed his irritation as a Muslim, and as a teacher who had dominantly Muslim students. Yasin explained that the school cafeteria meat is not halal. Though a common American belief is that if the meat is not pork, Muslims are permitted to eat it; this is incorrect. For the meat to be halal, the slaughter and preparation of the animal must meet particular requirements beyond a basic requirement of not being pork. Muslims are permitted to eat Jewish kosher meat, who also have 
particular slaughter and preparation requirements. A frustrated Yasin turned to me, and I paraphrase, if a large Jewish refugee population in the United States were to protest, Americans would advocate for the Jews and ensure that school cafeterias would provide kosher food for their students. Yasin's frustration appeared to be from two perceptions: 1) the Muslim students often do not have a suitable lunch option that supported their beliefs, and 2) a dominant number of Americans are more open to idea of advocating for Jews than Muslims.

Yasin perceived other religious influences in this public-school district. At one lunch, I casually inquired about his recent professional development session on classroom management. He described the session to be solely from the presenter's perspective with propaganda from a Christian agenda. The presenter used Christian terminology to regularly convey a message; teachers need to love their students. Confused at his essential idea, I interjected, "But you do love these kids"! Yasin readily agreed but pressed, the students need much more from an effective teacher and the presenter needed to include more than one perspective. Before more could be discussed, we were interrupted by students' inquisitiveness of whether the cafeteria food was halal.

In these ways, Yasin focused his advocacy on cultural awareness and sensitivity, in particular as it applied to religion. His audiences were within the school system, and the Community Center attendees. Yasin's advocacy was mostly directed towards recognition of Islamic traditions and beliefs, yet he also recognized Christian traditions and beliefs.

One of my favorite anecdotes came from a story where Yasin used a students' religion to communicate a message. Aware this story was politically incorrect, Yasin 
issued a disclaimer, "I'm not supposed to say this, I know this is a secular school". Then he described that in the first few weeks of school, a problem occurred between an Afghani boy and Somali girl. Yasin pulled the Afghani boy aside and guided him to examples from Mohammad's life to be a peace builder. The Afghani boy patiently listened to Yasin before saying, "Teacher, you know what, I am Christian”. Yasin, a Muslim, had assumed the Afghani boy was Muslim as well! However, not skipping a beat, Yasin recalled and cited peace-building stories from the Bible. Yasin described this as a foundational moment where he connected to the boy's deep values, "he became happy because it made sense when you share this stuff with them", then connecting to his own values, he continues, "This is a deep value, and this is who you are, and God does appreciate that." The family of the boy was so appreciative of Yasin's concern for their child that they invited Yasin to dine at their house for supper. Through the rejection of a traditional American educational norm, although admittedly politically incorrect, Yasin connected to a student and his family. On the last day of school, the boy cried when it was time to say goodbye to Yasin for the summer.

\section{Abigail}

Abigail is not a migrant to the United States. Abigail's identity as a White teacher, and a Christian may illustrate how other White-American teachers might be culturally responsive to multicultural students. Indeed, in the student voice results, Abigail scored the highest average rating when compared with Yasin and Marlon -who identified more with their students' background and ethnicities. Among these cases and categories, Abigail was rated highest in transparency, discipline, engage, and trust. Individually, the student perceived Abigail's strongest categories as transparency and 
understand. Four items, in the categories above, indicated $90 \%$ or more students agreed; Abigail explained difficult things clearly and checked for student understanding. Additionally, these items indicated students learned to correct their mistakes and treated Abigail with respect.

Just as these results indicate the students' respect for Abigail, Abigail articulated her value for her students.

"I can't believe I landed my dream job after two years of teaching". I couldn't imagine doing anything else. I knew when I started teaching that I wanted to teach math. But I knew that I loved these kinds of kids. You get to see not just one cultural group, but the world in your classroom everyday. It's really cool.

Abigail valued her students for their backgrounds and perspectives. In this way, Abigail is able to view the world through her students. Abigail broadly smiled as she described her job as her dream job. Later, Abigail described her students as generally respectful, eager to learn, and happy. Observations found evidence of the existence of these traits, and many more things, such as, classroom interactions that flowed with peaceful orchestration of previously explicit expectations.

Abigail established classroom routines and expectations, such that, the students knew what to do and how to act. The students entered the room, sat down and began their warm-up problems. Meanwhile Abigail greeted the students, inquired about personal matters, redirected students, and took attendance. At the start of one lesson, Abigail's dialogue included: Where is your brother today; Did anyone ever talk to Astur, did she have her baby; What's going on here, why aren't you doing your work?

When the students completed their warm-up, they assisted other classmates -a specific expectation for this time. Students requested assistance without the appearance of embarrassment or reluctance. Then Abigail checked and reviewed the warm-up. 
Afterwards, Abigail directed student attention to the mathematical and English learning targets of the day. Transitioning to the daily learning, Abigail guided the students in/to their next activity. These activities were designed to engage the students to build their conceptual understandings. Multiple times per class, Abigail or the students provided, received or requested explanations for the reason(s) something worked mathematically. For any lesson, Abigail might ask students to teach their peers, reason about the mathematics, or consider \& generalize the mathematical pattern. Abigail concluded class through reflection on the students' learning by returning to the learning targets. In these ways, many of the content practices in Abigail's classroom revealed student learning that reflected the CCSS-M mathematical practices.

To exemplify, here is a snapshot of these interactions. Abigail asked Shalom, "Do you want to teach". Shalom appeared hesitant, but Abigail encouraged Shalom. Shalom proceeded to the front of the class, and wrote under the document camera. As Shalom provided an explanation, she correctly wrote out the mathematics but incorrectly mixed some her language; using 30 instead of 13, and multiply instead of add. Disagreeing with Shalom, a couple students made some grunting noises. Immediately Abigail interjected, "When we disagree, we don't say "Argh', we raise our hand". Quickly, a student's hand went up and Shalom called on the student, who asked, "Why did you do times". Shalom attempted to give an explanation, but became puzzled. A student approached Shalom, and they discussed quietly. While they conferred, Abigail pushed the class, "Is it important if it's times or plus", then probed, "What would happen if we had a times pattern", and then rephrased a students' explanation, "Yeah, it'll be a 
geometric or exponential pattern". Then Abigail directed attention back to Shalom who correctly explained her reasoning to her peers.

To follow, I described the way Abigail is accessible to students outside of class time but during the school day. Abigail issued an open invitation for her students to come to her classroom during their lunch, her planning time, to practice mathematics. At this time, Abigail greeted the students and exchanged some personal dialogue. The students walked in the door, grabbed a tablet, and selected a seat. Abigail supervised but rarely assisted during this time. So much so, Abigail continued with normal planningtime, such as, the interviews for this research. It was evident that the students were expected to work, but it was also a relaxed atmosphere with occasional jokes. Much like Abigail's classroom environment, if (and when) necessary the students assisted one another.

Abigail advocated for students individually. One day Abigail mentioned a student had called her late in the evening. Abigail answered the phone and found the student in a serious crisis. Abigail spent a significant amount of time counseling the student.

Eventually, Abigail inquired whether the student needed to be transported to a safe place. The student's response demonstrated his shifted focus from his original crisis, "Oh no, I have a test tomorrow". For the time being, Abigail's mind was eased. The next day, Abigail followed-up with support through the authorized channels.

\section{Student Interaction Summary}

Imagine students choosing to show up for optional mathematic practice during their lunch, or for three hours on Saturdays. Further, imagine these students not receiving 
any type of credit for their extra work. Abigail and Yasin never have to imagine this scenario; their practice sessions had steady groups of students attend these opportunities.

The teachers each made themselves accessible to students in very different ways. For Abigail, lunch time provided space for the students to practice mathematics with continued connection to students personally. Yasin and Marlon used this time to provide students with advice or connect to students personally.

The teachers also advocated for the students in very different ways. Yasin pushed for the inclusion of multiple perspectives in the school and the local community. Marlon conveyed knowledge related to education to the local Latinx community. Abigail advocated for individual students based on their needs.

The teachers also show various types of relations to three different communities. Yasin devoted weekly amounts of time to the broad Community Center. Marlon's voice was present in his publications in the local Latinx community newspaper. While Abigail's classroom reflected practices that followed Ladson -Billings' (2009) community of learners.

These three highly-rated teachers hold a lot of contrasting characteristics, yet student voice results indicate outcomes of effective and positive student-teacher relationships. Interactions share features of teacher availability to students outside of class time, and teacher advocacy for students. Interactions differed among teachers; each teacher had their own instructional styles and pedagogy.

Surely the students need more than nurture, love, connection and care. Indeed, the teachers did provide other skills to setup students for success. In the next section, we will see themes that meet students' language needs. 


\section{Language Attention}

Each teacher engaged the students in expressive strategies (speaking and writing), and receptive strategies (listening and reading). I searched across teachers and created a matrix that compared language codes with the number of instances from each teacher. This matrix illuminated that collectively the teachers did not prefer one strategy over another, and if the teacher used a strategy once, the teacher was prone to repeated use of that specific strategy. Table 5 (below) reveals categories, codes and frequencies. Often times the codes were language strategies.

Table 5

Language: Categories, Codes and Frequencies

\begin{tabular}{llc}
\hline Categories & Codes & Frequency \\
\hline Explicit Strategy & English push* & 16 \\
& For the directions & 6 \\
Expressive & To approach a problem & 16 \\
& Sentence frames & 7 \\
& Sentence writing & 10 \\
& Repeating words & 9 \\
Receptive & Other & 6 \\
& Color coding & 17 \\
Vocabulary & Non-verbal response required & 7 \\
& Visuals & 31 \\
Other & Academic language -Technical* & 32 \\
& Academic language -Precursory* & 35 \\
& Social language* & 45 \\
& Language switching & 9 \\
& Learning target & 3 \\
& Meaningful gesture* & 28 \\
& Organizational technique & 22 \\
& Range of abilities* & 12 \\
& Simplified language* & 8 \\
\hline
\end{tabular}

* Characteristic of all three teachers

The teachers commonly and frequently focused on social and academic language.

Two common codes were not identified as categories: simplified language and 
meaningful gesture. The reasons were: simplified language did not occur frequently, and the majority of meaningful gesture instances were from one teacher.

Each teacher intentionally developed students' English with several common areas of explicit attention. Teachers showed explicit attention to Social Languageeveryday instructional and conversational language- and Academic Language - content specific language that included English and mathematics content (WiDA Consortium, 2012). The subtheme of Social Language Support incorporated the social and academic language of English because the academic English was commonly multiple years below the grade level standards. In contrast, the academic language of mathematics was partitioned in two subthemes because of the numerous course-level and precursory language. I determined the classification of the mathematical language in comparison to the course's CCSS-M standards. If the mathematical language was introduced at course level or one course level below CCSS-M standards, I classified it as Technical. If the mathematical language was introduced at two course levels below CCSS-M standards, I classified it as Precursory.

The teachers commonly integrated these subthemes into their instruction. In the following vignette, Abigail exemplified the integration of the English and mathematical language.

Abigail: What are we going to do today in class?

Barkhad, reading the mathematics learning target: Today I will convert quadratic equations from standard form to factored form, so that I can predict the $\mathrm{x}$-intercepts.

Abigail: Thanks Barkhad. Okay class, so what does convert mean? Convert. Natalia: Change

Abigail: Means change, right! Change from one form to another form. So we are converting from standard form to factored form. How do we convert an equation or expression from standard form to factored form? 
Manuel gives an inaudible answer.

Abigail: What is the names of the process that we use to change from standard form to factored form?

Nigel: GCF

Abigail: GCF is a noun. What I am looking for is a verb.

Alejandro: Simplify.

Abigail: Simplify would be going from factored form to standard form when you multiply these out. What is a verb that means - it's up here - that means change from standard form to factored form?

Zhen: Factor.

Abigail: Factor, right! Factor is a noun and a verb. So as a verb, factor is when we convert from standard from to factored form, it's called factored quadratic equations and expressions. Why will we factor today?

Eldora: Because today we are convert quadratic equations from standard form to factored form.

Abigail: You started from the beginning. This first part here is what we are going to do. Then do you see this comma and so...

Eldora reads: So I can predict the $\mathrm{x}$-intercepts.

Abigail: Right. This use of SO here; SO I can predict the x-intercept. It's kind-of like our cause and effect [references a cause and effect sentence frame on the board]. I'm saying, I'm going to do this [indicates cause] because the results [indicates effect] - so I can say what the $\mathrm{x}$-intercepts are. Okay? [pause] So that is what we will be working on today.

*Bold indicates emphasized words

In this vignette, there are several examples that provide examples of language support. This vignette is a typical beginning to Abigail's class; an introduction to corresponding mathematics and English learning targets. The English learning target was "Today I will use sentence frames to explain my thinking, and to show cause and effect". In lines 4-8, Abigail initially referred to convert as the English form "to change", then linked convert to the context of the mathematics language "change from one form to another". In line 19, factor was identified as both a noun and verb, then applied to the 
mathematics learning target "convert quadratic equations from standard form to factored form" (line 22-23).

The English learning target was intentionally coordinated to support the students to reach the mathematics learning target. Abigail provided sentence frames (social language), and used these sentence frames throughout class. Even the mathematics learning target was written in one of the provided sentence frames: , so . Towards the end of class, students used these sentence frames to express

their prediction of the $\mathrm{x}$-intercepts (mathematics). In these ways, the mathematics and English learning targets integrated with one another. Together, the students were able to express how to generalize the prediction of the x-intercepts (mathematics target).

\section{Social Language Support}

I gave them [the students] a half sheet of paper that said, 'Did you do blank, circle yes or no'. I had kids who circled both answers, and kids who circled none. I was like, 'Oh wow, they don't understand yes or no'. That's kind of like, after hello, here is yes or no. - Abigail

All three teachers described a challenge of their students not being immersed enough in the English language. Due to the lack of native English speakers, one teacher classified the school as not-America, and described the school to be comparable to an English school in a foreign country. Another teacher commented on the linguistic dominance of the Spanish speakers, "Everybody here learns Spanish. We could be SSL [Spanish as a second language] instead of an ESL [English as a second language] school". The general and mutual teacher concern was that the lack of English immersion meant students, especially Spanish speakers, developed their English at a slower rate.

To balance this, multiple times during class, the teachers directed students to specifically use their native or English language. Marlon instructed two of his Arabic 
speakers, "You will tell me what you did, in Arabic. And, you [pointed to another student] you will translate". Yasin encouraged his middle school students to continue to listen and try to understand English, "It is like watching cartoons, do you understand everything? No. But you watch them anyway right? [students nodded in agreement] And you enjoy it right? [students agreed with excited murmurs]". Abigail also directed students to use a specific language. Sometimes it was a simple reminder, such as when Yago volunteered to teach a small group that included Spanish and Somali students, Yago spoke in English so that the Somali students could also understand him. However, when a Spanish speaker did not yet understand, Abigail directed Yago, "Okay, explain in Spanish before you go".

Marlon created opportunities for students to use their social English. Marlon asked, "How was your weekend?" Then retorted to himself, "But Mister Marlon, this is not math". Marlon explained the importance of practicing English while in school. "If you stay here and don't speak English, then maybe...", Marlon exaggerated, "you will stay here six years". The students laughed, and although Marlon conveyed this with humor, he was serious about his idea; practice English or you will never learn.

Yasin took time to discuss the grammar rules of social English. One instance appeared to be an accidental opportunity made into a chance for student learning. Raiya used "gave-ed" -a generalization of a past tense rule for regular verbs onto an irregular verb. Yasin wrote three irregular verbs on the board with their past and present tenses: gave $\mid$ give, had $\mid$ have, find $\mid$ found. Yasin explained that these common verbs are irregular verbs, and do not follow the regular grammar rules. Approximately four 
students and Raiya vocalized their appreciation with some Ooo's and Aahh's, and even more students wrote down these words for future reference.

The teachers' social language support was often quick, and appeared impromptu. Marlon offered this tip, "You need to memorize verbs: learn, teach, eat, sleep, walk, write, watch". Abigail corrected sentence structures with some humor, "equation colon blah blah blah is not a sentence". Yasin asked, "Do you know what recipe is". The students did not know, so Yasin asked, "How about muffins". Yasin googled "muffin" and displayed the picture as he explained "recipe".

For some language, more attention was required for the students to comprehend the mathematics. Every day Yasin illustrated mathematics problems on his smartboard. Yasin looked up pictures online, drew visuals on the board, used meaningful gestures or tangible objects (e.g., play money). Yasin used organizational schemes to understand word problems, i.e., graphic organizer, idiosyncratic method, etc. In one word problem, for instance, Yasin highlighted and underlined some text, wrote "What are we looking for" on the board, drew a picture of someone typing, created 9 groups of 6 , and drew a before /after chart \& picture. For the majority of these instances, the comprehension of the problem required knowledge of the social English and the mathematical language. In the next section, I described the ways the teachers supported students in the technical academic language of mathematics.

\section{Technical Language of Mathematics}

Instructional strategies for technical language resembled the strategies for social language: unique and frequent according to the teacher. Marlon was likely to push English, yet switch between languages. Yasin was likely to request his students to repeat 
after him, demonstrate a think-aloud, instruct with visuals or utilize an organizational scheme. Abigail was likely to use learning targets, consistent gestures, sentence frames, sentence writing, and color-coordination.

Marlon frequently directed his class to practice their mathematics in English. His explicit language directions were given an average of twice per lesson, while Abigail and Marlon both averaged less than once per class. At the same time, Marlon tended to be flexible with the language selection, especially as he circulated to individual or groups of students. The students might ask Marlon questions in Spanish, which Marlon responded to with appeared intent: Spanish, English, or in English with pointed directions for a student to translate (even it was a Spanish translation). If the students inquired about the mathematics in English, continued to not understand after an English explanation, then Marlon explained again in Spanish. In these ways, Marlon and his students appeared to intentionally balance language and use language as a resource.

As indicated in the previous subtheme, every day Yasin illustrated mathematics problems visually. These illustrations served a dual purpose to visually represent both the social language and mathematical concepts. Yasin incorporated various mathematical models: part-part-whole, bar, and idiosyncratic models. These models served for students to visualize the mathematics and language. For instance, using the bar model, Yasin represented the distances of two runners with two rectangles. The rectangles were intended to portray approximate comparisons of the two runners, rather than the exact proportions of the runners' distances. This created a visualization of the mathematical concept that corresponded to the mathematical language. Yasin and his student regularly 
setup these visualizations, and analyzed the mathematics together. In this way, Yasin integrated the mathematical concepts with language.

Abigail supported academic language development with numerous tools and resources. Abigail color coordinated mathematical content with highlighters, colored pens, and dry erase markers. Color coordinated materials included: classroom posters, student's work, and Abigail's work. Abigail described her intention to support her students with this color coordination;

[W] do a lot of the multiple representation stuff where you say, here is the $y$ intercept on a table, and a graph and an equation. Then take the same yellow highlighter, and color them all the same color. Here is the $y$-intercepts, here, here, here. So that, hopefully, even if they don't understand the words that they are using, they are saying, 'Yellow, yellow, yellow; what do these have in common?'

Abigail passed out highlighters for her students to mimic her, then identified the multiple representations with her work displayed under the document camera. Abigail desired her students to draw connections within the multiple representations, particularly, the students who do not understand English.

In addition to color coordination, Abigail demonstrated and encouraged gestures that corresponded to the academic language of mathematics. The students mimicked these gestures. For vertex, the gesture was two hands in an arch form, and may point up or down -but not left or right (because that would be mathematically incorrect for a function). If it had been awhile since the students had used a vocabulary word, then Abigail accompanied the gesture with a verbal reference to a tangible object. For instance, vertex was accompanied with the bottom of the ocean or the top of a mountain. 
Once a gesture had been adopted for a mathematical vocabulary word, the gesture was used consistently ${ }^{10}$ for the remainder of the school year.

If Abigail perceived her students did not understand, she adapted her instruction.

In one of these instances, Abigail attributed the extensive amounts of academic vocabulary as the barrier to student comprehension. So Abigail re-instructed her students with two chunks of instruction. First, Abigail directed the students' attention to the classroom model of a graph and quadratic function with labeled parts. Then she provided the first chunk of instruction: the students were to label the parts of each graph and function: vertex, axis, intercepts, etc. In the second chunk, Abigail modeled sentences with her provided sentence frames, and re-instructed her students with the original instructions. The students initiated their work after these chunked instructions.

\section{Precursory Concepts and Language}

Marlon - "But not only in math, even in their native language, too. Because they don't receive any instructional education at the school because they will be out of the school for 2-3 years."

The students came from various academic backgrounds. Many of the students' educational backgrounds included illiteracy in students' native language, limited or interrupted formal education, literacy with a different alphabet and number system, or no access to learn the CCSS-M. All teachers independently expressed these educational

${ }^{10}$ As my data approached saturation, I recognized the frequency and consistency of Abigail's gestures. I spectate that it took me longer to recognize this frequency because I am accustomed to American Sign Language (ASL); ASL was a focus area of my undergraduate degree. Although Abigail's gestures were not ASL, and she never studied ASL, they could be comparable to Home Signs - gestures used consistently to communicate (typically with a family of a deaf child) without community recognition, nor with a complete language. 
backgrounds as a challenge. However, the teachers utilized multiple strategies to build up students' knowledge and language to course level mathematics.

Each teacher expected the students to use mathematic language. The teachers used mathematical language that their students imitated. For instance, Yasin asked the students what operation should be used for the problem. Rather than respond with minus or take away, the students exclaimed the word that Yasin used, "difference". In Abigail's classroom, even students' discussions in their native language were interjected with mathematical language, such as, "product". One class, Marlon expressed emphasis on the mathematical language, "When we work with equations, we don't always work with integers". In that same lesson, Jesenia imitated both the mathematical language and the verbal emphasis, "Put the sign negative in the denominator of the fraction".

The teachers never determined any language or the meaning(s) too minor for attention, even when the language or content was several years below the students' current grade level. For instance, Yasin created 9 groups of 6 to show the meaning of product, even though the CCSS-M introduced product in the third grade.

Abigail also questioned her high school students about product's symbol and meaning. Shortly following, Abigail built on this knowledge, and introduced the Zero Product Property (ZPP) by name with an emphasis on product. Abigail asked, "What numbers could I use that would have a product of zero, and a sum of two". Taldalesh indicated that a product of zero requires at least one factor of zero. Then Abigail guided the students to extend this concept to the factored form of a quadratic equation to generalize the pattern of the $\mathrm{x}$-intercepts, and reason about the ZPP. In this way, Abigail connected product properties across multiple mathematical courses. 
Abigail's language strategies included: restating/rephrasing, use of native and English languages, and student discourse. For example, Taldalesh stated the reasoning behind the ZPP that Eldora rephrased. Then Yago expressed he did not understand, and Eldora requested permission to explain in Spanish. Abigail granted this request, and directed the students to teach one another the reasoning. Initially, 4-5 students explained to those students near them in groups that ranged from 2-7 people. Of these initial conversations, one student explained in English while the rest explained in their native languages. The students began to understand, and the students who understood moved to other students to offer explanations. At this second round, more students explained in English and the groups ranged from 2-4 people who might differ in languages. Some students had enough time to move to a third round of explanation. At this round, the majority of student groups spoke in English in partners or triads. In this way, the students took ownership of the ZPP, and their classmates' learning.

Both Abigail and Yasin demonstrated the use of precursory concepts and language to foster their students' development of mathematics. Yasin considered student reasoning as essential to mathematical development. Although Yasin's students were extremely limited in their formal education, Yasin consistently provided opportunities for his students to reason. In one instance, Yasin asked his students to setup a subtraction expression - a second grade standard. Xabiib responded correctly with $\$ 67.80$ - $\$ 38.30$. Yasin wrote Xabiib's response on the board with another option, \$38.30 - \$67.80. Then Yasin requested his students determine the correct expression and reason about their choice. His students discussed with their partners before Yasin called on several students. The students believed that Yasin's expression was incorrect but their 
explanation did not satisfy Yasin. So Yasin attempted to convince the class of his incorrect answer with a flawed conception of mathematics. Yasin encouraged his students to discuss their reasoning again. Soon, Miski who had made a previous attempt to reason, shared another reason and convinced her classmates that Xabiib's expression was accurate.

Abigail responded to inaccurate student conceptions. These responses were sometimes quick. For instance, when a student responded with "negative zero". Abigail responded, "Is there a negative zero? Zero is the only number that doesn't have a positive or a negative". Other responses were more extensive.

Abigail noticed several students unknowingly un-balance an equation by erasing a positive two without subtracting a two on the other side. Abigail addressed,

When I move this two to the other side, the way I do this is with a minus two on both sides. This is the same, minus two, minus two - that makes a zero here, which is why you say positive two changes to negative two. But you are not just changing, you are putting something equal on both sides.

Abigail noticed her students' furrowed eyebrows and scrunched faces, "I don't think I have you yet". Abigail simulated a balanced scale, lifted her hands to equivalent heights and asked "Are these equal". Keeping her hands as the platforms of the scale, Abigail indicated an imbalanced scale, tilted to one side and asked "Are these equal". The students continued to give Abigail the same facial appearances. So Abigail picked a student volunteer to simulate the scale and grabbed some props: tape dispenser, stapler, paperclip, etc. Abigail placed or relocated these various props in his hands, and asked questions to the students on the concept of a balanced scale. In a little while, several students provided verbal aha's, and quickly discussed to one another. Then the students were able to practice completing the square. From this sole lesson, Abigail included 
student development in the mathematics of zero (third grade), exponents (eighth grade), and equality (sixth grade). This was all an addition to the original learning target to change the quadratic equation to vertex form.

The teachers also provided guidance to their students in matters not related to mathematics or language. In the next theme, the teachers' guided students to academic habits, and life guidance.

\section{Positioned Students for a Successful Future}

Interweaving Culture and Language Attention addressed two of the research questions, particularly the questions that addressed multicultural instructional practices and language. The third dominant theme emerged as Positioned Students for a Successful Future, rather than a more direct reference to the third component of critical knowledge. This theme was supportive of a subsection within the observation tool: 'information is searched and probed', as well as a prerequisite to, 'a critical approach of arguments, assumptions, worldviews or beliefs which are explicit or inferred'.

The data appeared to be influenced by two underlying teacher perceptions. Namely, the teachers' consciousness of the students' 1) trajectory in America, and 2) need for more information to be successful in America. These perceptions tended to align with some of the students' education backgrounds. Specifically, the majority of the students had interrupted or limited formal education, and each teacher had students identified with this background: Marlon with approximately 7 students, Abigail with 27 students, and all of Yasin's students. Table 6 (below) revealed the common teacher codes. 
Table 6

Critical Knowledge: Categories, Codes and Frequencies

\begin{tabular}{llc}
\hline Categories & Codes & Frequency \\
\hline Knowledge to Perform & Instructional guidance & 20 \\
& Mathematics* & 23 \\
Thinking About... & Set-up* & 16 \\
& How to learn math* & 43 \\
& Life or life skills* & 41 \\
& Reason why* & 19 \\
& The problem* & 38 \\
Real Life Mathematics & Thinking & 21 \\
& Application* & 7 \\
& Background* & 9 \\
& Examines society issue & 4 \\
Other & Future* & 16 \\
& Exercise your brain* & 9 \\
& Higher motivation for education* & 11 \\
& Teacher care for students* & 13 \\
& Multiple ways* & 16 \\
& Range of abilities* & 12 \\
\hline
\end{tabular}

* Characteristic of all three teachers

From the mutual codes, three common subthemes emerged. First, each teacher supported their students through explicit instruction of learner habits and skills. Second, the teachers commonly guided their students with information for life, and related the responsibilities of school with the responsibilities of life. Third, the teachers perceived mathematics education to incorporate foundational benefits for their students beyond the classroom.

\section{Learner Habits and Skills}

The teachers mutually provided explicit instruction on learner habits and skills. The teachers' strategies collectively included: the way to approach and decipher a problem, note taking, self-checking, and appropriate occasions to independently pick up classroom supplies (e.g., dictionary). Yasin vocalized that the students had never been taught these strategies, "[the students] need to ask questions, reread, rethink, read aloud, 
think aloud, but they don't have those tools because they haven't seen such a thing before". Abigail humorously exemplified the extent of her students reading, or rather not-reading, the directions;

They don't think about what it actually says, which is why the other day when I put 'Do not copy the directions', not only did they copy the directions, they copied 'Do not copy the directions' on their paper.

The students lacked the reading skills to comprehend the directions, but they also lacked the skills to search for the meaning of the directions. Yasin and Abigail discussed the students' tendency to ignore the directions, describing students to "randomly multiply" or “throw some math around" (respectively).

Every day, Yasin decoded mathematics problems for comprehension. In a typical problem, Yasin requested a student to read the problem aloud. Then Yasin decoded the text with multiple visual displays: underlined key words, sketches, and picture. One day as Yasin decoded the text, he stopped and turned to the students, "Am I solving the problem right now?".

In a possible attempt to please their teacher, the students shouted "YES"!

"No" asserted Yasin, "I'm only understanding the problem... Understanding the problem is $99 \%$ of the solution". Yasin referenced the lengthy time commitment and persistence to comprehend -without solving- the problem. Later, Yasin reiterated the necessity to understand a problem with a life problem, "Maybe you want to solve cancer, you need to understand cancer first."

Abigail asked her students to write useful and specific information for students to examine and review for their quiz. Abigail provided the sentence frame, "Self-me, this is what I need to know". Abigail displayed the students' responses on the overhead, and 
together the class analyzed one another's responses for accuracy and usefulness. Correct student responses were generalizable: useful, specific, and correct. Other student responses were too general to be useful, and two student responses were specific but incorrect mathematically. The majority of student responses were general. These general responses resembled the response of this student, "I need to know how to solve all the equations, and I need get 100 on my quiz". Abigail rephrased and asked, "You need to know everything. Is that useful". Abigail explained how this information was too general to be helpful, then she moved to another response. Of the responses, approximately four student responses were generalizable. For instance, one student wrote -in either humor or an identity crisis, "Dear Voldemort". Abigail laughed and continued, "This is what you need to know: Factor form tells the $x$ intercept it can simplify to standard form.

Standard form tells the $y$ intercept it can convert to a vertex form or...". Abigail questioned the class, "Is that useful", "Would that help you on your quiz". Abigail purposed this class activity so that the students may identify generalizable information, and contemplate this information so the students may learn how to study.

\section{Life Guidance}

The teachers commonly guided their students with education or life information, and connected school responsibilities to life. The teachers equipped students with information about the American education system, and for the students' personal development.

Marlon informed students of the basic graduation and high school requirements. This information included a broad scope: high school credits, behavior, and selfdiscipline. Marlon guided students to American expectations and responsibilities. He 
stated, "Remember you come to a new country, and you don't know the rules. You must listen and learn this country's rules insides and outside of school". Marlon connected students' success in the classroom with student success in life. He related class expectations to employment expectations, i.e., be on time. He reflected on this as a way for immigrants to give back to American society, "If you are a responsible student, you will be a responsible worker. Then you will serve society well. When we -immigrantscome into this country, we need to be responsible with this country".

Marlon addressed the American expectation ${ }^{11}$ of academic honesty through an explanation of how American teachers use test scores. Marlon presented the natural consequences of cheating. I rephrased; when a student receives a $90 \%$ on a test, the teacher assumes the student knows the information from the test. The teacher makes efforts to assist students with low scores to gain the necessary knowledge. If a student cheats, the teacher will not know the student needs help. Then Marlon intensely concluded, "You don't lie to me - the teacher. You lie to yourself because you know nothing”.

Yasin also discussed academic honesty, but approached the topic differently. Yasin related his background to his students' background, "I am from the middle east. I know what you are thinking; I want to help my friends. But it is not okay...". Later, Yasin indicated his intentional guidance of students through cultural issues. Yasin said,

Since I am the weird Turkish guy -you know immigrant- I have the privilege to talk about lots of things. I can touch it, those issues. About the native guys this is their culture is, and they are so nice, they don't talk about these kinds of things. I am doing that. I feel like this must be my responsibility to do that - If there is a

\footnotetext{
${ }^{11}$ My experience informed me that several cultures only consider cheating as bad if they get caught.
} 
job split and responsibility sharing, this must be mine. It is kind of the dirty part, but I am glad I am doing that.

Above, Yasin described American teachers as "so nice, they don't talk about these kinds of things". Yasin elected it his responsibility to discuss the topics related to American cultural expectations.

Abigail guided students for success through her general encouragement of students' personal dispositions. This encouragement might have effected their life on a broader scale. Abigail encouraged and guided students to consider the ways their attitude and motivation might affect their happiness in life. For instance, once Abigail announced a pop quiz, and a student loudly groaned. Rather than calling out the student directly, Abigail responded by taking a brief moment to discuss the benefits of having a positive attitude in life.

In this subtheme, the teachers guided students to a broader picture for the students' future. The teachers explicitly connected classroom responsibilities and expectations as relevant to their life, i.e., the workplace, character development. The teachers reflected beliefs that the students benefit from their guidance.

\section{Purpose of Mathematics Education: Teacher Perceptions}

The teachers expressed mathematics education to have foundational benefits for their students' lives beyond the classroom. Teachers perceived mathematics education to be useful for life skills, reasoning skills, and the eventual graduation from high school.

Abigail attributed middle school (rather than high school) mathematics as the more useful and foundational curriculum to life outside of school. Abigail exemplified her view; an attorney visited her classroom to volunteer, but was unable to successfully

complete the students' assignment. Indicating the attorney's double doctorate degree and 
status as a University instructor, Abigail commented, “Clearly, you don't need to know how to do this [solve quadratic equations] to be successful because she's highly successful". She expressed the value of solving quadratic equations or other high school mathematics as the mental exercise: ability to think logically, development of numeracy, and the practical aspect of a high school diploma. Not trying to deemphasize these attributes, Abigail recognized education as a path that may help her students overcome potentially difficult life situations.

Education is a key to helping them to get out of what has been, sometimes, a desperate situation, and sometimes actually make a life for themselves here... just getting a diploma is going to make a huge difference in these kids' future... I know how much value that has...

Abigail focused on a broader vision -a better life for her students. For Abigail's students, a high school diploma may make more opportunities accessible for her students.

Marlon asserted that mathematics isn't just another course or subject, it is a life tool. To the students, Marlon referred to math skills in everyday life that included:

money sense in a grocery store, a daily tool for a construction worker, and for careers that required a University degree. Additionally, Marlon related how mathematics influenced a television show. On this show, if the contestant spends as little as 1 cent more than their allowance, it is an automatic loss.

Yasin described the ultimate goal of mathematics as it's explanation, and defense. He discussed the beauty of multiple ways to problem solve on the condition that the explanation and defense held reasonableness. This "math talk" is an important goal for Yasin,

I need to do more and more number talks - so valuable. I just wanted to build the confidence that math is going to be subject in their future, in their school life, in America. It's going to save their life. 
One instance of this math talk unfolded in a problem with Nancy, a fictitious character, who cleans houses for $\$ 25$ per house. Deviating from the original question, Yasin inquired about the size of the house, and the time it takes to clean the house. The class determined that it takes eight hours to clean a four to five-bedroom house, so Nancy could earn \$25 each day she worked. Yasin questioned the reasonableness of Nancy’s wages, but the students did not recognize the $\$ 25$ per day as inadequate wages for living expenses. To provide context, Yasin specified the minimum wage, the average cost of rent in their neighborhood, and asked more questions. These questions included, "Can Nancy pay her rent? Do you think this is happening in America? How come? So how are they paying their rent?"

Yasin remarked on Nancy's situation, "Nancy's story is real. This is happening in America". Throughout this time, students occasionally offered an operation or number in an attempt to solve the problem. Yasin responded with "This is not that kind of math. This is math talk". Yasin expressed the desire to understand his students' thinking, reasoning, and number sense as it applies to life.

\section{Summary}

Examination of these teacher practices revealed prevalent themes and subthemes emerged among teacher practices, along with differences among specific instructional practices and strategies. The teachers built positive relationships with their students and communities, advocated for students' well-being, and conducted this in accordance to their own identities, culture, and passion. Teachers revealed their consciousness and positive regard for students' cultural differences, and negotiation of mathematical procedural practices. Teachers offered language support that differed in strategies, but 
met students' social and academic language for English and mathematics content. Teachers explicitly led their students to habits, skills and responsibilities to set them up for success. This explicit guidance appeared driven by their perceptions of the purpose(s) of mathematics education, and their students' ability to navigate the American education system to be successful in America.

In relation to the Development Based Interactions, the data revealed the implementation of students' content practices. These practices were a result of the pedagogical access provided by teachers, and commonly included skills of a learner, guidance in life, social and academic language attention. Along the route, teachers recognized students' cultural distinctions, and encouraged students' mathematical preferences. This allowed students to make connections to their native and American cultures, and fostered students' identity. The teachers did not provide common agency practices, so the information on agency was inconclusive. 


\section{CHAPTER V}

[T]he curriculum and our classrooms should reflect both things that are new to them-windows - that will stretch their minds and bodies as well as things that are affirming-mirrors - that will help them maintain a sense of wholeness while in the classroom.

Rochelle Gutiérrez (2015)

\section{DISCUSSION}

This chapter is organized into three parts. The first part summarizes the research: the problem, purpose statement, research questions, methodology and major findings. The second part relates the major findings to the literature. The third part describes implications, future study recommendations, and final remarks.

\section{Summary of the Research}

\section{Overview of the Problem}

Mathematics classrooms aligned to the CCSS-M mathematical practices prepare students for the professional $21^{\text {st }}$ century workplace (NRC, 2012). However, opportunities for mathematical proficiency are not equitable across some student groups (Moses, 2001), specifically student groups of Black, Latinx, and ELs (Ladson-Billings, 2006; 2008). These student groups are systematically underserved in their education, and directed on a trajectory towards a future of low economic status (Moses, 2001). Be that as it may, not all mathematics teachers underserve these students, and, as Gutiérrez (2008) suggests, researchers should focus on occurrences of successful education for 
traditionally underserved students to determine how to better support these students systematically.

\section{Purpose Statement and Research Questions}

Following Gutiérrez' (2008) recommendation, I designed my research on highlyrated teacher practices in the context of multicultural mathematics classrooms. Aguirre and Zavala (2013) constructed eight CRMT dimensions that combine two literature bases: culturally responsive pedagogy and pedagogical mathematics knowledge. My interest veered towards the research on the three of these eight dimensions, three that focused more specifically on culturally responsive pedagogy, and that formed the basis of my research questions:

To what extent, and in what ways, do highly student-rated teachers incorporate 1) multicultural instructional practices, 2) language support and 3) critical knowledge in their multicultural classrooms?

\section{Review of Methodology}

In review of the CRMT research, I found no CRMT research that examined practices of effective teachers who were first identified by a student measure. I identified this as a gap, and designed this research to identify effective teachers from the results of a student voice survey in which students rated their teachers across numerous qualities.

Therefore, these teachers are referred to as highly-rated teachers. This research is situated in multicultural American classrooms of a sheltered instruction school in the 2017 sociopolitical environment, several months after President Trump became president, a tense time to be an immigrant in the United States with the new president's commitment to restricting migration to the United States. Essential to the design was the focus on a 
multicultural classroom, defined as classrooms that (1) had a majority of students from underserved student groups and (2) had students from at least three cultures.

I created a qualitative, multiple case design to examine the practices of three teachers. The design was selected for the possibility of direct replication under various contextual circumstances (Yin, 2014). The data collection included teacher interviews, classroom observations and artifacts. Teacher practices were examined and analyzed for commonalities across teachers. Identified practices and themes were then compared back to the research literature.

\section{Major Findings}

Examination of these highly-rated teachers' practices revealed several prevalent themes and subthemes. The prevalent themes are cultural consciousness, language attention, and positioned students for a successful future. The first two themes were noticeably associated to the research questions about culture and language, while the third theme was less recognizable to the research question on critical knowledge. The emergent data within the critical knowledge dimension did not support a prevalent critical knowledge theme. Instead, the theme was supportive of a subsection within the CRMT observation tool, 'information is searched and probed', and a prerequisite of 'a critical approach of arguments, assumptions, worldviews or beliefs which are explicit or inferred'. To follow, I discuss each of the prevalent themes and their subthemes.

The first theme emerged from the three subthemes as teacher practices of cultural consciousness. The teachers commonly recognized students' cultural distinctions, expectations and experiences. The recognition of culture allowed these teachers to refer to shared student experiences, customs or objects. Cultural recognition also allowed 
teachers to respond to the students in accordance with their culture. Teachers discussed culture directly, acknowledgement, comfort and the occasional humor. The teachers encouraged students' use of their preferred or cultural procedures to solve mathematics problems. When necessary to demonstrate an American convention, the teachers communicated this in a direct, informative, and non-judgmental manner. And last, the student-teacher interactions varied but resulted in positive relationships and featured student accessibility to the teachers outside of class time, and teacher advocacy for their students. Joined together, the subthemes revealed the teachers recognized students' cultural distinctions, flexibility and encouragement for students' use of their preferred procedures, and built individual teacher-student relationships.

In the second theme, teachers paid explicit and frequent attention to language. The subthemes revealed the teachers attended to students' social English and academic language of mathematics with explicit support. The teachers commonly used the academic language of mathematicians. For instance, Abigail introduced mathematical properties to her students by name i.e., Zero Product Property. Oftentimes, the teachers used everyday references to push mathematical concepts. The students' background may have never provided opportunities to learn the CCSS-M standards. The teachers frequently educated their students on precursory concepts and related language with their course standards. A particularly interesting finding was that each teacher used selected language support strategies and re-used the strategy across multiple lessons, but these selected strategies were unique to each teacher. In other words, these highly-rated teachers did not collectively prefer one strategy over another. 
As previously indicated, the third theme emerged as a small section within critical knowledge. This prevalent theme described the ways the teachers jointly positioned students for a successful future. The teachers were mindful of the purposes in mathematics education, and the role it placed in their students' future. In view of the students' American future, the teachers guided students for success in America through explicit instructions on learning habits and skills, and American cultural norms. Teachers expressed mathematics education, particularly middle school standards, to have foundational benefits for their students' life. If students' situations are desperate - to use Abigail's word, then it's probable that some students may not have their basic needs met. Collectively, the teachers did not demonstrate the use of mathematics to change a societal issue. Yasin demonstrated the use of mathematics to understand and critique a societal issue. However, Yasin's students did not demonstrate evidence that this deepened their understanding of mathematics or oppressive societal issues.

\section{Findings Related to the Literature}

One major finding in this study is that highly-rated teachers did not need to identify with each of their students' unique cultures, but connected to their students through other ways. This included recognizing students' cultural distinctions, responding accordingly using references that were familiar to the students, making themselves available outside of class, and advocating on their students' behalf.

The teachers demonstrated awareness of a variety of student cultural groups through their frequent references about students' cultures and communities. The teachers did not display evidence of the mathematical connections to students' culture with the depth demonstrated by Meaney et al (2013) who embedded the aspirations of the Māori 
community into the mathematics curriculum, and described the relationship between math achievement and mathematics identity development as complementary. Relative to Meaney et al (2013), the case study teachers' references were minor connections to students' culture and community. Yet, these minor connections may have sent a major message to students. Potentially, minor references may communicate that the teachers value the students' culture.

The research on student perspectives has described the importance on the teacher -student relationships (Howard, 2002; Id-deen, 2016; Slaughter-Defoe and Carlson, 1996). Black students preferred teachers who created community classroom environments, connected with students' family (Howard, 2002), and took initiative to connect with students (Id-deen, 2016). Latinx students preferred teachers who were fair, caring, and praised effort (Slaughter-Defoe and Carlson, 1996). Consistent with these research findings, this study found that each of these teachers made an effort to build positive relationships. But, the way in which each teacher built relationships was quite different. For example, Yasin was very active in the broad migrant community, and Marlon's voice was present in the Latinx community newspaper, while Abigail was not as active in the broad community, but implemented classroom practices reflective of the CCSS -M mathematical practices and Ladson-Billing's (2009) community of learners. In general, the specific ways that each teacher engaged with the students varied, but each of these teachers had ways in which they attempted to connect to students. Therefore, these findings suggests that there was no set list of relationship building teaching practices, rather a collective mixture of efforts that resulted in these teachers being highly rated in their multicultural classrooms. 
I cross-referenced data from this study with Ladson-Billings' (2009) culturally relevant teaching characteristics. Of these characteristics, the following were evident across these highly-rated teachers:

- demonstrated teacher-student interactions that were fluid, humanely equitable, and extended to interactions beyond the classroom and into the community [social relations]

- connected with all their students [social relations]

- encouraged students to teach each other and be responsible for one another [social relations]

- assisted students to develop necessary skills [conceptions of knowledge]

- took student diversity and individual differences into account [conceptions of knowledge]

These six characteristics may indicate that these culturally relevant teaching characteristics are significant in multicultural classrooms and that these are the teaching characteristics that are visible to students. Some of Ladson-Billings' (2009) characteristics were noticed in only one of the case study classrooms. For example, Abigail expected students to teach each other and be responsible for each other, reflecting a community of learners. During one class, Yasin critiqued an equity issue by using mathematics. Marlon viewed himself as part of the Latinx community, and encouraged his students to give back to their communities. Several culturally responsive characteristics did not appear in the data collection for any of these three teachers (e.g., teachers view teaching as an art), which may mean they occurred, but not during data collection. Or it could be they were not prevalent in these teachers' classrooms, which 
may mean that they were not as visible to students or not as critical to meeting students' needs as the six characteristics listed above.

These research findings also support and add to O'Day (2009) findings. O’Day found that 'just good instruction' was not sufficient, but that ELs find explicit language support in oral development, vocabulary, and syntax important to their learning. Each of these highly-rated teachers provided explicit language support. They decoded text even when it took a significant portion of the class time. The teachers expressed the challenges of their students learning Spanish before English, not using English, or not increasing their English at the expected rate. The teachers addressed this challenge through guidance of the students' language - both native and English. This study indicates beyond being important to student learning, explicit language support strategies are visible to students as evident in the high student ratings of these teachers across categories.

Gutiérrez (2015) argues that students need to view themselves and the world through their mathematics curriculum. Additionally, Ladson-Billings (2009) recommends teachers assist students to develop necessary skills embedded within their learning. Such practices were evident across the case study teachers in that they were explicit about the purpose of mathematics education with their students and that they found ways to position students to be successful in their future. For example, the teachers provided explicit explanations, demonstration and incorporation of educational habits, responsibilities and expectations. The teachers connected the students' future with classroom responsibilities and expectations, and guided students to make informed decisions. 
In relation to the use of mathematics as an analytical tool to understand, critique or change social issues, Abigail consistently asked students to practice mathematics similar to mathematicians, and once Yasin used mathematics to critique a social issue. To elaborate, Abigail consistently encouraged her students to formulate hypothesis, generalize mathematical concepts, and support one another in collaboration, which aligns to the formation of human agency to work as mathematicians (Bell \& Pape, 2012; Dunleavy, 2015). Yasin discussed the issue of Nancy who works for very little, and still cannot pay her bills, which aligns with an oppressive context due to society structures. Yet, just as Brantlinger (2014) did not find evidence that the critical perspectives deepened mathematical understanding or understanding of social power structures, neither was this evidence found with Yasin's students. None of the teachers engaged their students in mathematics to change an oppressive system and improve society (i.e., Gutstein, 2006; 2007). However, each teacher demonstrating ways they advocated for their students outside of the classroom context.

\section{Conclusions}

Researchers have found that student perceptions are a strong predictor of effective teachers (e.g., Ferguson, 2012; Kyriakides, 2005; Wilkerson et al., 2000). This research, based on multicultural students' ratings of teachers, has implications for teacher practices.

\section{Connections to CRMT}

Because much of the research on CRMT has been conducted in bilingual settings, the findings of this study add to the literature on mathematics teaching practices that meet the needs of multicultural learners. Additionally, this study used the voices of 
multicultural students as a lens to assess which teachers are responsive to their students' needs. The teaching practices found across such highly-rated teachers provide important insights into what students notice in terms of their teacher's efforts to meeting their learning needs and to care about them as learners. The teacher practices that were prevalent across teachers included: an emphasis on positive teacher -student relationships, teacher presence in the community, and the explicit support of language.

\section{Specialized Recommendations for Multicultural Classrooms}

Beyond identifying CRMT categories that are particularly prominent in highlyrated multicultural teachers' classrooms, a number of teacher practices emerged that provide insights into what may be important to the learning and perceptions of multicultural students in their mathematics classrooms. First, using explicit language instruction is important, but which strategies are used may not be. There are many options for how a teacher might support language acquisition in a classroom. The good news is that a teacher need not learn or use a large set of strategies, but rather regularly use a subset of strategies. Second, teachers should focus on decoded text over nondecoded text, which means selecting shorter and high quality texts to support mathematics learning. When many languages are represented within a classroom, translation or root word strategies are not necessarily effective (as they may be in a bilingual classroom). Therefore, spending more time on less text can help all students have access to the meaning of the text. Third, multicultural teachers should discuss culture and individual differences in direct, informative, and non-judgmental manners with occasional lighthearted humor. 
Multilingual classrooms may pose challenges that are not as evident in the bilingual schools. Teachers indicated their students were possibly hindered in their own English growth when one non-English language (Spanish) dominated the classroom. Students whose native language was not Spanish were not only trying to learn English, but often times in situations where their peers were speaking Spanish, adding a third language into complexities of learning about mathematics. While supporting use of native language is important, multicultural teachers must consider the diverse languages in their classroom and set classroom norms that value language, but at the same time ensure that each child has access to the thinking of their peers and therefore may establish clear expectations (and rationale) for English language usage in mathematical discourse.

Students may prefer and may benefit from teacher references to familiar objects or norms. These benefits may incorporate a lighter language load for students, assist the students to feel more classroom -community oriented in the long term, or be an indication of teachers' knowledge about their students' diversity and individual differences.

Each of these teachers devoted time to talk with students about their future, it's very possible that the students interpreted this as the teachers caring for them. Therefore attending to students' futures may be a promising strategy for building relationships with students, and helping students to see that their teacher cares about them.

The teachers did not engage their students in mathematics to change an oppressive system and improve society. They did each advocate for their students in multiple ways outside of the classroom, while remaining true to their own identities and passions. The aforementioned data in combination with the lack of data to support the critical 
knowledge dimension implies some characteristics of the critical knowledge dimensions may need to be revisited in terms of what it may look like in the classroom and what is important for students' mathematical learning.

This research provides the teacher practices within cultures, language support, and critical knowledge. The differences among these teachers' identity and practices imply there are multiple ways to be a culturally responsive mathematics teacher. The multiple ways should be explored in more research on effective teachers in multicultural classrooms.

\section{Recommendations for Further Research}

Few studies have focused specifically on multicultural classrooms (i.e., classrooms with students from three or more countries in which most of the students do not have a shared nationality or language). Additionally, few studies have used student voices as the initial lens by which teaching practice is examined. In general, more research in either of these areas is needed.

Based on what was learned in this study, future research may explore if the themes identified in this study for highly-rated teachers might be generalized to other effective multicultural mathematics classrooms in the United States. Connecting these findings to student outcomes may be a part of this future research, studying the way in which students' language develops, mathematical thinking emerges, and mathematical dispositions are evident are all things that could add to the knowledge base of what teaching practices best support students in multicultural classrooms. 
The differences between this research and the literature indicate areas for farther research across other effective multicultural classrooms and teacher practices. These future research questions may address:

(1) better understanding an effective balance of English and students' native language use in mathematics classrooms,

(2) how many and how often are explicit language strategies needed in order to best support English and mathematical learning in a multicultural classroom, and

(3) What might an expanded list of familiar context include in a classroom with students from many countries? To what extent might such familiar references be about students' culture and to what extent might they focus on their lived and shared immigration experiences?

(4) What forms of teacher advocacy for students inside and outside of the classroom impact student learning of mathematics?

Finally, more research is certainly needed in terms of critical mathematics. The field can benefit from understanding to what level of specificity and how frequently students benefit from guidance on specific life skills, and the extent that they see the potential mathematics has to learn about their world.

Abigail described her students as coming from desperate situations. So research may explore potential connections among students Maslow's hierarchy (e.g., selfactualization), and the students' use of mathematics as an analytical tool to understand, critique or transform an equity issue. Additional research may explore connections among students' higher cognitive development, and the mathematics as an analytical tool to understand, critique or transform an equity issue. 
It is clear that each of these teachers was seen as supportive and effective by their students, yet the way in which they interacted with students was unique. This implies that there are many routes toward being responsive to students in multicultural classrooms. Future research on multicultural mathematics classrooms may further investigate such general categories and specific teaching practices.

\section{Concluding Remarks}

This study has focused on using the perspectives of culturally diverse students related to highly effective teachers and has teased out themes that provide insights into making mathematics instruction more effective for these learners. This endeavor has unveiled some important findings. For example, having a teacher know and make specific cultural connections may not be necessary, but making an effort to invite cultural connections is. This is good news for the many classrooms in which the teacher is not familiar with a child's culture, classrooms that have many cultures represented, and classrooms that have significant student turn-over making it difficult to study and learn about different cultures.

Similarly, this study has suggested that there is not one way to build studentteacher relations, but that building such relations does matter. Across these highly-rated teachers a variety of practices were noted that connected to a student. These practices can become part of teacher preparation and ongoing teacher learning. Some teachers may feel that some of these 'fit' their age-level or their own personality better.

Finally, this study found that while language supports and connections to culture were part of regular practice, occurring within every lesson, critical mathematics was not regularly noticed. In fact, there was only 1 instance across all case studies of using 
mathematics as an analytical tool for equity or social justice issues. It is not surprising that this would not affect students' ratings of their teachers, as they would not know to miss this connection. But, it is a lingering challenge to the field that we must continue to put forth effort not only to help students feel valued and supported in mathematics learning but to see how the very mathematics they are learning can be used to impact their world. 


\section{REFERENCES}

Aguirre, J. M., \& Zavala, M. D. R. (2013). Making culturally responsive mathematics teaching explicit: A lesson analysis tool. Pedagogies: An International Journal, $8(2), 163-190$.

Allexsaht-Snider, M., \& Hart, L. E. (2001). "Mathematics for all": How do we get there? Theory Into Practice, 40(2), 93-101.

Ardasheva, Y., \& Tretter, T. R. (2012). Perceptions and use of language learning strategies among ESL teachers and ELs. TESOL Journal, 3(4), 552-585.

Ardasheva, Y., \& Tretter, T. R. (2013). Contributions of individual differences and contextual variables to reading achievement of English language learners: An empirical investigation using hierarchical linear modeling. TESOL Quarterly: A Journal for Teachers of English to Speakers of Other Languages and of Standard English as a Second Dialect, 47(2), 323-351.

Bartell, T. G. (2013). Learning to teach mathematics for social justice: Negotiating social justice and mathematical goals. Journal for Research in Mathematics Education, 44(1), 129-163.

Belenky, D. M., \& Nokes, T. J. (2009). Examining the role of manipulatives and metacognition on engagement, learning, and transfer. Journal of Problem Solving, 2(2), 102-129. 
Bell, C. V., \& Pape, S. J. (2012). Scaffolding students' opportunities to learn mathematics through social interactions. Mathematics Education Research Journal, 24(4), 423445.

Boaler, J. (1997). Experiencing school mathematics: Teaching styles, sex and setting. Buckingham, Bucks: Open University Press.

Boaler, J. (2002a). The development of disciplinary relationships: Knowledge, practice, and identity in mathematics classrooms. For the learning of mathematics, 22(1), $42-47$.

Boaler, J. (2002b). Learning from teaching: Exploring the relationship between reform curriculum and equity. Journal for research in mathematics education, 33(4), 239-258.

Boaler, J. (2003). When learning no longer matters - standardized testing and the creation of inequality. Phi Delta Kappan, 84(7), 502-506.

Boaler, J. (2006). How a detracked mathematics approach promoted respect, responsibility, and high achievement. Theory Into Practice, 45(1), 40-46.

Boaler, J. (2008). Promoting 'relational equity' and high mathematics achievement through an innovative mixed-ability approach. British Educational Research Journal, 34(2), 167-194.

Boaler, J., \& Greeno, J. G. (2000). Identity, agency and knowing in mathematics worlds. In J. Boaler (Ed.), Multiple perspectives on mathematics teaching and learning (pp. 171-200). Westport, CT: Ablex Publishing.

Boser, U. (2014). Teacher diversity revisited: A new state-by-state analysis. Washington, D.C.: Center for American Progress. 
Brantlinger, A. (2014). Critical mathematics discourse in a high school classroom: Examining patterns of student engagement and resistance. Educational Studies in Mathematics: An International Journal, 85(2), 201-220.

Brenner, M. E. (1998a). Adding cognition to the formula for culturally relevant instruction in mathematics. Anthropology \& Education Quarterly, 29(2), 214-244.

Brenner, M. E. (1998b). Development of mathematical communication in problem solving groups by language minority students. Bilingual Research Journal, 22(24), 149-174.

Burton, L. (1999). The practices of mathematicians: What do they tell us about coming to know mathematics? Educational Studies in Mathematics, 37(2), 121-143.

Butler, F. M., Miller, S. P., Crehan, K., Babbitt, B., \& Pierce, T. (2003). Fraction instruction for students with mathematics disabilities: Comparing two teaching sequences. Learning Disabilities Research \& Practice, 18(2), 99-111.

Cornell, D., Shukla, K., \& Konold, T. R. (2016). Authoritative school climate and student academic engagement, grades, and aspirations in middle and high schools. AERA Open, 2(2), 1-18.

Council of Chief State School Officers [CCSSO]. National Governors Association Center for Best Practices. Common Core State Standards for Mathematics. National Governors Association Center for Best Practices, Council of Chief State School Officers, Washington D.C. 2010.

Cramer, K. A., Post, T. R., \& delMas, R. C. (2002). Initial fraction learning by fourthand fifth-grade students: A comparison of the effects of using commercial 
curricula with the effects of using the rational number project curriculum. Journal for research in mathematics education, 33(2), 111-144.

DeAraujo, Z. U. (2012). Transferring demand: Secondary teachers' selection and enactment of mathematics tasks for english language learners. (Doctoral Dissertation), University of Georgia.

Dickson, G. L., Chun, H., \& Fernandez, I. T. (2016). The development and initial validation of the student measure of culturally responsive teaching. Assessment for Effective Intervention, 41(3), 141-154.

DiSessa, A. A., Hammer, D., Sherin, B., \& Kolpakowski, T. (1991). Inventing graphing: Meta-representational expertise in children. Journal of Mathematical Behavior, $10,117-160$.

Dunleavy, T. K. (2015). Delegating mathematical authority as a means to strive toward equity. Journal of Urban Mathematics Education, 8(1), 62-82.

Echevarría, J., Vogt, M., \& Short, D. J. (2008). Making content comprehensible for English learners: The SIOP model (3rd ed.). Boston, MA: Pearson Education, Inc.

Enyedy, N., Rubel, L., Castellon, V., Mukhopadhyay, S., Esmonde, I., \& Secada, W. (2008). Revoicing in a multilingual classroom. Mathematical Thinking and Learning: An International Journal, 10(2), 134-162.

Ferguson, R. F. (2012). Can student surveys measure teaching quality? Phi Delta Kappan, 94(3), 24-28.

Fine, M., Stoudt, B., \& Futch, V. (2005). A quantitative and qualitative cohort analysis of graduation and dropout rates: Teaching and learning in a transcultural academic 
environment The Internationals Network for Public Schools. The Graduate Center: City University of New York.

Fujimura, N. (2001). Facilitating children's proportional reasoning: A model of reasoning processes and effects of. Journal of Educational Psychology, 93(3), 589-603.

García, O., \& Sylvan, C. E. (2011). Pedagogies and practices in multilingual classrooms: Singularities in pluralities. The Modern Language Journal, 95(3), 385-400.

Gay, G. (2000). Culturally responsive teaching: Theory research and practice. New York: Teachers College Press.

Gay, G. (2009). Preparing culturally responsive mathematics teachers. In B. Greer, S. Mukhopadhyay, S. Nelson-Barber \& A. Powell (Eds.), Culturally responsive mathematics education (pp. 189-206). New York, NY: Routledge.

Gee, J. P. (2005). An introduction to discourse analysis: Theory and method (2nd ed.). New York: Routledge.

Glesne, C. (2016). Becoming qualitative researchers: An introduction (pp. 330).

Greeno, J. G., \& Hall, R. P. (1997). Practicing representation. Phi Delta Kappan, 78(5), 361-367.

Gregory, A., \& Ripski, M. B. (2008). Adolescent trust in teachers: Implications for behavior in the high school classroom. School Psychology Review, 37(3), 337353.

Gregory, A., Skiba, R. J., \& Noguera, P. (2010). The achievement gap and the discipline gap: Two sides of the same coin? Educational Researcher, 39(1), 59-68. 
Gregson, S. A. (2013). Negotiating social justice teaching: One full-time teacher's practice viewed from the trenches. Journal for research in mathematics education, 2013(44), 164-198.

Gresalfi, M. S., \& Cobb, P. (2006). Cultivating students' discipline-specific dispositions as a critical goal for pedagogy and equity. Pedagogies: An International Journal, 1(1), 49-57.

Gutiérrez, R. (2002). Enabling the practice of mathematics teacher in context: Towards a new equity research agenda. Mathematical Thinking \& Learning, 4(2\&3), 145187.

Gutiérrez, R. (2007). Context matters: Equity, success, and the future of mathematics education. Paper presented at the Proceedings of the 29th annual meeting of the North American Chapter of the International Group for the Psychology of Mathematics Education, Reno.

Gutiérrez, R. (2008). A "gap-gazing" fetish in mathematics education? Problematizing research on the achievement gap. Journal for research in mathematics education, 39(4), 357-364.

Gutiérrez, R. (2013). The sociopolitical turn in mathematics education. Journal for research in mathematics education, 44(1), 37-68.

Gutiérrez, R. (2015). HOLA: Hunt for Opportunities-Learn-Act. Mathematics Teacher, 109(4), 270-277.

Gutstein, E. (2003). Teaching and learning mathematics for social justice in an urban, Latino school. Journal for research in mathematics education, 34(1), 37. 
Gutstein, E. (2006). "The real world as we have seen it": Latino/a parents' voices on teaching mathematics for social justice. Mathematical Thinking \& Learning: An International Journal, 8(3), 331-358.

Gutstein, E. (2007). "And that's just how it starts": Teaching mathematics and developing student agency. Teachers College Record, 109(2), 420-448.

Hamre, B. K., \& Pianta, R. C. (2005). Can instructional and emotional support in the first-grade classroom make a difference for children at risk of school failure? Child Development, 76(5), 949-967.

Hansen-Thomas, H. (2009). English language learners and math: Discourse, participation, and community in reform-oriented, middle school mathematics classes. Charlotte, NC: Information Age Publishing, Inc.

Hiebert, J., \& Stigler, J. W. (2000). A proposal for improving classroom teaching: Lessons from the TIMSS video study. The Elementary School Journal, 101(1), 320.

Hollins, E. R., \& Spencer, K. (1990). Restructuring schools for cultural inclusion: Changing the schooling process for African American youngsters. Journal of Education, 172(2), 89-100.

Howard, T. C. (2002). Hearing footsteps in the dark: African American students' descriptions of effective teachers. Journal of Education for Students Placed at Risk, 7(4), 425-444.

Hubert, T. L. (2014). Learners of mathematics: High school students' perspectives of culturally relevant mathematics pedagogy. Journal of African American Studies, $18(3), 324-336$. 
Hwang, W. Y., Su, J. H., Huang, Y. M., \& Dong, J. J. (2009). A study of multirepresentation of geometry problem solving with virtual manipulatives and whiteboard system. Journal of Educational Technology \& Society, 12(3), 229247.

Id-Deen, L. (2015). African American students' perspectives on their experiences in their mathematics classroom in the context of teacher turnover in an urban school. Retrieved from ProQuest Dissertations. (AAT 3720308)

Id-Deen, L. (2016). Hidden casualties of urban teacher turnover: Black students share their experiences. Journal of Urban Learning, Teaching and Research, 12, 142149.

INPS Board of Directors. (2013). International network for public schools. Retrieved June 25, 2016, from http://internationalsnps.org

Jefferson-Isaac, S. M. (2006). They count also: The experiences of African American girls in elementary school with mathematics. (Doctor of Education Dissertation), Hofstra University. Available from WorldCat ProQuest database.

Kane, T. J., McCaffrey, D. F., Miller, T., \& Staiger, D. O. (2013). Have we identified effective teachers?: Validating measures of effective teaching using random assignment. Measures of Effective Teaching (MET) project. Bill and Melinda Gates Foundation.

Kitchen, R. S. (2005). Making equity and multiculruralism explicit to transform mathematics education. In A. J. Rodríguez \& R. S. Kitchen (Eds.), Preparing mathematics and science teachers for diverse classrooms: Promising strategies 
for transformative pedagogy (pp. 33-60). Mahwah, NJ: Lawrence Erlbaum Associates, Publishers.

Kyriakides, L. (2005). Drawing from teacher effectiveness research and research into teacher interpersonal behaviour to establish a teacher evaluation system: A study on the use of student ratings to evaluate teacher behaviour. Journal of Classroom Interaction, 40(2), 44-66.

Ladson-Billings, G. (1994). The dreamkeepers: Successful teachers of African American children (1st ed.). San Francisco: Jossey-Bass Publishers.

Ladson-Billings, G. (2006). From the Achievement Gap to the Education Debt: Understanding Achievement in U.S. Schools. Educational Researcher, 35(7), 312.

Ladson-Billings, G. (2008). A Letter to Our Next President. Journal of Teacher Education, 59(3), 235-239.

Ladson-Billings, G. (2009). The dreamkeepers: Successful teachers of African American children (2nd ed.). San Francisco: Jossey-Bass Publishers.

Langlie, M. L. (2008). The effect of culturally relevant pedagogy on the mathematics achievement of Black and Hispanic high school students (Doctor of Philosophy Dissertation), Northeastern University, Boston, MA.

Lee, P. W. (1999). In their own voices: An ethnographic study of low-achieving students within the context of school reform. Urban Education, 34(2), 214-244.

Leinwand, S., Brahier, D. J., Huinker, D., Berry III, R. Q., Dillon, F. L., Larson, M. R., ... Smith, M. S. (2014). Principles to actions: Ensuring mathematical success for all. Reston, VA: NCTM. 
Lipka, J., Hogan, M. P., Webster, J. P., Yanez, E., Adams, B., Clark, S., \& Lacy, D. (2005). Math in a cultural context: Two case studies of a successful culturally based math project. Anthropology \& Education Quarterly, 36(4), 367-385.

Lockhart, P. (2009). A mathematician's lament: How school cheats us out of our most fascinating and imaginative art form. New York, NY: Bellevue Literary Press.

Love, A., \& Kruger, A. C. (2005). Teacher beliefs and student achievement in urban schools serving African American students. The Journal of Educational Research, 99(2), 87-98.

Lubienski, S. T. (2008). On "gap gazing" in mathematics education: The need for gaps analyses. Journal for Research in Mathematics Education, 39(4), 350-356.

Lubienski, S. T., \& Gutiérrez, R. (2008). Bridging the gaps in perspectives on equity in mathematics education. Journal for Research in Mathematics Education, 39(4), 365-371.

Martin, D. B. (2003). Hidden assumptions and unaddressed questions in "mathematics for all". The Mathematics Educator, 13(2), 7-21.

Maxwell, J. A. (2005). Qualitative research design: An interactive approach (2nd ed.). Thousand Oaks, CA: Sage Publications.

McGee, E., \& Martin, D. (2011). "You would not believe what I have to go through to prove my intellectual value!" Stereotype management among academically successful black mathematics and engineering students. American Educational Research Journal, 48(6), 1347-1389. 
Meaney, T., Trinick, T., \& Fairhall, U. (2013). One size does not fit all: Achieving equity in Māori mathematics classrooms. Journal for Research in Mathematics Education, 44(1), 235-263.

Measures of Effective Teaching (MET) project. (2010). Working with teachers to develop fair and reliable measures of effective teaching. Bill and Melinda Gates Foundation. http://www.metproject.org

Measures of Effective Teaching (MET) project. (2012). Gathering feedback for teaching: Combining high -quality observations with student surveys and achievement gains. Bill and Melinda Gates Foundation. http://www.metproject.org

Miles, M. B., Huberman, A. M., \& Saldaña, J. (2013). Qualitative data analysis (3rd ed.). Thousand Oaks, CA: Sage.

Miron, L. F., \& Lauria, M. (1998). Student voice as agency: Resistance and accommodation in inner-city schools. Anthropology \& Education Quarterly, 29(2), 189-213.

Moffett, G., Malzahn, K., \& Driscoll, M. (2014). Multimodal communication: Promoting and reveaing students' mathematical thinking. In K. Karp (Ed.), Annual perspectives in mathematics education 2014: Using research to improve instruction. Reston, VA: NCTM.

Monk, S. (2003). Representation in school mathematics: Learning to graph and graphing to learn. In J. Kilpatrick, W. G. Martin \& D. Schifter (Eds.), A research companion to "principles and standards for school mathematics" (pp. 250-262). Reston, VA: NCTM. 
Monk, S., \& Nemirovsky, R. (1994). The case of Dan: Student construction of a functional situation through visual attributes. Research in Collegiate Mathematics Education, 1, 139-168.

Moschkovich, J. N. (1999). Supporting the participation of English language learners in mathematical discussions. For the Learning of Mathematics, 19(1), 11-19.

Moschkovich, J. N. (2002). A situated and sociocultural perspective on bilingual mathematics learners. Mathematical Thinking and Learning, 4(2\&3), 189-212.

Moschkovich, J. N. (2008). I went by twos, he went by one: Multiple interpretations of inscriptions as resources for mathematical discussions. The Journal of the Learning Sciences, 17(4), 551-587.

Moschkovich, J. N. (2013). Principles and guidelines for equitable mathematics teaching practices and materials for English language learners. Journal of Urban Mathematics Education, 6(1), 45-57.

Moses, R. P., \& Cobb, C. E., Jr. (2001). Radical equations: Math literacy and civil rights. Boston: Beacon Press.

Murray, C., \& Zvoch, K. (2011). Teacher-student relationships among behaviorally atrisk African American youth from low-income backgrounds: Student perceptions, teacher perceptions, and socioemotional adjustment correlates. Journal of Emotional and Behavioral Disorders, 19(1), 41-54.

Murray, S. L. (2014). Culturally relevant literacy for 4th and 5th grade African American males: Honoring students' voices. (Doctor of Philosophy in Education Dissertation), University of Missouri-St. Louis. Available from PsycINFO database. 
National Center for Education Statistics (NCES). (2016). The condition of education 2016. Washington, DC: United States Department of Education.

National Council of Teachers of Mathematics (NCTM). (2003). A research companion to principles and standards for school mathematics. J. Kilpatrick, W. G. Martin \& D. Schifter (Eds.). Reston, VA: Author.

National Research Council (NRC). (2001). Adding it up: Helping children learn mathematics. Kilpatrick, J., Swafford, J., \& Findell, B. (Eds.). Mathematics Learning Study Committee, Center for Education, Division of Behavioral and Social Sciences and Education. Washington, DC: National Academy Press. National Research Council (NRC). (2012). Education for life and work: Developing transferable knowledge and skills in the 21st century. Washington, D.C.: Author.

O'Day, J. (2009). Good instruction is good for everyone - or is it? English language learners in a balanced literacy approach. Journal of Education for Students Placed at Risk, 14(1), 97-119.

Pais, A., Fernandes, E., Matos, J. F., \& Alves, A. S. (2012). Recovering the meaning of "critique" in critical mathematics education. For the Learning of Mathematics, $32(1), 28-33$.

Phelan, P., Yu, H. C., \& Davidson, A. L. (1994). Navigating the psychosocial pressures of adolescence: The voices and experiences of high school youth. American Educational Research Journal, 31(2), 415-447.

Pickering, A. (1995). The mangle of practice: Time, agency, and science. Chicago: University of Chicago Press. 
Polikoff, M. S. (2015). The stability of observational and student survey measures of teaching effectiveness. American Journal of Education, 121(2), 183-212.

Rey, R. B., Smith, A. L., Yoon, J., Somers, C., \& Barnett, D. (2007). Relationships between teachers and urban African American children: The role of informant. School Psychology International, 28(3), 346-364.

Rubinstein-Avila, E., \& Lee, E. H. (2014). Secondary teachers and English language learners (ELLs): Attitudes, preparation and implications. Clearing House, 87(5), 187-191. doi: 10.1080/00098655.2014.910162

Saldaña, J. (2013). The coding manual for qualitative researchers (2nd ed.). Los Angeles: Sage.

Schoenfeld, A. H. (2002). Making mathematics work for all children: Issues of standards, testing, and equity. Educational Researcher, 31(1), 13-25.

Schunk, D. H., \& Richardson, K. (2011). Motivation and self-efficacy in mathematics education. In D. J. Brahier (Ed.), Motivation and disposition: Pathways to learning mathematics (73 ed., pp. 13-30). Reston, VA: National Council of Teachers of Mathematics.

Setati, M. (2005). Teaching mathematics in a primary multilingual classroom. Journal for Research in Mathematics Education, 36(5), 447-466.

Sheets, R. H. (1996). Urban classroom conflict: Student-teacher perception: Ethnic integrity, solidarity, and resistance. The Urban Review: Issues and Ideas in Public Education, 28(2), 165-183. 
Shein, P. P. (2012). Seeing with two eyes: A teacher's use of gestures in questioning and revoicing to engage English language learners in the repair of mathematical errors. Journal for Research in Mathematics Education, 43(2), 182.

Simon, M. K. (2006). Dissertation and scholarly research: Recipes for success. Dubuque, Iowa: Kendall / Hunt publishing company.

Skovsmose, O. (1994). Towards a critical mathematics education. Educational Studies in Mathematics, 27(1), 35-57.

Slaughter-Defoe, D. T., \& Carlson, K. G. (1996). Young African American and Latino children in high-poverty urban schools: How they perceive school climate. Journal of Negro Education, 65(1), 60-70.

Smith, S. P. (2003). Representation in school mathematics: Children's representations of problems. In J. Kilpatrick, W. G. Martin \& D. Schifter (Eds.), A research companion to "principles and standards for school mathematics" (pp. 263-274). Reston, VA: NCTM.

Soter, A. O., Wilkinson, I. A., Murphy, P. K., Rudge, L., Reninger, K., \& Edwards, M. N. (2008). What the discourse tells us: Talk and indicators of high-level comprehension. International Journal of Educational Research, 47(6), 372-391.

Stinson, D. W., \& Wager, A. A. (2012). A sojourn into the empowering uncertainties of teaching and learning mathematics for social change. In D. W. Stinson \& A. A. Wager (Eds.), Teaching mathematics for social justice: Conversations with educators (pp. 3-18): National Council of Teachers of Mathematics.

Stylianou, D. A., \& Silver, E. A. (2004). The role of visual representations in advanced mathematical problem solving: An examination of expert-novice similarities and 
differences. Mathematical Thinking and Learning: An International Journal, 6(4), 353-387.

Toth, P. D. (2006). Processing instruction and a role for output in second language acquisition. Language Learning, 56(2), 319-385.

Tschannen-Moran, M., Bankole, R. A., Mitchell, R. M., \& Moore, D. M., Jr. (2013).

Student academic optimism: A confirmatory factor analysis. Journal of Educational Administration, 51(2), 150-175.

Turkan, S., Oliveira, L. C. D., Lee, O., \& Phelps, G. (2014). Proposing a knowledge base for teaching academic content to English language learners: Disciplinary linguistic knowledge. Teachers College Record, 116, 1-30.

Turner, E. E. (2012). Critical mathematical agency in the overcrowding at francis middle school project. In E. Tan \& A. C. Barton (Eds.), Empowering science and mathematics education in urban schools (pp. 51-76): The University of Chicago Press.

Tyler, K. M., Boykin, A. W., \& Walton, T. R. (2006). Cultural considerations in teachers' perceptions of student classroom behavior and achievement. Teaching \& Teacher Education, 22(8), 998-1005.

Vandergrift, L., \& Tafaghodtari, M. H. (2010). Teaching 12 learners how to listen does make a difference: An empirical study. Language Learning, 60(2), 470-497.

Varley Gutiérrez, M. (2012). Community spaces as part of hybrid math learning spaces: Integrating multiple funds of knowledge. In E. Tan \& A. C. Barton (Eds.), Empowering science and mathematics education in urban schools (pp. 145-165). Chicago and London: The University of Chicago Press. 
Wagner, D. (2007). Students' critical awareness of voice and agency in mathematics classroom discourse. Mathematical Thinking \& Learning: An International Journal, 9(1), 31-50.

Walton, G. M., \& Spencer, S. J. (2009). Latent ability: Grades and test scores systematically underestimate the intellectual ability of negatively stereotyped students. Psychological Science, 20(9), 1132-1139.

Walton, G. M., Spencer, S. J., \& Erman, S. (2013). Affirmative meritocracy. Social Issues and Policy Review, 7(1), 1-35.

WiDA Consortium. (2012). The English language development standards kindergartengrade 12. University of Wisconsin: Board of Regents.

Wilkerson, D. J., Manatt, R. P., Rogers, M. A., \& Maughan, R. (2000). Validation of student, principal, and self-ratings in $360^{\circ}$ feedback. Journal of Personnel Evaluation in Education, 14(2), 179-192.

Yin, R. K. (2014). Case study research: Design and methods (5th ed.). Los Angeles: SAGE Publications, Inc.

Zahner, W., \& Moschkovich, J. N. (2010). Talking while computing in groups: The notso-private functions of computational private speech in mathematical discussions. Mind, Culture, and Activity, 17(3), 265-283. 
APPENDICES 


\begin{abstract}
APPENDIX A
Survey Comparison: Student Voice and Tripod
\end{abstract}

\begin{tabular}{|c|c|c|}
\hline $\begin{array}{c}\text { Category } \\
\text { (Student Voice / } \\
\text { Tripod) }\end{array}$ & Both surveys & Tripod survey only \\
\hline $\begin{array}{l}\text { Support } \\
\text { / Challenge }\end{array}$ & $\begin{array}{l}\text { In this class, we learn a lot almost } \\
\text { every day. } \\
\text { In this class, we learn to correct } \\
\text { our mistakes. } \\
\text { My teacher doesn't let people give } \\
\text { up when the work gets hard. } \\
\text { In this class, my teacher accepts } \\
\text { nothing less than our full effort. }\end{array}$ & $\begin{array}{l}\text { My teacher wants me to explain } \\
\text { my answers-why I think what I } \\
\text { think. } \\
\text { My teacher asks questions to be } \\
\text { sure we are following along } \\
\text { when s/he is teaching. } \\
\text { My teacher asks students to } \\
\text { explain more about the answers } \\
\text { they give. }\end{array}$ \\
\hline $\begin{array}{l}\text { Transparency } \\
\text { / Clarify }\end{array}$ & $\begin{array}{l}\text { My teacher explains difficult } \\
\text { things clearly. } \\
\text { My teacher has several good ways } \\
\text { to explain each topic that we cover } \\
\text { in this class. } \\
\text { If you don't understand } \\
\text { something, my teacher explains it } \\
\text { another way. } \\
\text { My teacher knows when the class } \\
\text { understands, and when we do not }\end{array}$ & $\begin{array}{l}\text { When s/he is teaching us, my } \\
\text { teacher thinks we understand } \\
\text { when we don't* }\end{array}$ \\
\hline $\begin{array}{l}\text { Understand } \\
\text { / Consolidate }\end{array}$ & $\begin{array}{l}\text { My teacher checks to make sure } \\
\text { we understand what s/he is } \\
\text { teaching us. } \\
\text { The comments that I get on my } \\
\text { work in this class help me } \\
\text { understand how to improve. } \\
\text { We get helpful comments to let us } \\
\text { know what we did wrong on } \\
\text { assignments. }\end{array}$ & $\begin{array}{l}\text { My teacher takes the time to } \\
\text { summarize what we learn each } \\
\text { day. }\end{array}$ \\
\hline $\begin{array}{l}\text { Discipline } \\
\text { / Control }\end{array}$ & $\begin{array}{l}\text { Students in this class treat the } \\
\text { teacher with respect. } \\
\text { My classmates behave the way my } \\
\text { teacher wants them to. } \\
\text { Our class stays busy and does not } \\
\text { waste time. } \\
\text { Student behavior in this class is } \\
\text { under control. }\end{array}$ & $\begin{array}{l}\text { Student behavior in this class } \\
\text { makes the teacher angry* } \\
\text { Student behavior in this class is } \\
\text { a problem* } \\
\text { I hate the way that students } \\
\text { behave in this class* }\end{array}$ \\
\hline
\end{tabular}




\begin{tabular}{|c|c|c|}
\hline $\begin{array}{l}\text { Engage } \\
\text { / Captivate }\end{array}$ & $\begin{array}{l}\text { I like the ways we learn in this } \\
\text { class. } \\
\text { My teacher makes lessons } \\
\text { interesting. } \\
\text { My teacher makes learning } \\
\text { enjoyable. }\end{array}$ & $\begin{array}{l}\text { This class does not keep my } \\
\text { attention-I get bored* }\end{array}$ \\
\hline $\begin{array}{l}\text { Nurture } \\
\text { / Care }\end{array}$ & $\begin{array}{l}\text { My teacher in this class makes me } \\
\text { feel that s/he really cares about } \\
\text { me. } \\
\text { My teacher really tries to } \\
\text { understand how students feel } \\
\text { about things. } \\
\text { My teacher seems to know if } \\
\text { something is bothering me. }\end{array}$ & \\
\hline $\begin{array}{l}\text { Trust } \\
\text { / Confer }\end{array}$ & $\begin{array}{l}\text { My teacher respects my ideas and } \\
\text { suggestions. } \\
\text { My teacher wants us to share our } \\
\text { thoughts. } \\
\text { Students speak up and share their } \\
\text { ideas about class work. } \\
\text { My teacher gives us time to } \\
\text { explain our ideas. }\end{array}$ & $\begin{array}{l}\text { Students get to decide how } \\
\text { activities are done in this class. }\end{array}$ \\
\hline
\end{tabular}

* Reverse coded 


\section{APPENDIX B \\ Interview Questions}

\section{Interview 1}

1. You could teach anywhere in the district. What has kept you at this specific school?

2. If your colleagues would tell me about some of your professional successes, what might be some things they mention?

3. What are times you felt success as a teacher?

4. What are possible considerations your make for your students' language needs? (Needs such as, the technical mathematics jargon and your ELs.)

5. In what ways do you support student language development within your lesson?

6. What might be some challenges you have personally overcome as a teacher of so many different cultures?

\section{Interview 2}

1. How might you encourage your students to use mathematics in their personal and/or community life?

2. What attitudes about mathematics do your students bring into the classroom? AND What attitudes do you hope to instill in the students before they move to the next school year?

3. When planning a lesson, what things do you consider about the students' background? (i.e., prior mathematical experiences)

4. What are some ways you teach your students to approach a problem?

5. How might students approach a problem when they enter your class? How might 
you want them to approach the problem by the time they leave your class?

6. In what ways might you incorporate mathematical application problems in your classroom? (Prompt for examples, if necessary)

7. I heard you say, __ Can you tell me more about that?

Optional:

How might you possibly influence your students' relationship to mathematics?

How might you develop these mathematician qualities throughout the school

year? What are some ways you consider your students to be mini-mathematicians

OR future mathematicians?

If your classroom had a motto or mantra, what might it be? What might be some broad goals (approaches, strategies, or a motto) that you focus on throughout the school year?

\section{Interview 3}

1. How might you recognize "challenging" students as responding to you in a beneficial manner?

2. You indicated your students identify as White, Black, Latinx, Somali, and Karen (ethnicities will change according to the classroom). What might be some ways you negotiate student cultures within the classroom?

3. Describe a time when a cultural conflict occurred in your classroom. How did you handle the conflict? What might you do if the situation (or a similar situation) occurs?

4. How might you appeal or respond to your students as individuals - with different 
values from your own (rather than a group)?

5. Describe a time when your classroom expectations and students' cultural expectations conflicted. How might you respond if a similar situation occurred in the near future?

6. What are some possible other ways you consider students' culture and mathematics in everyday teaching practice?

7. If you could change how mathematics teachers educate, what might you focus on? Please elaborate. 


\section{APPENDIX C}

\section{Lesson Observation Tool}

Adapted from Aguirre \& Zavala (2013) and the chapter 2 Literature Review (right column)

\section{Academic language support and scaffolding strategies for ELs}

Attention to:
- $\quad$ students' linguistic funds of knowledge.

- L1 usage, or hybrid language (ex. codeswitching) is observed among teacher and students, in a variety of interactions

- the development of mathematical discourse and meaning making, not students' production of "correct" English.

Use of ESL strategies, during whole class and/or small group instruction and discussions,

- such as gesturing, use of objects, cognates, revoicing,

- graphic organizers and

- manipulatives

The main focus is the development of mathematical discourse and meaning making, not students' production of "correct" English.
How does the lesson utilize L1 (home language) to support academic language development for ELs?

How does the lesson provide ESL scaffolding strategies to support academic language development for ELs?
Inclusive of student(s)

- various linguistic levels,

- collaboration with peers, teachers and in communities of practice

Student academic discourse with

- metacognitive learning techniques,

- multiple representations within mathematics, and

- engagement of students in discourse practices, both receptive (listening, writing)

- and expressive (speaking, reading). 


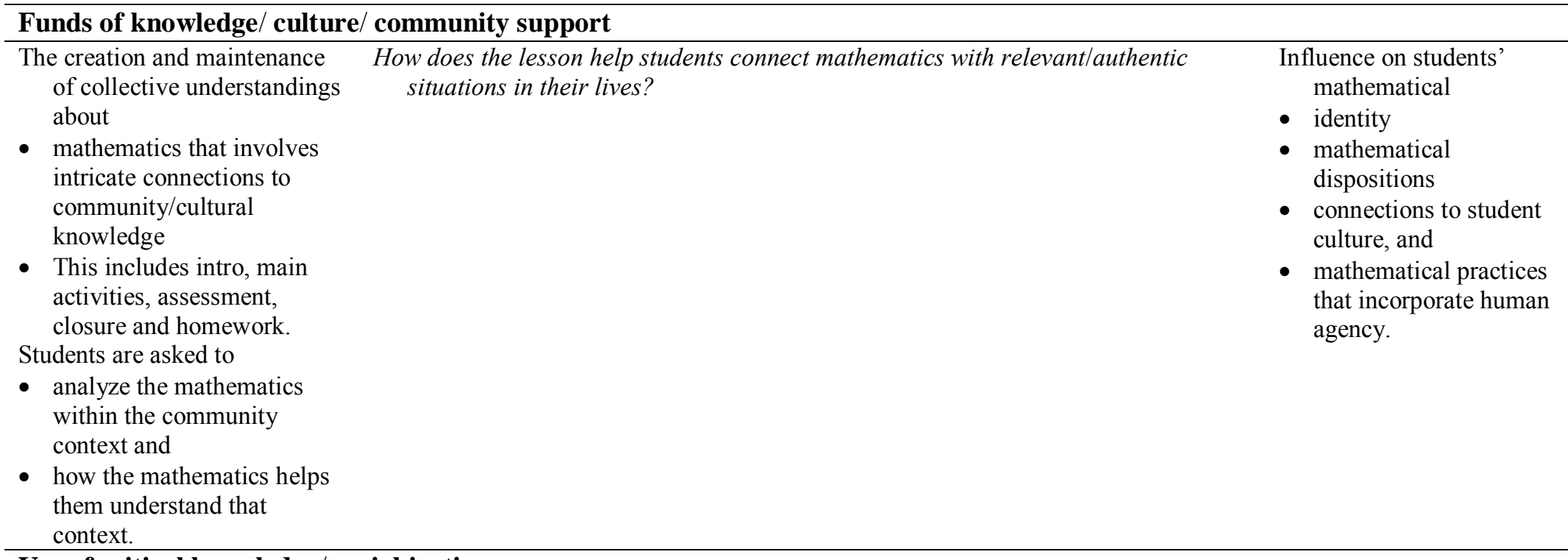

How does the lesson help students connect mathematics with relevant/authentic

Use of critical knowledge/ social justice

Mathematics as an analytical tool to

- understand an issue/ context,

- formulate mathematically based arguments to address the issues

- and provide substantive pathways to

change/transform the issue.

(1)
How does the lesson support students' use of mathematics to understand, critique, and change an important equity or social justice issue in their lives?

ss

(1)
A critical approach of arguments, assumptions,

worldviews or beliefs which are explicit or inferred. Information /text is

- searched,

- probed,

- interrogated.

This may look like,

- Mathematician Practices,

- the power to critique society,

- the challenge of injustices. 
CURRICULUM VITA

\section{Rose M Glasser}

Email: glasser.rose@gmail.com

Phone: (502) 592-1999

\section{Education and Certifications}

2017 Doctor of philosophy: Curriculum and instruction. University of Louisville, Louisville, KY

2015 Certified cognitive coach. "Thinking Collaborative" with Dr. Maggie McGatha.

2014 National board certified teacher: Mathematics early adolescence.

2014 Professional growth and effectiveness system. District training.

2013 Louisville writing project graduate. Program directed by Jean Wolph. Site of National writing project.

2013 How to learn math for teachers. Certification. Stanford University with Dr. Jo Boaler. Online course.

2012 English as a second language (ESL) certification. University of Louisville, Louisville, KY

2010 Masters of arts in teaching: Middle and secondary mathematics education. University of Louisville. Louisville, KY

2008 Bachelors of arts: Secondary education mathematics. University of Kentucky. Lexington, KY.

\section{Coaching Experience}

2014-2015 Mentor teacher to Morgan Reeves (assistant teacher), ESL Newcomer Academy, Jefferson County Public Schools (JCPS). Louisville, Ky. 
2014 Cooperative teacher to Anne Miller (student teacher), ESL Newcomer Academy, JCPS. Louisville, Ky.

2012-2015 Collaborative teacher with Stacey Dunn (contact information provided in references), ESL Newcomer Academy, JCPS. Louisville, Ky.

2014-2015 Leadership roles. ESL Newcomer Academy, JCPS. Louisville, Ky.

* Middle school mathematics team leader

* Student Voice survey leader

\section{Middle and High School Experience}

2011-2015 Mathematics teacher. ESL Newcomer Academy, JCPS. Louisville, Ky.

* $6^{\text {th }}$ grade mathematics to English learners (ELs)

* Mixed middle school mathematics classes to ELs with Significantly Interrupted or limited Formal Education (SIFE)

* $9^{\text {th }}$ grade special topics mathematics to ELs with SIFE

$* 9^{\text {th }} \& 10^{\text {th }}$ grade algebra I to ELs with SIFE

2010- $2011 \quad 7^{\text {th }}$ grade Mathematics teacher. T.T. Knight Middle School, JCPS. Louisville, Ky.

\section{University Experience}

2016 -2017 Instructor, University of Louisville. Courses include:

* General methods. Undergraduate.

* The Teaching profession. Undergraduate.

* Exploring teaching within a sociopolitical context of p-12 schools. Graduate.

2015 - 2016 Research Assistant, University of Louisville. Projects include:

* Middle school mathematics diagnostic teacher assessments in mathematics and science (DTAMS) with Dr. Susan A Peters.

* Research assistant to Dr. Lateefah Id-Deen.

2016 Teaching Assistant, University of Louisville. Courses include:

* Advanced methods: number and algebra with Dr. Jennifer Bay-Williams.

* Reading and writing across the curriculum with Dr. Penny Howell.

* Mathematics methods (for Elementary Teachers) with Dr. Lateefah Id-Deen.

2015 Presenter. New Neighbors Center, Indiana University Southeast. New Albany, IN.

2015 Instructor, Spalding University. Introduction to linguistics. Graduate. 


\section{Publication}

Bay-Williams, J. M., Glasser, R., \& Bronger, T. (2013). Algebra describes the world. In Margo Gottlieb \& Gisela Ernst-Slavit, (Eds). Academic language demands for language learners: Mathematics, grades 3-5: Promoting content and language learning. Corwin: Thousand Oaks, CA.

\section{Presentation Experience}

Glasser, R. M. (2017). Socio-cultural factors impacting educational outcomes. Dialogue on Diversity conference. Bellarmine University. Louisville, Ky.

Glasser, R. M. (2017). Highly student - rated mathematics teachers of multicultural classrooms, Poster presentation. Spring Research Conference. University of Cincinnati, Cincinnati, $\mathrm{OH}$.

Miller, K.E. \& Glasser, R.M. (2016). Do you speak math? Southeast Regional Teachers of English to Speakers of Other Languages conference. Louisville, Ky.

Glasser, R.M. (2015). Yes, I can: WiDA 'Can Do' descriptors. Scribner Middle School, New Neighbors Center. Multiple sessions. New Albany, IN.

Bay-Williams, J.M. \& Glasser, R.M. (2015). Strategies for supporting algebraic thinking with English Language Learners. National Conference for Teachers of Mathematics Regional Conference. Nashville, TN.

Glasser, R.M. \& Dunn, S.E. (2014). Math: Teach more by talking less! National WorldClass Instructional Design and Assessment Conference. Atlanta, GA.

Glasser, R.M., Bay-Williams, J. M. \& Bronger, T. (2013). ELLs and algebraic thinking. National Conference for Teachers of Mathematics Regional Conference. Las Vegas, NV.

Glasser, R.M. \& Bay-Williams, J. M. (2013). Numbers, languages, and standards, Oh MY!! Kentucky Teachers of English to Speakers of Other Languages. State Conference. Louisville, KY.

\section{Community Service}

2015 Louisville refugee simulation. Language school volunteer.

2015 WIDA alignment study (invited). ELD standards \& CCSSO ELPD framework. WIDA consortium. Middleton, W.I.. 
2014 Math in Focus books fundraiser. Donor’s choose. Over $\$ 2,000$ collected.

2013 Financial literacy course advocate: Dave Ramsey's Foundation of Personal

Finance. Classroom scholarship granted with renewability options. Sponsored by Fifth Third bank.

\section{Professional Affiliations}

National Council of Teachers of Mathematics (NCTM).

TODOS: Mathematics for All

\section{Student Voice Results}

2014-2015 Student-rated percent positive responses

Engage $98 \%$

Nurture $91 \%$

Support $88 \%$

Discipline $87 \%$

\section{Trust 98\%}

Understand 96\%

Transparency 97\% 